\title{
Improving the accuracy of CT in diagnosing internal herniation after gastric bypass surgery
}

Citation for published version (APA):

Ederveen, J. C. (2020). Improving the accuracy of CT in diagnosing internal herniation after gastric bypass surgery. [Doctoral Thesis, Maastricht University]. GVO drukkers \& vormgevers B.V. https://doi.org/10.26481/dis.20201126je

Document status and date:

Published: 01/01/2020

DOI:

10.26481/dis.20201126je

Document Version:

Publisher's PDF, also known as Version of record

\section{Please check the document version of this publication:}

- A submitted manuscript is the version of the article upon submission and before peer-review. There can be important differences between the submitted version and the official published version of record. People interested in the research are advised to contact the author for the final version of the publication, or visit the DOI to the publisher's website.

- The final author version and the galley proof are versions of the publication after peer review.

- The final published version features the final layout of the paper including the volume, issue and page numbers.

Link to publication

\footnotetext{
General rights rights.

- You may freely distribute the URL identifying the publication in the public portal. please follow below link for the End User Agreement:

www.umlib.nl/taverne-license

Take down policy

If you believe that this document breaches copyright please contact us at:

repository@maastrichtuniversity.nl

providing details and we will investigate your claim.
}

Copyright and moral rights for the publications made accessible in the public portal are retained by the authors and/or other copyright owners and it is a condition of accessing publications that users recognise and abide by the legal requirements associated with these

- Users may download and print one copy of any publication from the public portal for the purpose of private study or research.

- You may not further distribute the material or use it for any profit-making activity or commercial gain

If the publication is distributed under the terms of Article $25 \mathrm{fa}$ of the Dutch Copyright Act, indicated by the "Taverne" license above, 
Improving the accuracy of CT in diagnosing internal herniation after gastric bypass surgery

Jeannette Ederveen 
Improving the accuracy of CT in diagnosing internal herniation after gastric bypass surgery

(c) J.C. Ederveen, 2020

ISBN 978-94-6332-682-7

Layout Loes Kema

Print GVO drukkers \& vormgevers B.V.

All rights reserved. No part of this thesis may be reproduced in any form, by print, photocopy, digital file, internet or any other means without permission from the author or the copyright-owning journals for previously published chapters.

The research for this thesis was performed in and supported by Catharina Hospital Eindhoven.

This thesis was printed on $100 \%$ recycled materials. 


\title{
Improving the accuracy of CT in diagnosing internal herniation after gastric bypass surgery
}

\author{
PROEFSCHRIFT \\ ter verkrijging van de graad van doctor aan de Universiteit Maastricht, \\ op gezag van de Rector Magnificus, Prof.dr. Rianne M. Letschert \\ volgens het besluit van het College van Decanen, \\ in het openbaar te verdedigen \\ op donderdag 26 november 2020 om 14.00 uur \\ door \\ Jannetje Clasina Ederveen
}




\section{Promotor}

Prof. dr. S.G.F. Robben

\section{Copromotores}

Dr. J. Nederend (Catharina Ziekenhuis, Eindhoven)

Dr. S.W. Nienhuijs (Catharina Ziekenhuis, Eindhoven)

\section{Beoordelingscommissie}

Prof. dr. J.W.M. Greve (voorzitter)

Prof. dr. N.D. Bouvy

Dr. F.B.M. Joosten (Rijnstate Ziekenhuis, Arnhem)

Dr. J.B.C.M. Puylaert (AmsterdamUMC, Amsterdam) 


\section{Table of contents}

$\begin{array}{lll}\text { Chapter 1. General introduction } & 7\end{array}$

Chapter 2. Predictive value of abdominal CT in evaluating internal 17 herniation after bariatric laparoscopic Roux-en-Y gastric bypass

Br J Surg 2018; 105(12): 1623-1629

Chapter 3. Diagnosing internal herniation after laparoscopic

Roux-en-Y gastric bypass: usefulness of systematically reviewing $\mathrm{CT}$ scans using ten signs

Eur Radiol 2018; 28(9): 3583-3590

Chapter 4. Structured CT reporting improves accuracy in diagnosing internal herniation after laparoscopic Roux-en-Y gastric bypass

Eur Radiol 2020; 30(6): 3448-3454

Chapter 5. Lessons learned after CT misdiagnoses of internal herniation after gastric bypass

Submitted

Chapter 6. Internal herniation and weight loss in patients after

Roux-en-Y gastric bypass

Obes Surg (2020); 30(7): 2652-2658

Chapter 7. General discussion

Chapter 8. Valorisation

Chapter 9. Summary

Chapter 10. Samenvatting (Dutch) 109

Chapter 11. Dankwoord (Dutch)

Chapter 12. Curriculum Vitae

Chapter 13. List of Publications 



\section{Chapter 1.}

General introduction 
Obesity is a global health problem with an increasing prevalence in adults as well as children in developed as well as developing countries ${ }^{1}$. Obesity is defined as a body mass index (BMI; weight/heigth ${ }^{2}$ ) of $30.0 \mathrm{~kg} / \mathrm{m}^{2}$ or higher. A BMI between $25.0 \mathrm{~kg} / \mathrm{m}^{2}$ and $29.9 \mathrm{~kg} / \mathrm{m}^{2}$ is defined as overweight ${ }^{2}$. At least one third of the world's adult population are either overweight or obese ${ }^{3}$. Being overweight or obese results in a number of comorbidities which are a source of disease burden, diminished life expectancy and even mortality ${ }^{2-6}$. The increase in disease burden also increases healthcare costs ${ }^{5}$.

There are numerous lifestyle and pharmaceutical interventions to reduce body weight, however they seem to be minimal effective ${ }^{7}$. Bariatric surgery is the only proven modality for long-term results ${ }^{8,9}$. In the Netherlands the indication for bariatric surgery is a BMI of $40 \mathrm{~kg} / \mathrm{m}^{2}$ or higher, or a BMI between 35 and 40 $\mathrm{kg} / \mathrm{m}^{2}$ with serious comorbidities. The number of surgical options to diminish obesity is ever growing. From gastric banding and gastric reduction by means of sleeve gastrectomy, to a complete rearrangement of the digestive system by means of gastric bypass and its minor variants. Even with the higher costs of bariatric surgery, it is found to be cost effective due to the good outcomes in weight loss and reduction of comorbidities ${ }^{8}$.

The use of surgical techniques in the battle against obesity has increased with the increase of obese patients. A total of 40.765 bariatric operations were performed in the time period 2013-2018 in the Netherlands ${ }^{10}$. Gastric bypass surgery is currently the most used bariatric measure in the Netherlands, however sleeve gastrectomy is increasingly being used ${ }^{10}$. The most used gastric bypass procedure is the Roux-en-Y gastric bypass (Fig. 1).

During the Roux-en-Y gastric bypass procedure a small part of the stomach at the level of the oesophagus is stapled off: the gastric pouch. Furthermore, another dissection is made in the small bowel at around $80 \mathrm{~cm}$ from the stomach. The large part of the stomach, containing the cells producing digestive fluids, and the duodenum with the entry of the bile and pancreatic fluids are hereby disconnected from the digestive tract. This part of bowel with the digestive fluids is called the biliopancreatic limb. The pouch is then connected to the remaining small bowel, the jejunum and further on the ilium. However, without the digestive fluids food can't be processed. Therefore, the biliopancreatic limb is connected to the digestive tract around $150 \mathrm{~cm}$ past the pouch, this point is called the jejuno-jejunostomy and the bowel loop between the pouch and the jejuno-jejunostomy is called the alimentary limb. In current literature there is some debate about the ideal limb lengths for a good nutritional status and maximum weight loss ${ }^{11-14}$. The above-mentioned lengths are the commonly used limb lengths in the Netherlands.

Small parts of the mesentery are dissected from the jejunum to make the connections of the gastric bypass ${ }^{15}$. Because of the displacement of the 
bowel loops, that are now no longer fully connected to the mesentery, two openings are created. The first opening lies between the alimentary limb and the transverse colon. This opening is called Petersen's space. Furthermore, there is another opening at the level of the jejuno-jejunostomy, also called the mesenteric opening, because of the disconnection in the mesenteric membrane at this point ${ }^{16}$.

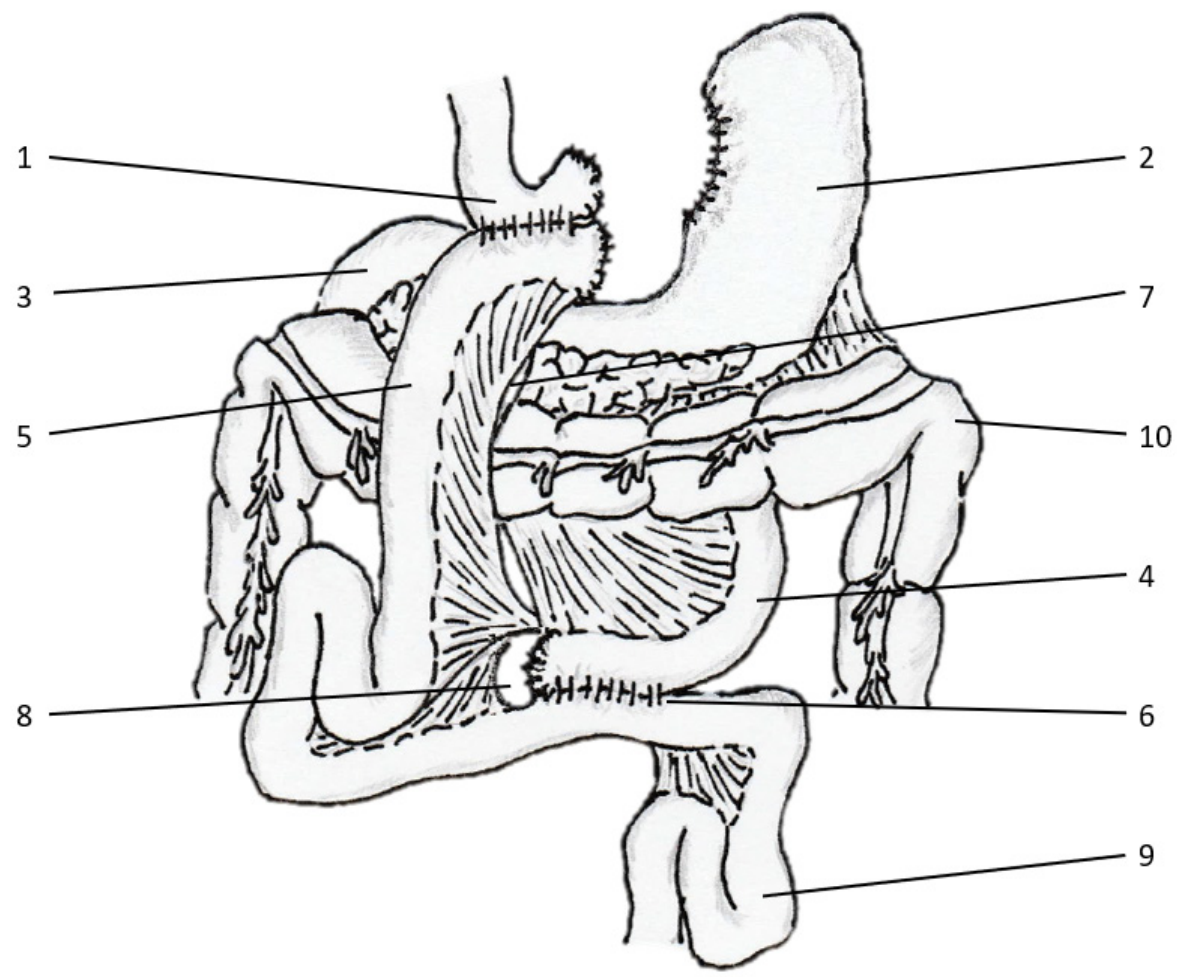

Fig. 1. Anatomy after gastric bypass surgery

1 = gastric pouch; 2 = stomach remnant; 3 = duodenum; 4 = biliary limb; 5 = alimentary limb; 6 = jejuno-jejunostomy; 7 = Petersen's space; 8 = mesenteric opening; 9 = jejunum; $10=$ colon

After a gastric bypass procedure multiple complications can occur. There is a difference between early and late complications, and minor and major complications. Early complications occur within 30 days after the operation. Major complications are mainly classified as resulting in death or reoperation, prolonged hospital stay of more than 7 days, or the need for blood transfusion. Early major complications reported after gastric bypass are bleeding, enterocutaneous fistula, infection, intestinal obstruction, anastomotic leaks, and torsion of enteroanastomosis ${ }^{17,18}$. Infection and bleeding were also seen as minor 
complications. Other early minor complications are dehydration and dysphagia ${ }^{17}$, 18. Late major complications are anastomotic ulcera, gastrojejunal stenosis, stricture, obstruction due to adhesions, hernia (both internal and at trocar-site), severe dumping syndrome, and dehydration ${ }^{19,20}$. Late minor complications are dumping, pneumonia, ulcer at gastrojejunal anastomosis, persisting trocarsite pain, diarrhoea, dehydration, hair loss, and anemia ${ }^{20}$. Other described complications are omental torsion or necrosis, pulmonary embolus and deep venous thrombosis, symptomatic cholelithiasis, cardiovascular complications, urinary tract infection, inadequate weight loss, and nutritional deficiencies ${ }^{15,17,19}$, ${ }^{21}$. The rate of complications differs between surgical techniques such as open and laparoscopic procedures and use of stapler devices. In current times most gastric bypass procedures are performed laparoscopically. Operating laparoscopically instead of open has many advantages in terms of perioperative complications, however it increases the risk of hernias by diminishing postoperative adhesions ${ }^{16}$, 21-23.

The previously described openings in the mesentery are the source of one of the late major complication after gastric bypass surgery, namely internal herniation (IH). An IH is the entrapment of a bowel loop or multiple bowel loops in one of these openings. There are two types of $\mathrm{IH}$, named after the site where they herniate, namely Petersen's herniation and mesenteric herniation ${ }^{21,} 24$. Furthermore, the alimentary limb can be positioned retrocolic or antecolic. With a retrocolic position of the alimentary limb another opening in the mesentery, the mesocolon in this instance, is created and therefore also another herniation space is created ${ }^{21}$. Multiple studies found a favouring for the antecolic positioning due to less $\mathrm{IHs}^{25-27}$. Therefore, a retrocolic position of the alimentary limb is nowadays not used. However, some patients with an older gastric bypass could still present with a retrocolic limb and herniation. Furthermore, closure of the mesenteric defects during the gastric bypass procedure was found to diminish $\mathrm{IH}$ and is therefore now standard practice ${ }^{28-30}$. The incidence of $\mathrm{IH}$ varies between $1.1 \%$ and $16 \%$ in recent studies, a meta-analysis found a incidence of $3.3 \%{ }^{24,26 \text {, }}$ 31,32 .

The goal of gastric bypass surgery is weight loss and reduction of morbidities related to obesity. However, the loss of intra-abdominal fat is also described as a risk factor for $\mathrm{IH}$ since it creates more room for bowel movement and possibly also enlarges the herniation sites by diminishing the fatty content ${ }^{16,19,22}$.

The most threatening of an $\mathrm{IH}$ is the risk of incarceration and eventually bowel ischemia. Incarceration causes abdominal pain, which might be more present after a meal due to the enhanced oxygen demand. Increased peristalsis may lead to cramping pain and colic. Sometimes the bowel repositions out of the herniation site without intervention leading to a reduction of complaints. IH can therefore be intermittent, with recurrence of symptoms at times of incarceration, but repositioning before ischemia ${ }^{23,24}$. 
Due to the risk of bowel ischemia a proper and early diagnosis of $\mathrm{IH}$ is necessary. A diagnostic laparoscopy is performed to make this diagnosis, if needed expanded with a therapeutic intervention ${ }^{23}$. However, the incidence of abdominal pain in patients after a gastric bypass surgery is high due to the possible complications of ulcera, dumping, and bowel obstruction, but also idiopathic, possibly due to adhesions or nerve damage. Operating all patients presenting with abdominal pain is not feasible with the potential risks of surgery. Therefore, the patients that most likely have an $\mathrm{IH}$ and need laparoscopy have to be discriminated from the general patient with abdominal complaints or patients with other complications. To select these patients a CT scan is increasingly used ${ }^{24,33-35}$. Ultrasound is not feasible because of its inability to properly visualize bowel location with an overview of the total intestines especially in obese patients. MRI can be used but there is less experience with this technique, resulting in lower accuracy. Moreover, technical limitations such as availability, duration and costs of a MRI reduce the use of this imaging technique. Currently, it is mostly used in pregnant patients in which radiation exposure is not desirable ${ }^{36,}$ ${ }^{37}$. Furthermore, fluoroscopy is described as imaging technique, however this is not widely used. ${ }^{37}$

The radiologist has to discriminate the normal postoperative anatomy after a gastric bypass from an $\mathrm{IH}$ or other complication. The signs of an $\mathrm{IH}$ are not always clear but the surgeons increasingly rely on the radiologist to make a correct diagnosis. Too much incorrect diagnoses means patients undergoing unnecessary operations with all the risks. However, if an IH is missed it can have potentially lethal consequences. Therefore, both the sensitivity and specificity of CT need to be high. To aid the radiologist different signs are formulated. One of the most known signs is the swirl sign. But also other signs are described ranging from relatively specific signs of bowel obstruction and displacement to more general signs such as mesenteric edema ${ }^{38-43}$. Furthermore, the aid of standardized reporting templates is found to be beneficial for both radiologist and surgeons. Radiologist make more complete and accurate reports, and surgeons better understand the reports and clinical value ${ }^{44-50}$.

The aim of this thesis was to investigate the usefulness of CT scans in diagnosing $\mathrm{IH}$. We searched for possible ways to improve the diagnosis on CT scan by using $\mathrm{CT}$ signs and structured reporting. Additionally, we investigated other factors that may help in the diagnostic process. 


\section{Outline of this thesis}

To investigate the diagnostic value of CT scans in diagnosing $\mathrm{IH}$, we explored the number of CT scans used in patients with a suspicion of $\mathrm{IH}$ after gastric bypass surgery and the accuracy of these CT scans in Chapter 2. Therefore, all patients with a gastric bypass were screened for CT scans and reoperations to identify patients with complaints of $\mathrm{IH}$. Reoperation reports and follow-up of 90 days were used as reference for the diagnosis made on CT scans. If in the period of 90 days after the CT scan no follow-up CT scan or reoperation was performed, the patient was considered to have no $\mathrm{IH}$. Due to the use of this follow-up period we could include all patients who underwent a CT scan.

Subsequently, we studied the use of ten CT signs. In Chapter 3 the CT signs were used to review the CT scans found in chapter two by means of a standardized reporting template with the ten $\mathrm{CT}$ signs and a 5-point Likert scale. This was performed by an abdominal radiologist, a radiologist in-training, and an intern with little experience. We investigated if the diagnostic accuracy improved using these ten signs to diagnose $\mathrm{IH}$, and if less-experienced readers could work with a standardized reporting template. In Chapter 4 we implemented the standardized template in clinical practice. All CT scans in our study centre from that point forward were documented on using the standardized template. These CT scans were compared with the previously reported CT scans with a free-text report.

In chapter 4 accuracy improved, however, not to a hundred percent. Therefore, in Chapter 5 we evaluated the misdiagnoses of $\mathrm{IH}$ on these previously reported CT scans. Patients complaints and surgery reports were thoroughly examined for possible other diagnoses. And all misdiagnosed CT scans were blindly reviewed by experienced readers to find possible wrongful diagnosis. The lessons learned from this evaluation were converted in recommendations for radiologists in diagnosing $\mathrm{IH}$.

There might be a range of other clinical diagnostics, such as symptoms and measurements, that can help in the diagnostic process of $\mathrm{IH}$. One of the clinical measurements postulated to influence $\mathrm{IH}$ is the amount of weight loss. In Chapter 6 we studied the influence of weight loss on the risk of developing $\mathrm{IH}$. The percentage of total weight loss was used as indicator for $\mathrm{IH}$ in the total post gastric bypass population and the patients presenting with complaints. Therefore, we used the preoperative and follow-up weights and weight at time of complaints. Furthermore, the type of complaints, such as cramping or colic pain and anorexia, were investigated as indicator for seriousness of the complaints and possible $\mathrm{IH}$. 


\section{References}

1. Ng M, Fleming T, Robinson M, Thomson B, Graetz N. Global, regional, and national prevalence of overweight and obesity in children and adults during 1980-2013 a systematic analysis for the Global Burden of Disease Study 2013. Lancet 384[9], 766-781. 30-8-2014. doi: 10.1016/S0140-6736(14)60460-8.

2. Apovian C. Obesity: Definition, Comorbidities, Causes, and Burden. Am J Manag Care 22[7], s176-185. 2016.

3. Seidell J, Halberstadt J. The global burden of obesity and the challenges of prevention. Ann Nutr Metab 66[Suppl 2], 7-12. 2015. doi: 10.1159/000375143.

4. GBD 2015 Obesity Collaborators, Afshin A, Forouzanfar M, Reitsma M, Sur P. Health Effects of Overweight and Obesity in 195 Countries over 25 Years. N Engl J Med 377[1], 13-27. 6-7-2017. doi: 10.1056/NEJMoa1614362.

5. Li Q, Blume S, Huang J, Hammer M, Ganz M. Prevalence and healthcare costs of obesity-related comorbidities: evidence from an electronic medical records system in the United States. J Med Econ 18[12], 1020-1028. 2015. doi: 10.3111/13696998.2015.1067623.

6. Williams E, Mesidor M, Winters K, Dubbert P, Wyatt S. Overweight and Obesity: Prevalence, Consequences, and Causes of a Growing Public Health Problem. Curr Obes Rep 4[3], 363-370. 2015. doi: 10.1007/s13679-015-0169-4.

7. Buchwald H, Avidor Y, Braunwald E et al. Bariatric Surgery: A Systematic Review and Meta-analysis. JAMA 292[1], 1724-1737. 13-10-2004.

8. Picot J, Jones J, Colquitt J et al. The clinical effectiveness and cost-effectiveness of bariatric (weight loss) surgery for obesity: a systematic review and economic evaluation. Health Technol Assess 13[41], 1-190, 215-357, iii-iv. 2009. doi: 10.3310/hta13410.

9. Colquitt J, Pickett K, Loveman E, Frampton G. Surgery for weight loss in adults. Cochrane Database Syst Rev [8]. 8-8-2014. doi: 10.1002/14651858.CD003641. pub4.

10. Welbourn R, Hollyman M, Kingsman R et al. Bariatric Surgery Worldwide: Baseline Demographic Description and One-Year Outcomes from the Fourth IFSO Global Registry Report 2018. Obes Surg 29[3], 782-795. 2019. doi: 10.1007/s11695-0183593-1.

11. Jarak I, Pereira S, Carvalho R et al. Gastric Bypass with Different Biliopancreatic Limb Lengths Results in Similar Post-absorptive Metabolomics Profiles. Obes Surg 30[3], 1068-1078. 2020. doi: 10.1007/s11695-019-04294-5.

12. Ruiz-Tovar J, Vorwald P, Gonzalez-Ramirez G et al. Impact of Biliopancreatic Limb Length $(70 \mathrm{~cm}$ vs $120 \mathrm{~cm}$ ), with Constant $150 \mathrm{~cm}$ Alimentary Limb, on Long-Term Weight Loss, Remission of Comorbidities and Supplementation Needs After RouxEn-Y Gastric Bypass: a Prospective Randomized Clinical Trial. 8. Obes Surg 29, 2367-2372. 2019. doi: 10.1007/s11695-019-03717-7.

13. Shah K, Nergaard B, Fagerland M, Gislason H. Distal gastric bypass: 2-m biliopancreatic limb construction with varying lengths of common channel. Surg Obes Relat Dis 15[9], 1520-1526. 2019. doi: 10.1016/j.soard.2019.05.003.

14. Ahmed B, King W, Gourash W et al. Proximal Roux-en-Y gastric bypass: Addressing 
the myth of limb length. Surgery 166[4], 445-455. 2019. doi: 10.1016/j. surg.2019.05.046.

15. Berbiglia L, Zografakis J, Dan A. Laparoscopic Roux-en-Y Gastric Bypass: Surgical Technique and Perioperative Care. Surg Clin North Am 96[4], 773-794. 1-8-2016. doi: 10.1016/j.suc.2016.03.003.

16. Iannelli A, Buratti M, Novellas S et al. Internal hernia as a Complication of Laparoscopic Roux-en-Y Gastric Bypass. Obes Surg 17[10], 1283-1286. 2007.

17. García-García M, Martín-Lorenzo J, Lirón-Ruiz R, Torralba-Martínez J, AguayoAlbasini J. Perioperative complications following bariatric surgery according to the clavien-dindo classification. Score validation, literature review and results in a single-centre series. Surg Obes Relat Dis 13[9], 1555-1561. 2017. doi: 10.1016/j. soard.2017.04.018.

18. Osland E, Yunus R, Khan S, Alodat T, Memon B, Memon M. Postoperative early major and minor complications in laparscopic vertical sleeve gastrectomy (LVSG) versus laparoscopic Roux-en-Y gastric bypass (LRYGB) procedures: a meta-analysis and systematic review. Obes Surg 26[10], 2273-2284. 2016. doi: 10.1007/s11695016-2101-8.

19. Hamdan K, Somers S, Chand M. Management of late postoperative complications of bariatric surgery. Br J Surg 98[10], 1345-1355. 2011. doi: 10.1002/bjs.7568.

20. Osland E, Yunus R, Khan S, Memon B, Memon M. Late postoperative complications in laparoscopic sleeve gastrectomy (LVSG) versus laparoscopic Roux-en-Y gastric bypass (LRYGB): Meta-analysis and systematic review. Surg Laparosc Endosc Percutan Tech 26[3], 193-201. 2016. doi: 10.1097/SLE.0000000000000279.

21. Blachar A, Federle M. Gastrointestinal complications of laparoscopic roux-en-Y gastric bypass surgery in patients who are morbidly obese: findings on radiography and CT. Am J Roentgenol 179[6], 1437-1442. 2002.

22. Ahmed A, Rickards G, Husain S, Johnson J, Boss T, O'Malley W. Trends in internal hernia incidence after laparoscopic Roux-en-Y gastric bypass. Obes Surg 17[12], 1563-1566. 2007.

23. Higa K, Ho T, Boone K. Internal Hernias after Laparoscopic Roux-en-Y Gastric Bypass: Incidence, Treatment and Prevention. Obes Surg 13[3], 350-354. 2003.

24. Kristensen S, Jess P, Floyd A, Eller A, Engberg A, Naver L. Internal herniation after laparoscopic antecolic Roux-en-Y gastric bypass: a nationwide Danish study based on the Danish National Patient Register. Surg Obes Relat Dis 12[2], 297-303. 2016. doi: 10.1016/j.soard.2015.10.059.

25. Cho M, Pinto D, Carrodeguas L et al. Frequency and management of internal hernias after laparoscopic antecolic antegastric Roux-en- $Y$ gastric bypass without division of the small bowel mesentery or closure of mesenteric defects: review of 1400 consecutive cases. Surg Obes Relat Dis 2[2], 87-91. 2006.

26. Geubbels N, Lijftogt N, Fiocco M, Leersum N, Wouters M, Brauw Ld. Meta-analysis of internal herniation after gastric bypass surgery. Br J Surg 102[5], 451-460. 2015. doi: 10.1002/bjs.9738.

27. Parakh S, Soto E, Merola S. Diagnosis and Management of Internal Hernias after Laparoscopic Gastric Bypass. Obes Surg 17[11], 1498-1502. 2007.

28. Aghajani E, Nergaard B, Leifson B, Hedenbro J, Gislason H. The mesenteric defects 
in laparoscopic Roux-en-Y gastric bypass: 5 years follow-up of non-closure versus closure using the stapler technique. Surg Endosc 31[9], 3743-3748. 2017. doi: 10.1007/s00464-017-5415-2.

29. Stenberg E, Szabo E, Ägren G et al. Closure of mesenteric defects in laparoscopic gastric bypass: a multicentre, randomised, parallel, open-label trial. Lancet 387[10026], 1397-1404. 2-4-2016. doi: 10.1016/S0140-6736(15)01126-5.

30. Stenberg E, Ottosson J, Szabo E, Näslund I. Comparing techniques for mesenteric defects closure in laparoscopic gastric bypass surgery-a register-based cohort study. Obes Surg 29[4], 1229-1235. 2019. doi: 10.1007/s11695-018-03670-x.

31. Rausa E, Bonavina L, Asti E, Maddalena G, Ricci C. Rate of Death and Complications in Laparoscopic and Open Roux-en-Y Gastric Bypass. A Meta-analysis and Metaregression Analysis on 69,494 Patients. Obes Surg 26[8], 1956-1963. 2016. doi: 10.1007/s11695-016-2231-z.

32. Magouliotis D, Tzovaras G, Tasiopoulou V, Christodoulidis G, Zacharoulis D. Closure of Mesenteric Defects in Laparoscopic Gastric Bypass: a Meta-Analysis. Obes Surg . 18-1-2020. doi: 10.1007/s11695-020-04418-2.

33. Geubbels N, Röell E, Acherman Y, Bruin S, Laar Avd, Brauw Ld. Internal Herniation After Laparoscopic Roux-en-Y Gastric Bypass Surgery: Pitfalls in Diagnosing and the Introduction of the AMSTERDAM Classification. Obes Surg 26[8], 1859-1866. 268-2016. doi: 10.1007/s11695-015-2028-5.

34. Sandvik J, Hole T, Klöckner C, Kulseng B, Wibe A. High-frequency of Computer Tomography and surgery for abdominal pain after Roux-en- $Y$ gastric bypass. Obes Surg 28[9], 2609-2616. 2018. doi: 10.1007/s11695-018-3223-y.

35. Riaz R, Myers D, Williams T. Multidetector CT imaging of bariatric surgical complications: a pictorial review. Abdom Radiol (NY) 41[1], 174-188. 2016. doi: 10.1007/s00261-015-0604-8.

36. Krishna S, Mclnnes M, Schieda N, Narayanasamy S, Sheikh A, Kielar A. Diagnostic Accuracy of MRI for Diagnosis of Internal Hernia in Pregnant Women With Prior Roux-en-Y Gastric Bypass. AJR Am J Roentgenol 211[4], 755-759. 2018. doi: 10.2214/AJR.17.19252.

37. Krishna S, Kielar A. Controversies and Pitfalls of Imaging Patients Postoperative Bariatric Surgery. Curr Radiol Rep 4[25], 1-11. 2016. doi: 10.1007/s40134-0160152-1.

38. Dilauro $M$, Mclnnes $M$, Schieda $N$ et al. Internal Hernia after Laparoscopic Rouxen-Y Gastric Bypass: Optimal CT Signs for Diagnosis and Clinical Decision Making. Radiology 282[3], 752-760. 2017. doi: 10.1148/radiol.2016160956.

39. Frøkjær J, Jensen W, Holt G, Omar H, Olesen S. The diagnostic performance and interrater agreement of seven CT findings in the diagnosis of internal hernia after gastric bypass operation. Abdom Radiol (NY) 43[12], 3220-3226. 2018. doi: 10.1007/s00261-018-1640-y.

40. Iannuccilli J, Grand D, Murphy B, Evangelista P, Roye G, Mayo-Smith W. Sensitivity and specificity of eight CT signs in the preoperative diagnosis of internal mesenteric hernia following Roux-en-Y gastric bypass surgery. Clin Radiol 64[4], 373-380. 2009. doi: 10.1016/j.crad.2008.10.008.

41. Kagoma Y, Gayer G. Computed Tomography of Internal Hernias Following 
Laparoscopic Roux-en-Y Gastric Bypass Surgery. Semin Ultrasound CT MR 39[2], 145-150. 2018. doi: 10.1053/j.sult.2017.11.002.

42. Lockhart M, Tessler F, Canon $\mathrm{C}$ et al. Internal hernia after gastric bypass: sensitivity and specificity of seven CT signs with surgical correlation and controls. Am J Roentgenol 188[3], 745-750. 2007.

43. Maier J, Herrasti Gallego A, Floyd A. Compression of the superior mesenteric vein - a sign of acute internal herniation in patients with antecolic laparoscopic Rouxen-Y gastric bypass. Eur Radiol 27[4], 1733-1739. 2017. doi: 10.1007/s00330-0164526-9.

44. Brook O, Brook A, Vollmer C, Kent T, Sanchez N, Pedrosa I. Structured Reporting of Multiphasic CT for Pancreatic Cancer: Potential Effect on Staging and Surgical Planning. Radiology 274[2], 464-472. 2015. doi: 10.1148/radiol.14140206.

45. Franconeri A, Fang J, Carney B et al. Structured vs narrative reporting of pelvic MRI for fibroids: clarity and impact on treatment planning. Eur Radiol 28[7], 3009-3017. 2018. doi: 10.1007/s00330-017-5161-9.

46. Franconeri A, Boos J, Fang J et al. Adnexal mass staging CT with a disease-specific structured report compared to simple structured report. Eur Radiol 29[9], 48514860. 2019. doi: 10.1007/s00330-019-06037-7.

47. Johnson T, Brinjikji W, Doolittle D, Nagelschneider A, Welch B, Kotsenas A. Structured Head and Neck CT Angiography Reporting Reduces Resident Revision Rates. Curr Probl Diagn Radiol 48[2], 114-116. 2019. doi: 10.1067/j.cpradiol.2018.04.003.

48. Poullos P, Tseng J, Melcher M et al. Structured Reporting of Multiphasic CT for Hepatocellular Carcinoma: Effect on Staging and Suitability for Transplant. Am J Roentgenol 210, 766-774. 2018. doi: 10.2214/AJR.17.18725.

49. Sala E, Freeman S. Structured reporting of pelvic MRI leads to better treatment planning of uterine leiomyomas. Eur Radiol 28[7], 3007-3008. 2018. doi: 10.1007/ s00330-018-5417-z.

50. Schoeppe F, Sommer W, Norenberg D et al. Structured reporting adds clinical value in primary CT staging of diffuse large B-cell lymphoma. Eur Radiol 28[9], 37023709. 2018. doi: 10.1007/s00330-018-5340-3. 


\section{Chapter 2.}

\section{Predictive value of abdominal CT in evaluating internal herniation after bariatric laparoscopic Roux-en-Y gastric bypass}

J.C. Ederveen, $\mathrm{MD}^{1}$

M.M.G. van Berckel, MD²

S.W. Nienhuijs, MD, $\mathrm{PhD}^{2}$

R.J.P. Weber, $M D^{3}$

J. Nederend, $\mathrm{MD}, \mathrm{PhD}^{1}$

${ }^{1}$ Department of Radiology, Catharina Hospital Eindhoven, The Netherlands

${ }^{2}$ Department of Surgery, Catharina Hospital Eindhoven, The Netherlands

${ }^{3}$ Department of Radiology, Sint Maartenskliniek Nijmegen, The Netherlands

Br J Surg 2018; 105(12): 1623-1629. doi: 10.1002/bjs.10886 


\begin{abstract}
Background

Internal herniation, a serious complication after bariatric surgery, is challenging to diagnose. The aim of this study was to determine the accuracy of abdominal $\mathrm{CT}$ in diagnosing internal herniation.

\section{Methods}

The study included consecutive patients who had undergone laparoscopic gastric bypass surgery between 1 January 2011 and 1 January 2015 at a bariatric centre of excellence. To select patients suspected of having internal herniation, reports of abdominal CT and reoperations up to 1 January 2017 were screened. CT was presumed negative for internal herniation if no follow-up CT or reoperation was performed within 90 days after initial CT, or no internal herniation was found during reoperation. The accuracy of abdominal CT in diagnosing internal herniation was calculated using two-way contingency tables.
\end{abstract}

\title{
Results
}

A total of 1475 patients were included ( $84.7 \%$ women, mean age 46.5 years, median initial BMI $41.8 \mathrm{~kg} / \mathrm{m}^{2}$ ). CT and/or reoperation was performed in 192 patients $(13 \%)$ in whom internal herniation was suspected. Internal herniation was proven laparoscopically in 37 of these patients. The incidence of internal herniation was $2.5 \%$. An analysis by complaint included a total of 265 episodes, for which 247 CT scans were undertaken. CT was not used to investigate 18 episodes, but internal herniation was encountered in one-third of these during reoperation. Combining the follow-up and intra-operative findings, the accuracy of CT for internal herniation has a sensitivity of $83.8 \%$ (95\% Cl 67.3-93.2\%), a specificity of $87.1 \%$ (95\% Cl $81.7-91.2 \%)$, a positive predictive value of $53.4 \%$ (95\% Cl $40.0-66.5 \%)$ and a negative predictive value of $96.8 \%(95 \% \mathrm{Cl} 92.9-$ $98.7 \%)$.

\section{Conclusion}

Abdominal CT is an important tool in diagnosing internal herniation, with a high specificity and a high negative predictive value. 


\section{Introduction}

The clinical diagnosis of internal herniation $(\mathrm{IH})$, a late complication of gastric bypass surgery, can be challenging. In the Netherlands, approximately 4000 gastric bypass surgeries were performed between 2013 and $2015^{1}$. The incidence of $\mathrm{IH}$ varied between $1.1 \%$ in a meta-analysis ${ }^{2}$ and $3.1 \%$ in a recent nationwide Danish study ${ }^{3}$. Therefore, IH after gastric bypass is a relevant problem and the prevalence of complaints with a suspicion of $\mathrm{IH}$ will be even higher.

Clinical symptoms are not specific for $\mathrm{IH}$ and vary in severity, ranging from intermittent symptoms in case of transient herniation of the bowel through a mesenteric defect, to severe and acute complaints after small bowel obstruction or strangulation of the vessels ${ }^{4-6}$. Because of the risk of strangulation, $\mathrm{IH}$ is a potentially life-threatening condition that requires surgical treatment. Laparoscopic surgery is the standard procedure for diagnosing $\mathrm{IH}$, but 19.5 to $28.1 \%$ of laparoscopies in patients suspected to have $\mathrm{IH}$ are negative ${ }^{3,5}$. To avoid unnecessary surgery, radiological imaging is frequently used in patients with suspected $\mathrm{IH}^{3,5}$.

There is limited evidence for the diagnostic accuracy of CT in diagnosing $\mathrm{IH}$. In 2007 , Agaba et al. ${ }^{7}$ reported a sensitivity of $66 \%$ and a specificity of $29 \%$ in 75 patients with acute abdominal complaints. More recently, Altieri et al..$^{8}$ noted a sensitivity of $76 \%$ and a specificity of $60 \%$ in a cohort of 50 patients. In other studies, 6, 9-14 with even smaller study populations, the sensitivity of CT ranged from $40 \%$ to $83.3 \%$. The technical aspects of CT have, however, changed and improved over the past decade, and different CT signs have been described to improve the value of $\mathrm{CT}$ in diagnosing $\mathrm{IH}$ (such as the swirl sign and venous congestion) ${ }^{15-18}$ (Fig. 1).

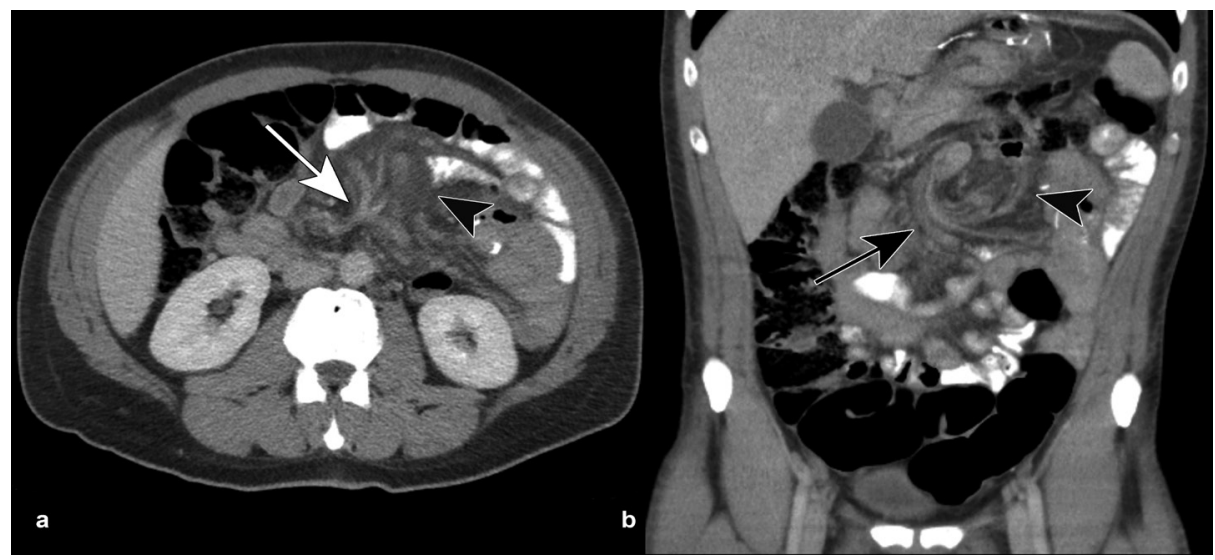

Fig. 1 a Axial and b coronal CT images of a patient with internal herniation, illustrating the swirl sign (black arrow), venous congestion (white arrow) and mesenteric oedema (arrowhead) 
The aim of this study was to evaluate the value of CT in diagnosing $\mathrm{IH}$ after gastric bypass surgery in terms of sensitivity, specificity, positive predictive value (PPV), and negative predictive value (NPV).

\section{Methods}

Patients were selected retrospectively from a database containing all patients who underwent bariatric surgery at Catharina Hospital, a bariatric centre of excellence. All consecutive patients who underwent laparoscopic gastric bypass between 1 January 2011 and 1 January 2015 were included. Information on demographics and type of surgery was extracted from the database. The local medical ethical review board waived ethical approval for this study.

\section{Surgical Technique}

All patients had undergone a laparoscopic Roux-en-Y gastric bypass (LRYGB) with an antecolic position of the jejunal limb. Both primary and secondary LRYGBs were included. Secondary LRYGB was performed on indication after sleeve gastrectomy, adjustable gastric banding or vertical banded gastroplasty. During the study interval, the routine technique was not to close mesenteric and Petersen defects, not to split the omentum, and an anti-rotation absorbable suture was used to fix the alimentary limb to the stomach remnant.

\section{Image Acquisition}

All CT images were acquired with Brilliance iCT 256-slice or Brilliance 64 CT scanners (Philips Medical, Best, the Netherlands) with a slice thickness of $1 \mathrm{~mm}$. Multiplanar reconstructions were available. One litre of diluted oral contrast (Telebrix ${ }^{\circledR}$ (ioxithalamate) $6 \mathrm{mg}$ iodine per $\mathrm{ml}$; Guerbet, Gorinchem, the Netherlands) was administered 90 min before imaging. All scans were performed $70 \mathrm{~s}$ after administration of $100 \mathrm{ml}$ intravenous contrast (Iomeron ${ }^{\circledR}$ (iomeprol) 300 mg iodine per ml; Bracco Imaging, Konstanz, Germany).

All images were interpreted by the attending radiologist. No standard method was used to interpret CT images acquired for clinical suspicion of $\mathrm{IH}$.

\section{Image analysis}

All abdominal CT scans performed for suspicion of IH until 1 January 2017 were cross-checked by identification number of patients undergoing gastric bypass. The CT reports and conclusions were reviewed for the radiological diagnosis or suspicion of $\mathrm{IH}$. In patients with a suspicion of $\mathrm{IH}$, the date of first complaints associated with $\mathrm{IH}$, types of complaint and outcome of reoperation were extracted from the electronic patient file. If the patient had a complaint episode evaluated at another hospital, the CT images and radiological report were requested and added to the study materials. 


\section{Reoperations}

All reoperations after the initial gastric bypass until 1 January 2017 were screened to select patients who had surgery for suspected $\mathrm{IH}$. Indications included clinical suspicion of $\mathrm{IH}$ without preoperative $\mathrm{CT}$, clinical suspicion of $\mathrm{IH}$ after a positive CT scan, but also clinical suspicion of IH after negative CT. Surgical reports were screened for the presence of $\mathrm{IH}$, defined as herniation of bowel through a mesenteric defect at the gastrojejunostomy (Petersen's space) or the jejunojejunostomy. Defects without bowel herniation were also documented, and recorded as having no $\mathrm{IH}$. Any mesenteric defects, at Petersen's space and/or jejunojejunostomy, found during reoperation were closed during the operation regardless of bowel herniation.

\section{Episode definition}

If neither CT nor reoperation was performed within 90 days after the initial CT, the episode of suspected IH was considered negative. New CT scans or reoperations after this period were considered to indicate new episodes of suspected $\mathrm{IH}$ in the analysis. If $\mathrm{CT}$ and reoperation were undertaken within the first 2 days of the start of symptoms, the episode was considered acute. A subgroup analysis was performed of the value of CT in an acute setting.

\section{Statistical Analysis}

All data were entered into a computerized spreadsheet (Excel®; Microsoft, Redmond, Washington, USA) and analysed using SPSS ${ }^{\circledR}$ version 21.0 (IBM, Armonk, New York, USA). Patient characteristics are presented as mean (SD) or median (range), depending on the normality of the distribution. Continuous data were compared with the independent-samples $t$ test or the Mann-Whitney $U$ test, as appropriate, and $\chi^{2}$ test or Fisher's exact test was used for analysis of categorical data. The sensitivity, specificity, PPV and NPV of CT were calculated using two-way contingency tables. The significance level was set at $p<0.05$.

\section{Results}

A total of 1475 patients underwent laparoscopic gastric bypass surgery with a median follow-up of 44 months. Patient characteristics are shown in Table 1.

In all, 192 patients (13.0\%) underwent CT and/or reoperation for abdominal complaints suspicious for $\mathrm{IH}$. The median time interval from gastric bypass surgery until the first episode of such complaints was 415 (range 0-1689) days. The types of complaint are summarized in Table 2. IH was found in 37 patients, an incidence of $2.5 \%$. On five occasions the $\mathrm{IH}$ was confirmed twice in the same patient. 
Table 1: Characteristics of patients after laparoscopic gastric bypass surgery with or without proven internal herniation

\begin{tabular}{|c|c|c|c|c|}
\hline Characteristic & $\begin{array}{l}\text { Total population } \\
(n=1475)\end{array}$ & $\begin{array}{l}\mathrm{IH} \\
(n=37)\end{array}$ & $\begin{array}{l}\text { No IH } \\
(n=1438)\end{array}$ & $p$-value \\
\hline $\begin{array}{l}\text { Sex } \\
\text { Male (n (\%)) } \\
\text { Female (n (\%)) }\end{array}$ & $\begin{array}{l}226(15.3) \\
1249(84.7)\end{array}$ & $\begin{array}{l}8(21.6) \\
29(78.4)\end{array}$ & $\begin{array}{l}218(15.2) \\
1220(84.8)\end{array}$ & $0.281^{*}$ \\
\hline Age $(y$, mean $( \pm S D))$ & $46.5( \pm 10.2)$ & $45.0(8.6)$ & $46.5(10.2)$ & $0.360^{\wedge}$ \\
\hline $\begin{array}{l}\text { Initial BMI (kg/m², } \\
\text { median (range)) }\end{array}$ & $41.8(22.7-80.7)$ & $41.4(32.9-48.3)$ & $41.8(22.7-80.7)$ & $0.390^{\sim}$ \\
\hline
\end{tabular}

${ }^{*}$ independent-samples $t$ test; ${ }^{\wedge} \chi^{2}$ test; $\sim$ Mann-Whitney $U$ test. $\mathrm{IH}=$ internal herniation; SD = standard deviation; $\mathrm{BMI}=$ body mass index.

Table 2: Types of symptom at presentation in patients with complaints compared with those with complaints and proven $\mathrm{IH}$

\begin{tabular}{|c|c|c|c|}
\hline Symptom & $\begin{array}{l}\text { Episodes without IH } \\
(\mathrm{n}=222)\end{array}$ & $\begin{array}{l}\text { Episodes with IH } \\
(\mathrm{n}=43)\end{array}$ & $p$-value* \\
\hline $\begin{array}{l}\text { Abdominal pain } \\
\text { Present } \\
\text { Absent } \\
\text { Missing }\end{array}$ & $\begin{array}{l}218(98.2) \\
3(1.4) \\
1(0.5)\end{array}$ & $43(100)$ & $0.657^{\wedge}$ \\
\hline $\begin{array}{l}\text { Abdominal cramping/colic } \\
\text { Present } \\
\text { Absent } \\
\text { Missing }\end{array}$ & $\begin{array}{l}41(18.5) \\
143(64.4) \\
38(17.1)\end{array}$ & $\begin{array}{l}14(32.6) \\
18(41.9) \\
11(25.6)\end{array}$ & 0.020 \\
\hline $\begin{array}{l}\text { Nausea/vomiting } \\
\text { Present } \\
\text { Absent } \\
\text { Missing }\end{array}$ & $\begin{array}{l}111(50.0) \\
64(28.8) \\
47(21.2)\end{array}$ & $\begin{array}{l}19(44.2) \\
17(39.5) \\
7(16.3)\end{array}$ & 0.364 \\
\hline $\begin{array}{l}\text { Abnormal defecation } \\
\text { Present } \\
\text { Absent } \\
\text { Missing }\end{array}$ & $\begin{array}{l}52(23.4) \\
122(55.0) \\
48(21.6)\end{array}$ & $\begin{array}{l}14(32.6) \\
20(46.5) \\
9(20.9)\end{array}$ & 0.429 \\
\hline $\begin{array}{l}\text { Anorexia } \\
\text { Present } \\
\text { Absent } \\
\text { Missing }\end{array}$ & $\begin{array}{l}50(22.5) \\
114(51.4) \\
58(26.1)\end{array}$ & $\begin{array}{l}8(18.6) \\
20(46.5) \\
15(34.9)\end{array}$ & 0.491 \\
\hline
\end{tabular}

Values in parentheses are percentages. IH = Internal herniation; * $\chi^{2}$ test; except; ^Fisher's exact test; the analysis excluded patients with missing data.

\section{CT results}

Among the 192 patients with complaints, there was a total of 265 episodes with a suspicion of IH (Fig. 2). A total of 247 CT scans were performed during 
these epsiodes (93.2\%), with a radiological suspicion of IH in 58 (23.5\%). Of the remaining 189 scans, 135 (54.7\%) showed no abnormalities and 54 (21.9\%) led to alternative diagnoses, mainly anastomotic complications. The median interval from the first clinical presentation with complaints suspected to indicate $\mathrm{IH}$ to CT was 8 (range 0-396) days.

\section{Reoperations}

A total of 90 reoperation reports were analysed. IH was confirmed in 42 reoperations (46.7\%). In the remaining 48 reoperations, no explanation for the complaints was found (13), possible herniation sites were closed without identification of $\mathrm{IH}(21)$, in nine operations adhesiolysis was undertaken with (6 of 9) or without (3 of 9) closure of possible herniation sites, the gastrojejunostomy was revised (3), and a gastric perforation was found and closed (2). Altogether, a mesenteric defect was closed with or without $\mathrm{IH}$ in 70 reoperations. Details of defects and herniation sites are shown in Table 3. There were no instances of $\mathrm{IH}$ that required bowel resection.

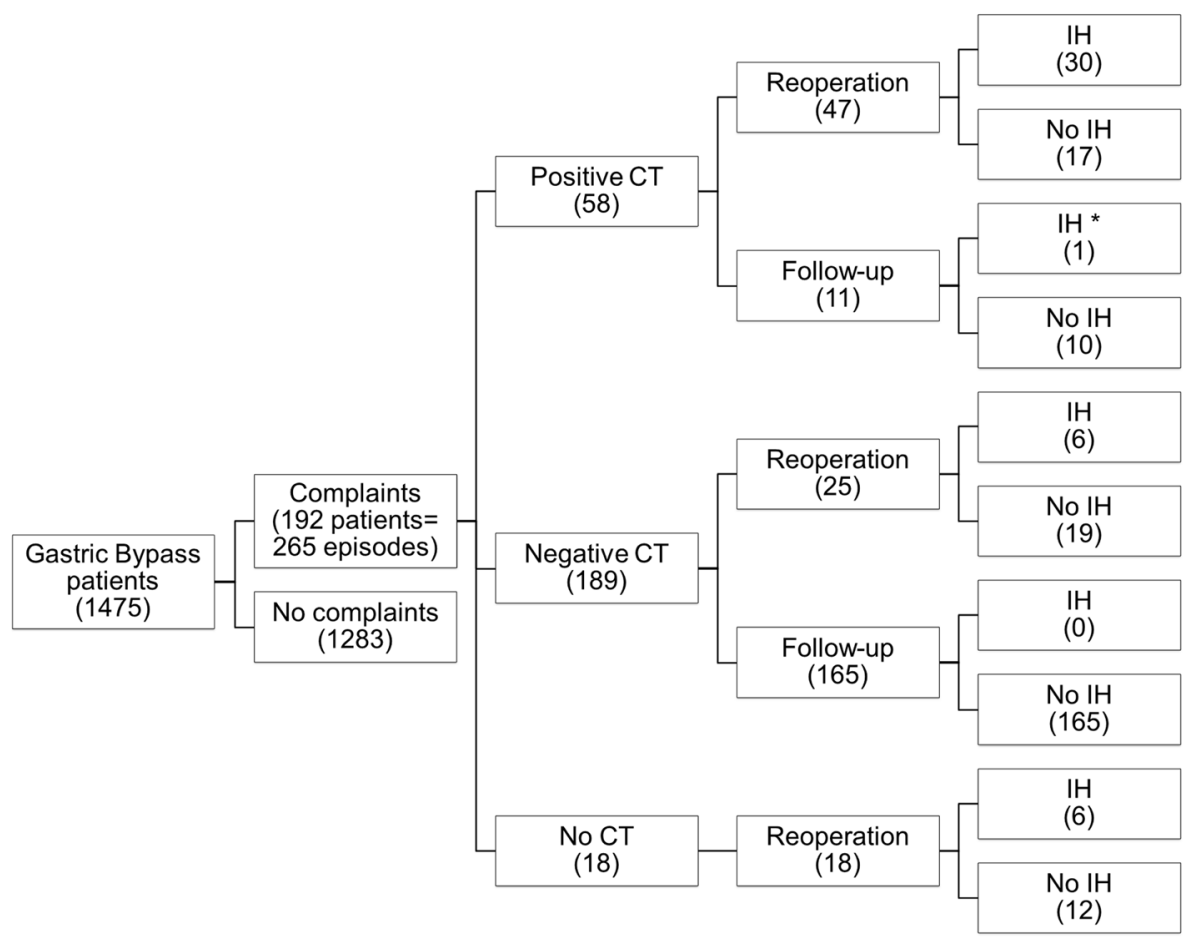

Fig. 2: Distribution of confirmed internal herniation $(\mathrm{IH})$ after reoperation with or without CT.

${ }^{*} \mathrm{~A}$ second positive CT was performed within 90 days of the first positive $\mathrm{CT}$, with subsequent reoperation. 
The median interval from start of complaints to operation was 25.5 (range 0-364) days, and that from CT to reoperation was 6 (range 0-74) days. CT and reoperation were undertaken within 2 days of the start of complaints in 17 of the 265 episodes (6.4\%).

Table 3: Types of herniation and defects observed and treated during reoperation

\begin{tabular}{lll}
\hline Type of herniation & $\begin{array}{l}\text { Herniation } \\
(\mathbf{n}=90)\end{array}$ & $\begin{array}{l}\text { Defects } \\
(\mathbf{n}=90)\end{array}$ \\
\hline Petersen & $22(24.4)$ & $25(27.8)$ \\
Jejunojejunostomy & $17(18.9)$ & $20(22.2)$ \\
Both & $3(3.3)$ & $25(27.8)$ \\
None & $48(53.3)$ & $20(22.2)$ \\
\hline
\end{tabular}

Values in parentheses are percentages.

\section{Accuracy of CT}

Data on the accuracy of CT in diagnosing internal herniation compared with operative findings, overall and in the acute setting, and compared with operative and follow-up findings, are summarized in Tables 4 and 5.

Table 4: Accuracy of CT in diagnosing IH overall and in the acute setting, with reoperation as reference

\begin{tabular}{|c|c|c|c|c|c|}
\hline & \multicolumn{2}{|c|}{ Internal herniation } & \multicolumn{2}{|l|}{ Defects } & \multirow[b]{2}{*}{$p$-value* } \\
\hline & $\mathrm{n}$ & $\%$ & $\mathrm{n}$ & $\%$ & \\
\hline \multicolumn{6}{|l|}{ Overall } \\
\hline Sensitivity & 30 of 36 & $83.3(66.5-93.0)$ & 39 of 54 & $72.2(58.1-83.1)$ & 0.222 \\
\hline Specificity & 19 of 36 & $52.8(35.7-69.2)$ & 10 of 18 & $55.6(31.3-77.6)$ & 0.847 \\
\hline $\begin{array}{l}\text { Positive } \\
\text { predictive value }\end{array}$ & 30 of 47 & $63.8(48.5-76.9)$ & 39 of 47 & $83.0(68.7-91.9)$ & 0.036 \\
\hline $\begin{array}{l}\text { Negative } \\
\text { predictive value }\end{array}$ & 19 of 25 & $76.0(54.5-89.8)$ & 10 of 25 & $40.0(21.8-61.1)$ & 0.010 \\
\hline \multicolumn{6}{|l|}{ Acute setting } \\
\hline Sensitivity & 10 of 10 & $100(65.5-100)$ & 11 of 11 & $100(67.9-100)$ & 1.000 \\
\hline Specificity & 4 of 7 & $57.1(20.2-88.2)$ & 4 of 6 & $66.7(24.1-94.0)$ & 0.725 \\
\hline $\begin{array}{l}\text { Positive } \\
\text { predictive value }\end{array}$ & 10 of 13 & 76.9 (46.0-93.8) & 11 of 13 & $84.6(53.7-97.3)$ & 0.619 \\
\hline $\begin{array}{l}\text { Negative } \\
\text { predictive value }\end{array}$ & 4 of 4 & $100(39.6-100)$ & 4 of 4 & $100(39.6-100)$ & 1.000 \\
\hline
\end{tabular}

Values in parentheses are $95 \%$ confidence intervals. ${ }^{*} \chi^{2}$ test. 
Internal herniation was found during reoperation after six negative CT scans. Reassessment of the images showed that the CT findings were not unequivocally negative in three of these patients. In one, the finding was described as an invagination, whereas in two others the surgeon had interpreted the CT scan as showing internal herniation. In the remaining three patients, persisting complaints led to reoperation between 16 and 41 days after the negative CT.

Table 5: Accuracy of $\mathrm{CT}$ in diagnosing IH, with reoperation and follow-up as reference

\begin{tabular}{lll}
\hline & \multicolumn{2}{l}{ Internal herniation } \\
\cline { 2 - 3 } & $\mathbf{n}$ & $\%$ \\
\hline Sensitivity & 31 of 37 & $83.8(67.3-93.2)$ \\
Specificity & 183 of 210 & $87.1(81.7-91.2)$ \\
Positive predictive value & 31 of 58 & $53.4(40.0-66.5)$ \\
Negative predictive value & 183 of 189 & $96.8(92.9-98.7)$ \\
\hline
\end{tabular}

Values in parentheses are $95 \%$ confidence intervals.

\section{Discussion}

In this investigation of the value of abdominal CT in diagnosing IH in symptomatic patients after laparoscopic gastric bypass surgery, the accuracy was calculated among 247 CT scans from a cohort of 1475 patients, using a combination of follow-up and reoperation as reference. This resulted in a sensitivity of $83.8 \%$, a specificity of $87.1 \%$, a PPV of $53.4 \%$, and a NPV of $96.8 \%$. In an acute setting, the sensitivity was $100 \%$, with a specificity of $57 \%$, PPV $77 \%$ and NPV $100 \%$, with reoperation as reference.

The incidence of $\mathrm{IH}$ in symptomatic patient is this study was $2.5 \%$. This is comparable to that in a recent meta-analysis by Geubbels et al. ${ }^{19}$, who reported an incidence of $2 \%$ among patients who had an antecolic LRYGB with the defects left open. The incidence in the group with closure of all defects was lower (1\%). Furthermore, in a recent $\mathrm{RCT}^{20}$, the incidence of $\mathrm{IH}$ decreased when defects were closed, from $7.3 \%$ to $2.2 \%$. As a result of these and other published findings, bariatric surgeons at the authors' unit started to close the defects during LRYGB from 2016 onwards.

The median interval from initial surgery to start of complaints indicative of $\mathrm{IH}$ was 14 (range 0-54) months. This is comparable to recent studies that reported a median time until $\mathrm{IH}$ diagnosis of 9 and 15 months respectively $\mathrm{y}^{3,5}$. The most frequent complaint was abdominal pain, which occurred in $98.5 \%$ of the episodes. Nausea or vomiting was reported in $49.1 \%$ of the episodes. Abdominal cramping or colic pain in the umbilical region was significantly more common in the IH group. Geubbels et al. ${ }^{5}$ reported that cramping or colic pain was the most 
common symptom in patients with $\mathrm{IH}$. Abdominal pain and nausea or vomiting were the most common complaints in several previous studies $3,4,7,11,12$.

A Petersen herniation was seen in half of those with an $\mathrm{IH}$ in this study (22 of 42). In older studies ${ }^{6,10,13,14}$, jejunojejunostomy hernias occurred more frequently than Petersen hernias, whereas more recent studies ${ }^{3,5,9,11}$ found more Petersen hernias, with rates ranging from $40.5 \%$ to $75 \%$. Defects were found to be equally distributed over the two sites in the present study.

The accuracy of abdominal CT in the present study was comparable to that in a recent smaller study of 52 reoperations ${ }^{8}$, which reported a sensitivity of $76 \%$ (versus $83 \%$ here) and specificity of $60 \%$ (versus 53\%). The findings were not in line with those in studies by Agaba et al. ${ }^{7}$ and Karilla-Cohen et al. ${ }^{21}$, in which sensitivities of $66 \%$ and $32 \%$, and specificities of $29 \%$ and $54 \%$, respectively were reported. The increase in accuracy in the present study compared to the Agaba study from $2008^{7}$, is likely to be explained by the development of more signs for diagnosis of $\mathrm{IH}$ on CT. Several studies ${ }^{15,18,21}$ have reported better diagnostic accuracy with the use of these CT signs. Furthermore, the quality of CT scanners and the use of multiplanar reconstructions might have contributed to the improvement in accuracy.

The accuracy of CT was investigated here using reoperation combined with a negative follow-up time of 90 days as reference. The authors assumed this combination to be the best way to evaluate the value of negative $\mathrm{CT}$, as the existence of $\mathrm{IH}$ is considered very unlikely after 90 days without the need for further imaging or surgery. There seem to be no data on including follow-up as a reference in current literature. When follow-up and reoperation was used as reference, there was an increase in specificity and negative predictive value. The accuracy of $\mathrm{CT}$ in diagnosing $\mathrm{IH}$ was comparable between the first or subsequent episodes, and between patients with one episode and those with more episodes. The PPV after CT was higher than that of episodes leading to reoperation without preoperative CT. Preoperative CT is therefore advised in all patients suspected to have $\mathrm{IH}$. The surgeon might nevertheless decide on surgical exploration despite negative radiological findings on the basis of clinical suspicion.

IH can be intermittent, resulting in more chronic abdominal pain. ${ }^{9}$ Owing to the absence of acute complaints, the interval between complaints, imaging and reoperation might be longer, with no $\mathrm{IH}$ visible on $\mathrm{CT} .{ }^{22}$ An additional analysis was performed in patients with open herniation sites, with the aim of identifying patients with a history of intermittent $\mathrm{IH}$. The presence of defects during reoperation might, however, not always be a definite indicator of intermittent $\mathrm{IH}$. Analysis of open herniation sites led to a decrease in NPV. The PPV increased, which might contribute to the hypothesis that intermittent $\mathrm{IH}$ was present at the time of $\mathrm{CT}$, but absent during reoperation. In an analysis including only patients treated in the acute setting, the diagnostic accuracy of CT did not differ 
between IH and observed defects. These findings could support the intermittent $\mathrm{IH}$ hypothesis. In an acute setting, the sensitivity and NPV increased, with a slight increase in specificity and PPV. This increase was not significant owing to the small number of patients in the acute setting.

The strength of the present study is the large population in which the accuracy of CT in diagnosing $\mathrm{IH}$ was investigated. By adding follow-up data, the clinical outcome data are more complete. There are also certain limitations to this study; abdominal CT was not undertaken in asymptomatic patients and no reoperations were performed in patients without IH on CT. These limitations are difficult to overcome, but adding the 90-day follow-up as a reference could compensate for this uncertainty. There is also selection bias, as not all patients with abdominal complaints were included. Patients were included in the cohort based on whether or not CT and/or reoperation were performed. On the other hand, the risk of $\mathrm{IH}$ was assumed to be very low in patients with abdominal complaints not severe enough to lead to CT or reoperation. Another limitation might be the follow-up time of 2-5 years, as the time until presentation with complaints varies from less than $24 \mathrm{~h}$ after surgery to 9 years ${ }^{19}$. Although $90 \%$ of IH develop within 20-36 months, longer follow-up might have resulted in a higher incidence ${ }^{3,5}$.

The use of specific CT signs, such as the swirl sign, might further improve the accuracy of CT in diagnosing $\mathrm{IH}$. Future research is needed on the benefit of systematic reading of CT images with use of the different signs described in the literature. Furthermore, more research into the follow-up after CT for suspected $\mathrm{IH}$ is desirable. Only a small percentage of patients undergo reoperation after CT; little is known about the development of complaints in other patients. Another problem is the high rate of CT imaging in the bariatric population, which is higher than that in the general population, with risks of repeated irradiation. CT could be replaced by MRI, but more research into the accuracy of MRI in diagnosing IH is required. More investigation of intermittent $\mathrm{IH}$ is also needed as this probably occurs frequently in patients with chronic abdominal complaints.

The present study has shown that abdominal CT is an important tool in diagnosing $\mathrm{IH}$. Owing to its high specificity and NPV, using CT in the diagnostic evaluation can prevent unnecessary reoperations. 


\section{References}

1. Welbourn R, Pournaras D, Dixon J et al. Bariatric Surgery Worldwide: Baseline Demographic Description and One-Year Outcomes from the Second IFSO Global Registry Report 2013-2015. Obes Surg doi: 10.1007/s11695-017-2845-9. 18-82017.

2. Rausa E, Bonavina L, Asti E, Maddalena G, Ricci C. Rate of Death and Complications in Laparoscopic and Open Roux-en-Y Gastric Bypass. A Meta-analysis and Metaregression Analysis on 69,494 Patients. Obes Surg 26[8], 1956-1963. 2016. doi: 10.1007/s11695-016-2231-z.

3. Kristensen S, Jess P, Floyd A, Eller A, Engberg A, Naver L. Internal herniation after laparoscopic antecolic Roux-en-Y gastric bypass: a nationwide Danish study based on the Danish National Patient Register. Surg Obes Relat Dis 12[2], 297-303. 2016. doi: 10.1016/j.soard.2015.10.059.

4. Garza E, Kuhn J, Arnold D, Nicholson W, Reddy S, McCarty T. Internal hernias after laparoscopic Roux-en-Y gastric bypass. Am J Med 188[6], 796-800. 2004.

5. Geubbels N, Röell E, Acherman Y, Bruin S, Laar Avd, Brauw Ld. Internal Herniation After Laparoscopic Roux-en-Y Gastric Bypass Surgery: Pitfalls in Diagnosing and the Introduction of the AMSTERDAM Classification. Obes Surg 26[8], 1859-1866. 268-2016. doi: 10.1007/s11695-015-2028-5.

6. Higa K, Ho T, Boone K. Internal Hernias after Laparoscopic Roux-en-Y Gastric Bypass: Incidence, Treatment and Prevention. Obes Surg 13[3], 350-354. 2003. Ref Type: Generic

7. Agaba E, Gentles C, Shamseddeen $\mathrm{H}$ et al. Retrospective analysis of abdominal pain in postoperative laparoscopic Roux-en-Y gastric bypass patients: is a simple algorithm the answer? Surg Obes Relat Dis 4[5], 587-593. 2008. doi: 10.1016/j. soard.2007.10.015.

8. Altieri M, Pryor A, Telem D, Hall K, Brathwaite C, Zawin M. Algorithmic approach to utilization of CT scans for detection of internal hernia in the gastric bypass patient. Surg Obes Relat Dis 11[6], 1207-1211. 2015. doi: 10.1016/j.soard.2015.02.010.

9. Al-Mansour M, Mundy R, Canoy J, Dulaimy K, Kuhn J, Romanelli J. Internal Hernia After Laparoscopic Antecolic Roux-en-Y Gastric Bypass. Obes Surg 25[11], 21062111. 2015. doi: 10.1007/s11695-015-1672-0.

10. Iannelli A, Buratti M, Novellas S et al. Internal hernia as a Complication of Laparoscopic Roux-en-Y Gastric Bypass. Obes Surg 17[10], 1283-1286. 2007.

11. Obeid A, McNeal S, Breland M, Stahl R, Clements R, Grams J. Internal Hernia After Laparoscopic Roux-en-Y Gastric Bypass. J Gastrointest Surg 18[2], 250-256. 2014. doi: 10.1007/s11605-013-2377-0.

12. Onopchenko A. Radiological Diagnosis of Internal Hernia after Roux-en-Y Gastric Bypass. Obes Surg 15[5], 606-611. 2005.

13. Parakh S, Soto E, Merola S. Diagnosis and Management of Internal Hernias after Laparoscopic Gastric Bypass. Obes Surg 17[11], 1498-1502. 2007.

14. Paroz A, Calmes J, Giusti V, Suter M. Internal Hernia after Laparoscopic Roux-en-Y Gastric Bypass for Morbid Obesity: A Continuous Challenge in Bariatric Surgery. Obes Surg 16[11], 1482-1487. 2006. 
15. Dilauro $M$, Mclnnes $M$, Schieda $N$ et al. Internal Hernia after Laparoscopic Rouxen-Y Gastric Bypass: Optimal CT Signs for Diagnosis and Clinical Decision Making. Radiology 282[3], 752-760. 2017. doi: 10.1148/radiol.2016160956.

16. Goudsmedt F, Deylgat B, Coenegrachts K, Moortele Kvd, Dillemans B. Internal hernia after laparoscopic Roux-en-Y gastric bypass: a correlation between radiological and operative findings. Obes Surg 25[4], 622-627. 2015. doi: 10.1007/s11695-0141433-5, doi: 10.1007/s11695-014-1433-5.

17. Iannuccilli J, Grand D, Murphy B, Evangelista P, Roye G, Mayo-Smith W. Sensitivity and specificity of eight CT signs in the preoperative diagnosis of internal mesenteric hernia following Roux-en-Y gastric bypass surgery. Clin Radiol 64[4], 373-380. 2009. doi: 10.1016/j.crad.2008.10.008.

18. Lockhart M, Tessler F, Canon $\mathrm{C}$ et al. Internal hernia after gastric bypass: sensitivity and specificity of seven CT signs with surgical correlation and controls. Am J Roentgenol 188[3], 745-750. 2007.

19. Geubbels N, Lijftogt N, Fiocco M, Leersum N, Wouters M, Brauw Ld. Meta-analysis of internal herniation after gastric bypass surgery. Br J Surg 102[5], 451-460. 2015. doi: 10.1002/bjs.9738.

20. Stenberg E, Szabo E, Ägren G et al. Closure of mesenteric defects in laparoscopic gastric bypass: a multicentre, randomised, parallel, open-label trial. Lancet 387[10026], 1397-1404. 2-4-2016. doi: 10.1016/S0140-6736(15)01126-5.

21. Karila-Cohen P, Cuccioli F, Tammaro P et al. Contribution of Computed Tomographic Imaging to the Management of Acute Abdominal Pain after Gastric Bypass: Correlation Between Radiological and Surgical Findings. Obes Surg 27[8], 19611972. 2017. doi: 10.1007/s11695-017-2601-1.

22. Greenstein A, O'Rourke R. Abdominal pain after gastric bypass: suspects and solutions. Am J Med 201[6], 819-827. 2011. doi: 10.1016/j.amjsurg.2010.05.007. 



\section{Chapter 3.}

\section{Diagnosing internal herniation after laparoscopic Roux-en-Y gastric bypass: usefulness of systematically reviewing CT scans using ten signs}

J.C. (Jeannette) Ederveen, MD ${ }^{1}$

M.M.G. (Marijn) van Berckel, MD2

S. (Saskia) Jol, MD ${ }^{1}$

S.W. (Simon) Nienhuijs, MD, PhD²

J. (Joost) Nederend, MD, $\mathrm{PhD}^{1}$

${ }^{1}$ Department of Radiology, Catharina Hospital Eindhoven, The Netherlands

${ }^{2}$ Department of Surgery, Catharina Hospital Eindhoven, The Netherlands 


\begin{abstract}
Objectives

To evaluate if systematically reviewing CT scans using ten signs leads to a better accuracy in diagnosing internal herniation $(\mathrm{IH})$, compared to the original report. Also, the difference in accuracy was analysed between experience levels.

\section{Methods}

Patients were retrospectively included if they had undergone laparoscopic gastric bypass surgery between 2011 and 2014, and if additional radiological examination was performed for suspected IH between 2011 and 2016. Out of 1475 patients who had undergone laparoscopic gastric bypass surgery, 183 patients had one or more additional radiological examinations. A total of 245 CT scans were performed. All were reassessed by an abdominal radiologist, a radiology resident and intern. Assessment was done using ten signs from previous literature. Overall suspicion of $\mathrm{IH}$ was graded using a 5-point Likert scale. Accuracy was calculated using two-way contingency tables. Interobserver agreement was calculated using Fleiss' Kappa.
\end{abstract}

\title{
Results
}

After 70 reoperations an $\mathrm{IH}$ was diagnosed in 48.6\% (34/70). There was an increase in specificity for diagnosing $\mathrm{IH}$ with reoperation as reference from $52.8 \%(19 / 36 ; 95 \% \mathrm{Cl} 35.7-69.2 \%)$ in the original report to $86.1 \%(31 / 36 ; 95 \%$ $\mathrm{Cl} 74.8-97.4 \%)$ for the radiologist ( $p=0.002), 77.8 \%(28 / 36 ; 95 \% \mathrm{Cl} 64.2-91.4 \%)$ for the resident $(p=0.026)$ and $77.8 \%(28 / 36 ; 95 \% \mathrm{Cl} 64.2-91.4 \%)$ for the intern $(p=0.026)$. Inter-observer agreement was good.

\section{Conclusion}

Systematically reviewing CT scans using a list of ten CT signs can improve specificity and thereby reduce unnecessary reoperations, especially in a high pre-test-probability population. The tool can be easily taught to less experienced readers. 


\section{Introduction}

Internal herniation $(\mathrm{IH})$ can be a serious complication after gastric bypass surgery and making the right diagnosis can be challenging. CT is often used in patients with abdominal complaints after gastric bypass surgery, but its accuracy for diagnosing $\mathrm{IH}$ is questioned. Differences between radiologists certainly exist; a lot of different signs can be used to diagnose $\mathrm{IH}^{1-3}$. Structured assessment using CT signs might simplify the radiological diagnosis of $\mathrm{IH}$. An improved accuracy and uniformity of reading abdominal $\mathrm{CT}$ to diagnose $\mathrm{IH}$ might prevent unnecessary surgery.

In The Netherlands, around 4000 gastric bypass surgeries were performed in the period 2013-2015. As a result of the rearrangement of the bowel during the gastric bypass procedure, two possible herniation ports arise. First is Petersen's space which lies between the alimentary limb and the transverse mesocolon after gastrojejunostomy. Second is the mesenteric defect at the location of the jejeuno-jejunostomy. The incidence of $\mathrm{IH}$ in a recent meta-analysis was $2.5 \%{ }^{5}$, thus making it a relevant problem. The prevalence of complaints with a suspicion of $\mathrm{IH}$ will be even higher. The gold standard to diagnose $\mathrm{IH}$ is reoperation. Obviously, this is an invasive method which should not be performed on all patients with symptoms of $\mathrm{IH}$. Therefore, $\mathrm{CT}$ is used to help make a diagnosis.

In recent literature the accuracy of $\mathrm{CT}$ for diagnosing $\mathrm{IH}$ varies from slight to moderate. In 2007, Agaba et al. ${ }^{6}$ found a sensitivity of $66 \%$ and a specificity of $29 \%$ in 75 patients with acute abdominal complaints. More recently, Altieri et al. ${ }^{7}$ found a sensitivity of $76 \%$ and a specificity of $60 \%$ in a population of 50 patients. Since 2007 CT technique has improved and different CT signs were developed.

Eight CT signs have been repeatedly described in diagnosing IH: (1) swirl sign, (2) small-bowel obstruction, (3) clustered loops, (4) mushroom sign, (5) hurricane eye sign, (6) small bowel behind SMA, (7) right-sided anastomosis and (8) enlarged nodes ${ }^{1-3,8,9}$. Recently two new signs were added: (9) venous congestion and (10) mesenteric oedema ${ }^{10}$ (Table 1, Fig. 1). These previous studies found conflicting results in small study populations, and were carried out by highly experienced readers ${ }^{1-3,8,9}$.

The aim of this study was to evaluate if systematically reviewing CT scans using 10 signs in case of a suspicion of $\mathrm{IH}$ leads to better accuracy in terms of sensitivity and specificity compared to the original report. The sensitivity and specificity of all different CT signs were investigated. Furthermore, the difference in accuracy in reading $\mathrm{CT}$ scans was analysed between levels of experience. 


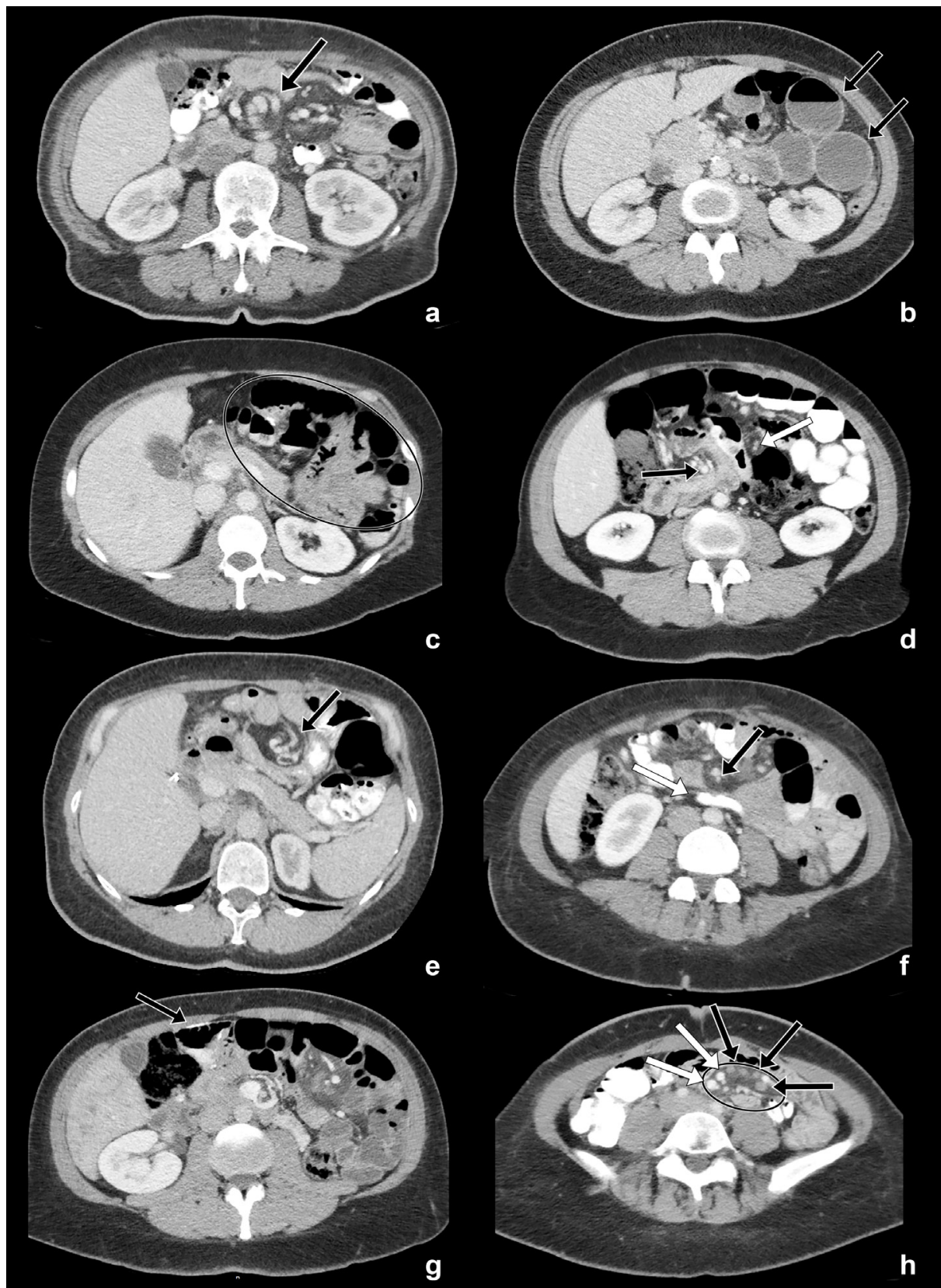

Fig. 1: Enhanced axial CT images after intravenous and oral contrast through the midabdomen. $\boldsymbol{a}$. Swirl sign (arrow): rotation of superior mesenteric artery and vein. $\boldsymbol{b}$. Small-bowel obstruction (arrow): multiple dilated bowel loops with air-fluid levels. c. Clustered bowel loops (circle): grouping of non-dilated small bowel near abdominal wall. d. Mushroom sign: protrusion of small bowel between superior mesenteric artery (black 
arrow) and one of its branches (white arrow). e. Hurricane eye sign (arrow): rotation of distal mesenteric fat and vessels closely surrounded by bowel. $f$. Small bowel posterior to superior mesenteric artery (SMA), other than duodenum. In this figure visible as a bowel (white arrow) behind the SMA (black arrow) caudal of the level of the duodenum. g. Right-sided anastomosis (arrow): right-sided location of the distal jejunal anastomosis.

h. Enlarged lymph nodes (black arrows): multiple enlarged lymph nodes in the mesentery, venous congestion (white arrows): enlargement of the mesenteric veins compared with the corresponding arteries, and mesenteric oedema (circle): haziness of the mesenteric fat.

Table 1: Ten CT signs for assessing internal herniation

\begin{tabular}{|c|c|c|}
\hline Sign & Figure & Description \\
\hline Swirl sign & $1 \mathrm{a}$ & $\begin{array}{l}\text { Swirled appearance of mesenteric fat or vessels at } \\
\text { the root of the mesentery }\end{array}$ \\
\hline Small-bowel obstruction & $1 b$ & Dilated small-bowel loops with air-fluid levels \\
\hline Clustered loops & $1 c$ & $\begin{array}{l}\text { Clustered loops of small bowel, mostly in the left } \\
\text { upper abdomen in case of Petersen herniation, } \\
\text { but also possible in other abdominal quadrants in } \\
\text { mesenteric herniation }\end{array}$ \\
\hline Mushroom sign & $1 d$ & $\begin{array}{l}\text { Mushroom shape of the herniated mesenteric root } \\
\text { with protrusion of bowel between SMA and its } \\
\text { branches }\end{array}$ \\
\hline Hurricane eye sign & $1 e$ & $\begin{array}{l}\text { Tubular or round shape of distal mesenteric fat } \\
\text { closely surrounded by bowel loops }\end{array}$ \\
\hline Small bowel behind SMA & $1 f$ & $\begin{array}{l}\text { Small bowel other than duodenum passing } \\
\text { posterior to the SMA }\end{array}$ \\
\hline Right-sided anastomosis & $1 \mathrm{~g}$ & $\begin{array}{l}\text { Right-sided location of the distal jejunal } \\
\text { anastomosis }\end{array}$ \\
\hline Enlarged nodes & $1 \mathrm{~h}$ & $\begin{array}{l}\text { The presence of enlarged mesenteric nodes as } \\
\text { a secondary sign of lymphatic obstruction from } \\
\text { mesenteric torsion }\end{array}$ \\
\hline Venous congestion & $1 \mathrm{~h}$ & $\begin{array}{l}\text { Tapering of mesenteric veins with subsequent } \\
\text { engorgement }\end{array}$ \\
\hline Mesenteric oedema & $1 \mathrm{~h}$ & Haziness of the mesenteric fat \\
\hline
\end{tabular}

SMA = superior mesenteric artery

\section{Methods}

Patients were retrospectively selected from a prospectively collected database of all patients who had undergone bariatric surgery between 1 January 2011 and 31 December 2014 in our bariatric centre of excellence. A total of 1475 patients had undergone laparoscopic gastric bypass surgery. During at least 2-year follow-up all CT scans in this population were reviewed and included if they had 
been requested for suspected $\mathrm{IH}$. In this patient population, 247 CT scans were performed in 184 patients due to suspicion of IH. Of these 247 CT scans, two CT scans were not available for reviewing and therefore excluded. In total 183 patients were included (Fig. 2). Also, all surgical reports concerning reoperations with an indication of suspected $\mathrm{IH}$ were collected within the same time interval. Clinical follow-up was performed by visits to the outpatients department of the obesity centre.

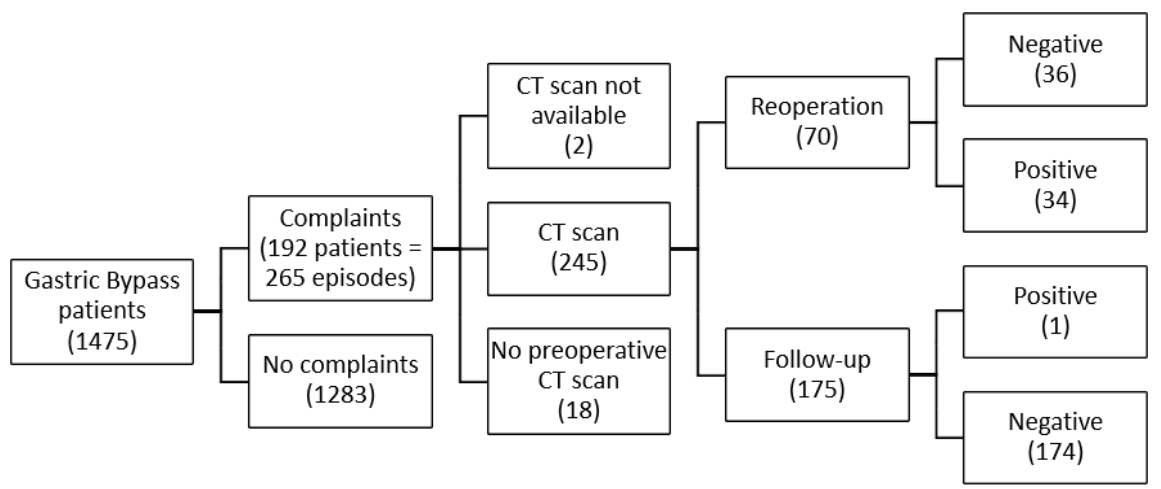

Fig. 2: Flow-chart of CT scan inclusion in the study and outcomes of episodes.

As some patients had multiple CT scans, a new CT scan was considered the beginning of a new episode. Episodes were divided into two groups: IH positive and $\mathrm{IH}$ negative. Episodes were considered $\mathrm{IH}$ positive if bowel herniation through a mesenteric defect was seen during reoperation within 90 days after the CT scan. An episode was considered negative when no $\mathrm{IH}$ was seen peroperatively, or negative clinical follow-up during a period of 90 days. The clinical follow-up was considered negative if no reoperation or repeat CT scan was performed within these 90 days. The local medical ethical review board waived ethical approval for this study.

\section{Surgical Technique}

All patients had undergone a laparoscopic Roux-en-Y gastric bypass (LRYGB) performed with an antecolic position of the jejunal limb. Both primary and secondary LRYGB were included. Secondary LRYGB was performed on indication after sleeve gastrectomy, adjustable gastric banding or vertical banded gastroplasty. During this study period, mesenteric and Petersen defects were not routinely closed.

\section{Image Acquisition and Analysis}

All CT scans were performed with either a Briliance iCT 256 slice or a Brilliance 64 CT scanner, with a slice thickness of $1 \mathrm{~mm}$ (Philips Medical, Best, the 
Netherlands). Multiplanar reconstructions were available. One litre of diluted oral contrast (Telebrix, ioxithalamaat $6 \mathrm{mg} \mathrm{I/mL;} \mathrm{Guerbet,} \mathrm{Gorinchem,} \mathrm{The}$ Netherlands) was administered 90 min before the CT scan. All scans were performed $70 \mathrm{~s}$ after administration of $100 \mathrm{~mL}$ intravenous contrast lomeron (iomeprol 300 mg I/mL; Bracco Imaging, Konstanz, Germany). Injection rate varied between 3 and $5 \mathrm{~mL} / \mathrm{s}$.

Of all included CT scans the original report was screened for suspicion of $\mathrm{IH}$. The original reports were made by radiologist or resident (under supervision of a radiologist) without structured use of the CT signs. They had access to the clinical information provided by the clinicians. All conclusions of the original CT reports were analysed and divided into suspicion or no suspicion of $\mathrm{IH}$. These findings were correlated with operation and follow-up findings.

After literature study, we found 15 signs with some overlapping conditions. We chose to investigate further the most described and most promising signs for the diagnosis of IH. Structured assessment of all CT scans was performed using a list of these 10 CT signs to score presence or absence: (1) swirl sign, (2) smallbowel obstruction, (3) clustered loops, (4) mushroom sign, (5) hurricane eye sign, (6) small bowel behind SMA, (7) right-sided anastomosis, (8) enlarged nodes, (9) venous congestion and (10) mesenteric oedema (Table 1, Fig. 1). Moreover, an overall impression of the suspicion of $\mathrm{IH}$ was scored, using a 5-point Likert scale, 1 being very unlikely, 2 being unlikely, 3 being undecided, 4 being likely and 5 being very likely an $\mathrm{IH}^{11}$. All CT scans were reassessed by three readers; an abdominal radiologist with 5 years of experience (JN), a fourth-year radiology resident specializing in abdominal imaging (SJ), and a radiology intern with little experience in cross-sectional imaging (JE). Before assessment of all CT scans, all three investigators underwent a tutorial with examples of CT images of the ten described signs ${ }^{1-3,8}$. The three readers independently performed the assessment and they were told all CT scans were performed in patients after a gastric bypass with a clinical suspicion of $\mathrm{IH}$. They had no knowledge of the original CT report or reoperation outcome.

\section{Statistical analysis}

All data were entered into a computerized spreadsheet (Excel; Microsoft, Redmond, WA, USA) and were analysed with Statistical Package for Social Sciences 21.0 (SPSS Inc. Chicago, IL, USA). Patient characteristics are listed as mean $( \pm S D)$ or median (range), depending on the normality of the distribution. Continuous data were compared with the independent sample $t$ test or MannWhitney test for not normally distributed data. Categorical data were compared with Chi-square test or Fisher's exact test. The sensitivity and specificity for overall impression and the 10 signs were calculated using two-way contingency tables. A 5-point Likert scale was used to score overall impression. The scale was digitised, considering 1-2 negative for $\mathrm{IH}$, and 3-5 positive for $\mathrm{IH}$. Sensitivity and specificity for overall impression and each sign were reported as a range from 
lowest to highest values across all three readers. Inter-observer agreement for all signs and overall impression was calculated using Fleiss' kappa for multiple readers. Kappa values can be interpreted as follows: <0.00: poor agreement, 0.00-0.20: slight agreement, 0.21-0.40: fair agreement, 0.41-0.60: moderate agreement, 0.61-0.80: substantial agreement, and 0.81-1.00: almost perfect ${ }^{12}$. The significance level was set at $p<0.05$.

\section{Results}

\section{Demographics}

Of the 183 included patients, $85.2 \%$ were female with a mean age of 44.4 years and a mean body mass index (BMI) of $40.9 \mathrm{~kg} / \mathrm{m}^{2}$. The CT scan population was significantly younger and had a lower baseline BMI; for patient demographics, see Table 2. The median follow-up time was 44 months. The median time interval from gastric bypass until the first episode of complaints suggestive of $\mathrm{IH}$ was 472 days (range 0-1,689 days).

Table 2: Patient demographics

\begin{tabular}{llll}
\hline Characteristic & $\begin{array}{l}\text { Included patients } \\
(\mathrm{n}=183)\end{array}$ & $\begin{array}{l}\text { Not included patients } \\
(\mathrm{n}=1292)\end{array}$ & $p$-value \\
\hline Sex & & & 0.820 \\
$\quad$ Male $(\mathrm{n}(\%))$ & $27(14.8)$ & $199(15.4)$ & \\
$\quad$ Female $(\mathrm{n}(\%))$ & $156(85.2)$ & $1093(84.6)$ & \\
Age $(\mathrm{y}$, mean $( \pm \mathrm{SD}))$ & $44.4( \pm 10.4)$ & $46.8( \pm 10.2)$ & 0.003 \\
Initial BMI $\left(\mathrm{kg} / \mathrm{m}^{2}\right.$, median (range)) & $40.9(22.7-69.6)$ & $41.9(22.0-80.7)$ & $<0.001$ \\
Operation & & & 0.791 \\
$\quad$ Primary $(\mathrm{n}(\%))$ & $126(68.9)$ & $922(71.4)$ & \\
$\quad$ Secondary after Sleeve $(\mathrm{n}(\%))$ & $27(14.8)$ & $114(8.8)$ & \\
$\quad \begin{array}{l}\text { Secondary after ABG }(\mathrm{n}(\%)) \\
\quad 21(11.5)\end{array}$ & $179(13.9)$ & \\
\hline Secondary after VGB $(\mathrm{n}(\%))$ & $9(4.9)$ & $77(6.0)$ & \\
\hline
\end{tabular}

$\mathrm{SD}=$ standard deviation; $\mathrm{BMI}=$ body mass index; $\mathrm{kg}$ = kilogram; $\mathrm{m}^{2}=$ square meters

After 70 CT scans a reoperation was performed, with a median of 6 days after CT (range 0-74 days). In 48.6\% (34/70) of all these operations IH was confirmed. In the other 36 operations, no explanation of complaints was found in 11 operations, possible herniation sites were closed in 13, adhesiolysis was performed with (4) or without (3) closure of possible herniation sites in 7, revision of the gastrojejunostomy was performed in 3 , and a gastric perforation was found in 2. In terms of episodes, 210 episodes were negative and 35 episodes were positive as one patient had two scans preoperatively. 


\section{Accuracy of CT}

Using reoperation as a reference

Using the conclusion of the original report resulted in a sensitivity and specificity for $\mathrm{IH}$ of $82.4 \%$ and $50 \%$, respectively. Sensitivity and specificity of overall impression for $\mathrm{IH}$ were $79.4 \%$ and $86.1 \%$ for reader $1,76.5 \%$ and $77.8 \%$ for reader 2 and $82.4 \%$ and $77.8 \%$ for reader 3 . The improvement of specificity was significant ( $p=0.0021-0.026$; Table 3).

Using reoperation and follow up as a reference

Using the conclusion of the original report resulted in a sensitivity and specificity for $\mathrm{IH}$ of $82.9 \%$ and $87.1 \%$, respectively. Sensitivity and specificity of overall impression for $\mathrm{IH}$ were $77.1 \%$ and $91.9 \%$ for reader $1,77.1 \%$ and $87.6 \%$ for reader 2 and $82.9 \%$ and $84.8 \%$ for reader 3 (Table 3 ).

The three best signs in terms of sensitivity were swirl sign (71.4-77.1\%), venous congestion (54.3-74.3\%) and mesenteric oedema (62.9-71.4\%). The three best signs in terms of specificity were right-sided anastomosis (99.5-100\%), small bowel behind SMA (90.5-100\%), and hurricane eye sign (94.8-98.1\%; Table 4). The sensitivity and specificity for the ten signs were also calculated using reoperation as a reference (Table 5).

The inter-observer agreement of overall impression using structured assessment was substantial $(0.67,95 \%-\mathrm{Cl} ; 0.59-0.74)$. Inter-observer agreement was calculated for all ten different signs (Table 6). 
Table 3: Comparison original report vs. systematic reviewing

\begin{tabular}{llll}
\hline & Original & $\begin{array}{l}\text { Systematic reviewing } \\
\text { Reader } 1\end{array}$ & $p$-value \\
\hline${ }^{*}$ Reoperation & & & \\
Sensitivity $(n=34)$ & $82.4(28)[64.8-92.6]$ & $79.4(27)[61.6-90.7]$ & 0.76 \\
Specificity $(n=36)$ & $52.8(19)[35.7-69.2]$ & $86.1(31)[69.7-94.8]$ & 0.0021 \\
Accuracy $(n=70)$ & $67.1(47)[54.8-77.6]$ & $82.9(58)[71.6-90.5]$ & 0.0318 \\
${ }^{*}$ Reoperation + Follow-up 90 days & & \\
Sensitivity $(n=35)$ & $82.9(29)[65.7-92.8]$ & $77.1(27)[59.4-87.1]$ & 0.55 \\
Specificity $(n=210)$ & $87.1(183)[81.7-91.2]$ & $91.9(193)[87.1-95.1]$ & 0.11 \\
Accuracy $(n=245)$ & $86.5(212)[81.5-90.4]$ & $89.8(220)[85.1-93.2]$ & 0.26 \\
\hline
\end{tabular}

All values are \%, (n), [95\% Confidence Interval]. Reader 1 abdominal radiologist; Reader 2 radiology resident; Reader 3 radiology intern

Table 4. Sensitivity and specificity for follow-up and reoperation combined ( $n=245)$

\begin{tabular}{lllll}
\hline Sign & Reader 1 & & Reader 2 \\
\cline { 2 - 5 } & $\begin{array}{l}\text { Sensitivity } \\
(\mathbf{n}=35)\end{array}$ & $\begin{array}{l}\text { Specificity } \\
(\mathbf{n}=210)\end{array}$ & $\begin{array}{l}\text { Accuracy } \\
(\mathbf{n}=245)\end{array}$ & $\begin{array}{l}\text { Sensitivity } \\
(\mathbf{n}=35)\end{array}$ \\
\hline Swirl sign & $71.4(25)$ & $94.8(199)$ & $91.4(224)$ & $74.3(26)$ \\
& {$[53.5-84.8]$} & {$[90.6-97.2]$} & {$[87.0-94.5]$} & {$[56.4-86.9]$} \\
Small bowel & $5.7(2)$ & $96.7(203)$ & $83.7(205)$ & $14.3(5)$ \\
obstruction & {$[1.0-20.5]$} & {$[93.0-98.5]$} & {$[78.3-88.0]$} & {$[5.4-31.0]$} \\
Clustered loops & $11.4(4)$ & $97.1(204)$ & $84.9(208)$ & $14.3(5)$ \\
& {$[3.7-27.7]$} & {$[93.6-98.8]$} & {$[79.7-89.0]$} & {$[5.4-31.0]$} \\
Mushroom sign & $54.3(19)[$ & $94.8(199)$ & $89.0(218)$ & $54.3(19)$ \\
& $36.9-70.8]$ & {$[90.6-97.2]$} & {$[84.2-92.5]$} & {$[36.9-70.8]$} \\
Hurricane sign & $51.4(18)$ & $95.2(200)$ & $89.0(218)$ & $22.9(8)$ \\
& {$[34.3-68.3]$} & {$[91.2-97.6]$} & {$[84.2-92.5]$} & {$[11.0-40.6]$} \\
Small bowel behind & $2.9(1)$ & $100(210)$ & $86.1(211)$ & $14.3(5)$ \\
SMA & {$[0.1-16.6]$} & {$[97.8-100]$} & {$[81.0-90.0]$} & {$[5.4-31.0]$} \\
Right-sided & $14.3(5)$ & $100(210)$ & $87.8(215)$ & $2.9(1)$ \\
anastomosis & {$[5.4-31.0]$} & {$[97.8-100]$} & {$[82.8-91.5]$} & {$[0.1-16.6]$} \\
Enlarged nodes & $37.1(13)$ & $94.3(198)$ & $86.1(211)$ & $54.3(19)$ \\
& {$[22.0-55.1]$} & {$[90.0-96.9]$} & {$[81.0-90.0]$} & {$[36.9-70.8]$} \\
Venous congestion $]$ & $74.3(26)$ & $95.2(200)$ & $92.2(226)$ & $71.4(25)$ \\
& {$[56.4-86.9]$} & {$[91.2-97.6]$} & {$[88.0-95.1]$} & {$[53.5-84.8]$} \\
Mesenteric & $62.9(22)[$ & $94.3(198)$ & $89.8(220)$ & $65.7(23)$ \\
oedema & $44.9-78.0]$ & {$[90.0-96.9]$} & {$[85.1-93.2]$} & {$[47.7-80.3]$} \\
Overall impression $]$ & $77.1(27)$ & $91.9(193)$ & $89.8(220)$ & $77.1(27)$ \\
& {$[59.4-87.1]$} & {$[87.1-95.1]$} & {$[85.1-93.2]$} & {$[59.4-87.1]$} \\
\hline
\end{tabular}

All values are \%, (n), [95\%-Confidence Interval]. Reader 1 abdominal radiologist Reader; 2 radiology resident Reader; 3 radiology intern; SMA = superior mesenteric artery 


\begin{tabular}{llll} 
Reader 2 & $p$-value & Reader 3 & $p$-value \\
\hline $76.5(26)[58.4-88.6]$ & 0.55 & $82.4(28)[64.8-92.6]$ & 1.00 \\
$77.8(28)[60.4-89.3]$ & 0.026 & $77.8(28)[60.4-89.3]$ & 0.026 \\
$77.1(54)[65.3-86.0]$ & 0.19 & $80.0(56)[68.4-88.3]$ & 0.085 \\
& & & \\
$77.1(27)[59.4-87.1]$ & 0.55 & $82.9(29)[65.7-92.8]$ & 1.00 \\
$87.6(184)[82.2-91.6]$ & 0.88 & $84.8(178)[79.0-89.2]$ & 0.48 \\
$86.1(211)[81.0-90.0]$ & 0.9 & $84.5(207)[79.2-88.7]$ & 0.52 \\
\hline
\end{tabular}

\begin{tabular}{lllll}
\hline & \multicolumn{5}{l}{ Reader 3} & \\
\hline $\begin{array}{l}\text { Specificity } \\
(\mathbf{n = 2 1 0 )}\end{array}$ & $\begin{array}{l}\text { Accuracy } \\
(\mathbf{n}=245)\end{array}$ & $\begin{array}{l}\text { Sensitivity } \\
(\mathbf{n}=35)\end{array}$ & $\begin{array}{l}\text { Specificity } \\
(\mathbf{n}=210)\end{array}$ & $\begin{array}{l}\text { Accuracy } \\
(\mathbf{n}=245)\end{array}$ \\
\hline $91.0(191)$ & $88.6(217)$ & $77.1(27)$ & $88.1(185)$ & $86.5(212)$ \\
{$[86.0-94.3]$} & {$[83.8-92.1]$} & {$[59.4-89.0]$} & {$[82.7-92.0]$} & {$[81.5-90.4]$} \\
$92.4(194)$ & $81.2(199)$ & $11.4(4)$ & $93.3(196)$ & $81.6(200)$ \\
{$[87.7-95.4]$} & {$[75.6-85.8]$} & {$[3.7-27.7]$} & {$[88.8-96.2]$} & {$[76.1-86.2]$} \\
$95.2(200)$ & $83.7(205)$ & $17.1(6)$ & $95.7(201)$ & $84.5(207)$ \\
{$[91.2-97.6]$} & {$[78.3-88.0]$} & {$[7.2-34.3]$} & {$[91.8-97.9]$} & {$[79.2-88.7]$} \\
$92.4(194)$ & $86.9(213)$ & $25.7(9)$ & $99.5(209)$ & $89.0(218)$ \\
{$[87.7-95.4]$} & {$[81.9-90.8]$} & {$[13.1-43.6]$} & {$[97.0-100]$} & {$[84.2-92.5]$} \\
$98.1(206)$ & $87.3(214)$ & $14.3(5)$ & $94.8(199)$ & $83.3(204)$ \\
{$[94.9-99.4]$} & {$[82.4-91.1]$} & {$[5.4-31.0]$} & {$[90.6-97.2]$} & {$[77.9-87.6]$} \\
$98.6(207)$ & $86.5(212)$ & $25.7(9)[$ & $90.5(190)$ & $81.2(199)$ \\
{$[95.5-99.6]$} & {$[81.5-90.4]$} & $13.1-43.6]$ & {$[85.5-93.9]$} & {$[75.6-85.8]$} \\
$99.5(209)$ & $85.7(210)$ & $8.6(3)$ & $99.5(209)$ & $86.5(212)$ \\
{$[97.0-100]$} & {$[80.5-89.7]$} & {$[2.2-24.2]$} & {$[97.0-100]$} & {$[81.5-90.4]$} \\
$84.8(178)$ & $80.4(197)$ & $8.6(3)$ & $97.6(205)$ & $84.9(208)$ \\
{$[79.0-89.2]$} & {$[74.8-85.1]$} & {$[2.2-24.2]$} & {$[94.2-99.1]$} & {$[79.7-89.0]$} \\
$76.7(161)$ & $75.9(186)$ & $54.3(19)$ & $94.3(198)$ & $88.6(217)$ \\
{$[70.2-82.1]$} & {$[70.0-81.0]$} & {$[36.9-70.8]$} & {$[90.0-96.9]$} & {$[83.8-92.1]$} \\
$79.5(167)$ & $77.6(190)$ & $71.4(25)$ & $88.6(186)$ & $86.1(211)$ \\
{$[73.3-84.6]$} & {$[71.7-82.5]$} & {$[53.5-84.8]$} & {$[83.3-92.4]$} & {$[81.0-90.0]$} \\
$87.6(184)$ & $86.1(211)$ & $82.9(29)$ & $84.8(178)$ & $84.5(207)$ \\
{$[82.2-91.6]$} & {$[81.0-90.0]$} & {$[65.7-92.8]$} & {$[79.0-89.2]$} & {$[79.2-88.7]$} \\
\hline
\end{tabular}


Table 5. Sensitivity and specificity for reoperation $(n=70)$

\begin{tabular}{lllll}
\hline Sign & Reader 1 & & Reader 2 \\
\cline { 2 - 5 } & $\begin{array}{l}\text { Sensitivity } \\
(\mathbf{n}=34)\end{array}$ & $\begin{array}{l}\text { Specificity } \\
(\mathbf{n}=36)\end{array}$ & $\begin{array}{l}\text { Accuracy } \\
(\mathbf{n}=70)\end{array}$ & $\begin{array}{l}\text { Sensitivity } \\
(\mathbf{n}=34)\end{array}$ \\
\hline Swirl sign & $73.5(25)$ & $94.4(34)$ & $84.3(59)$ & $73.5(25)$ \\
& {$[55.3-86.5]$} & {$[80.0-99.0]$} & {$[73.2-91.5]$} & {$[55.3-86.5]$} \\
Small bowel & $5.9(2)$ & $88.9(32)$ & $48.6(34)$ & $14.7(5)$ \\
obstruction & {$[1.0-21.1]$} & {$[73.0-96.4]$} & {$[36.6-60.7]$} & {$[5.5-31.8]$} \\
Clustered loops & $11.8(4)$ & $94.4(34)$ & $54.3(38)$ & $14.7(5)$ \\
& {$[3.8-28.4]$} & {$[80.0-99.0]$} & {$[42.0-66.1]$} & {$[5.5-31.8]$} \\
Mushroom sign & $55.9(19)$ & $88.9(32)$ & $72.9(51)$ & $55.9(19)$ \\
& {$[38.1-72.4]$} & {$[73.0-96.4]$} & {$[60.7-82.5]$} & {$[38.1-72.4]$} \\
Hurricane sign & $52.9(18)$ & $88.9(32)$ & $71.4(50)$ & $23.5(8)$ \\
& {$[35.4-69.8]$} & {$[73.0-96.4]$} & {$[59.2-81.3]$} & {$[11.4-41.6]$} \\
Small bowel behind & $2.9(1)$ & $100(36)$ & $52.9(37)$ & $11.8(4)$ \\
SMA & {$[0.2-17.1]$} & {$[88.0-100]$} & {$[40.6-64.8]$} & {$[3.8-28.4]$} \\
Right-sided & $14.7(5)$ & $100(36)$ & $58.6(41)$ & $2.9(1)$ \\
anastomosis & {$[5.5-31.8]$} & {$[88.0-100]$} & {$[46.2-70.0]$} & {$[0.2-17.1]$} \\
Enlarged nodes & $38.2(13)$ & $88.9(32)$ & $64.3(45)$ & $55.9(19)$ \\
& {$[22.7-56.4]$} & {$[73.0-96.4]$} & {$[51.9-75.1]$} & {$[38.1-72.4]$} \\
Venous congestion & $76.5(26)$ & $97.2(35)$ & $87.1(61)$ & $73.5(25)$ \\
& {$[58.4-88.6]$} & {$[83.8-99.9]$} & {$[76.5-93.6]$} & {$[55.3-86.5]$} \\
Mesenteric & $64.7(22)$ & $91.7(33)$ & $78.6(55)$ & $67.6(23)$ \\
oedema & {$[46.5-79.7]$} & {$[76.4-97.8]$} & {$[66.8-87.1]$} & {$[49.4-82.0]$} \\
Overall impression & $79.4(27)$ & $86.1(31)$ & $82.9(58)$ & $76.5(26)$ \\
& {$[61.6-90.7]$} & {$[69.7-94.8]$} & {$[71.6-90.5]$} & {$[58.4-88.6]$} \\
\hline
\end{tabular}

All values are \%, (n), [95\%-Confidence Interval]. Reader 1 abdominal radiologist; Reader 2 radiology resident; Reader 3 radiology intern; SMA = superior mesenteric artery

Table 6: Fleisch Kappa for three reviewers

\begin{tabular}{lll}
\hline Sign & Fleisch Kappa & $95 \% \mathrm{Cl}$ \\
\hline Swirl sign & 0.71 & $0.63-0.78$ \\
Small bowel obstruction & 0.64 & $0.57-0.72$ \\
Clustered loops & 0.048 & $-0.024-0.12$ \\
Mushroom sign & 0.41 & $0.33-0.48$ \\
Hurricane sign & 0.17 & $0.097-0.24$ \\
Small bowel behind SMA & 0.084 & $0.012-0.16$ \\
Right-sided anastomosis & 0.45 & $0.37-0.52$ \\
Enlarged nodes & 0.33 & $0.26-0.40$ \\
Venous congestion & 0.46 & $0.39-0.54$ \\
Mesenteric oedema & 0.56 & $0.49-0.63$ \\
Overall impression (1-5) & 0.35 & $0.30-0.39$ \\
Overall impression (1-2 vs 3-5) & 0.67 & $0.59-0.74$ \\
\hline
\end{tabular}

SMA = superior mesenteric artery; $\mathrm{Cl}=$ confidence interval 


\begin{tabular}{lllll}
\hline $\begin{array}{l}\text { Specificity } \\
(\mathbf{n}=36)\end{array}$ & $\begin{array}{l}\text { Accuracy } \\
(\mathbf{n}=70)\end{array}$ & $\begin{array}{l}\text { Seader } 3 \\
(\mathbf{n}=34)\end{array}$ & $\begin{array}{l}\text { Specificity } \\
(\mathbf{n}=36)\end{array}$ & $\begin{array}{l}\text { Accuracy } \\
(\mathbf{n}=70)\end{array}$ \\
\hline $88.9(32)$ & $81.4(57)$ & $76.5(26)$ & $77.8(28)$ & $77.1(54)$ \\
{$[73.0-96.4]$} & {$[70.0-89.4]$} & {$[58.4-88.6]$} & {$[60.4-89.3]$} & {$[65.3-86.0]$} \\
$77.8(28)$ & $47.1(33)$ & $11.8(4)$ & $80.6(29)$ & $47.1(33)$ \\
{$[60.4-89.3]$} & {$[35.2-59.4]$} & {$[3.8-28.4]$} & {$[63.4-91.2]$} & {$[35.2-59.4]$} \\
$86.1(31)$ & $51.4(36)$ & $17.6(6)$ & $94.4(34)$ & $57.1(40)$ \\
{$[69.7-94.8]$} & {$[39.3-63.4]$} & {$[7.4-35.2]$} & {$[80.0-99.0]$} & {$[44.8-68.7]$} \\
$80.6(29)$ & $68.6(48)$ & $26.5(9)$ & $97.2(35)$ & $62.9(44)$ \\
{$[63.4-91.2]$} & {$[56.2-78.9]$} & {$[13.5-44.7]$} & {$[83.8-99.9]$} & {$[50.4-73.9]$} \\
$97.2(35)$ & $61.4(43)$ & $14.7(5)$ & $97.2(35)$ & $57.1(40)$ \\
{$[83.8-99.9]$} & {$[49.0-72.6]$} & {$[5.5-31.8]$} & {$[83.8-99.9]$} & {$[44.8-68.7]$} \\
$100(36)$ & $57.1(40)$ & $26.5(9)$ & $86.1(31)$ & $57.1(40)$ \\
{$[88.0-100]$} & {$[44.8-68.7]$} & {$[13.5-44.7]$} & {$[69.7-94.8]$} & {$[44.8-68.7]$} \\
$100(36)$ & $52.9(37)$ & $8.8(3)$ & $100(36)$ & $55.7(39)$ \\
{$[88.0-100]$} & {$[40.6-64.8]$} & {$[2.3-24.8]$} & {$[88.0-100]$} & {$[43.4-67.4]$} \\
$75.0(27)$ & $65.7(46)$ & $8.8(3)$ & $97.2(35)$ & $54.3(38)$ \\
{$[57.5-87.3]$} & {$[53.3-76.4]$} & {$[2.3-24.8]$} & {$[83.8-99.9]$} & {$[42.0-66.1]$} \\
$61.1(22)$ & $67.1(47)$ & $52.9(18)$ & $91.7(33)$ & $72.9(51)$ \\
{$[43.5-76.4]$} & {$[[54.8-77.6]$} & {$[35.4-69.8]$} & {$[76.4-97.8]$} & {$[60.7-82.5]$} \\
$52.8(19)$ & $60.0(42)$ & $70.6(24)$ & $80.6(29)$ & $75.7(53)$ \\
{$[35.7-69.2]$} & {$[47.6-71.3]$} & {$[52.3-84.3]$} & {$[63.4-91.2]$} & {$[63.7-84.8]$} \\
$77.8(28)$ & $77.1(54)$ & $82.4(28)$ & $77.8(28)$ & $80.0(56)$ \\
{$[60.4-89.3]$} & {$[65.3-86.0]$} & {$[64.8-92.6]$} & {$[60.4-89.3]$} & {$[68.4-88.3]$} \\
\hline & & & &
\end{tabular}




\section{Discussion}

The aim of this study was to determine if systematically reviewing CT scans using ten different $\mathrm{CT}$ signs results in a better accuracy in diagnosing $\mathrm{IH}$, compared to the original report. In our study we reassessed 245 CT scans of laparoscopic gastric bypass patients with a suspicion of $\mathrm{IH}$. Reassessment was done by an experienced abdominal radiologist, a radiology resident and a radiology intern. The sensitivity did not improve using systematic reviewing in comparison to the original radiological reports. The overall specificity using reoperation as a reference improved and the specificity of all signs was high. Right-sided anastomosis had the highest combined specificity, and mesenteric oedema had the lowest combined specificity. Sensitivity and specificity were comparable for the abdominal radiologist, the resident and the intern.

Sensitivity for overall impression of $\mathrm{IH}$ was $76.4-82.4 \%$, and the specificity was $77.8-86.1 \%$. Only Lockhaert ${ }^{8}$ and Dilauro ${ }^{1}$ investigated overall impression. Our overall impression sensitivity was higher than the sensitivity described by Lockhaert (56-78\%), but lower in comparison to Dilauro et al. (96-99\%). The specificity was comparable with both previous articles $(78-89 \%$ and $77-90 \%$, respectively). The difference in sensitivity might be at least partially explained by the difference in incidence of $\mathrm{IH}$ in the studied population. Furthermore, both studies incorporated CT scans with alternate diagnoses (e.g. femoral hernia). Remarkably, in our study significant improvement in specificity was found when using reoperation as a reference. This was the group where the clinical suspicion for $\mathrm{IH}$ or another surgical emergency was high enough to perform a reoperation, even though the CT scan yielded negative for $\mathrm{IH}$. Especially in this group, structured assessment might help to prevent unnecessary operations.

The interobserver agreement was overall slight to substantial. Previous studies also found slight to substantial inter-observer agreement for most of the signs even when both readers were experienced ${ }^{1-3}$. A reason for the relatively low inter-observer agreement might be the subjective nature of the signs. The three most sensitive signs were swirl sign (71.4-77.1\%), venous congestion (54.3$74.3 \%)$, and mesenteric oedema (62.9-71.4\%). The sensitivity of swirl sign and mesenteric oedema were consistent with data from previous studies (53$100 \%$ and $39-73 \%$, respectively) $)^{1-3,8-10,13}$. Venous congestion was only reported in one study, Park et al. ${ }^{10}$ reported a higher sensitivity (79-84\%). Furthermore two previous studies used superior mesenteric vein (SMV) compression or SMV "beaking" as a sign ${ }^{1,9}$. These signs could be compared to venous congestion since this is a result of compression. Maier et al. ${ }^{9}$ found comparable sensitivity (67\%), while Dilauro et al. ${ }^{1}$ found a higher sensitivity (80-88\%). In most previous articles high specificities were found for right-sided anastomosis, small bowel behind SMA, and hurricane eye sign', 3,8. Mushroom sign, engorged nodes, or smallbowel obstruction were found to have higher specificities in three articles ${ }^{1-3}$. 
To our knowledge, we are the first to assess the difference in diagnostic accuracy between experience levels in reading CT scans using systematic reviewing. We found that both an intern and a resident, with less experience in reading CT scans can easily be trained in the structured assessment of CT scans in patients suspected of having $\mathrm{IH}$. The learning process consisted of a brief explanation of each sign with examples. This proved sufficient training to be able to assess the CT scans systematically. When using the systematic reviewing, a relatively good diagnostic accuracy was found. Inter-observer agreement for overall impression was substantial for the three readers. This did not change when the results of the intern were excluded.

Our study population is one of the largest presented thus far, and the first to include negative clinical follow-up as an adjunct to reoperation as a reference standard. There are, however, some limitations. The retrospective design of this study with no reoperation in all patients with complaints is a limitation, leading to uncertainty in the diagnosis of $\mathrm{IH}$ as intermittent $\mathrm{IH}$ can be self-limiting. Next to this, the intermittent nature of $\mathrm{IH}$ might also have resulted in not all $\mathrm{IH}$ having been scored peroperatively. Another limitation was the arbitrarily chosen cut-off point of 90 days follow-up. Regarding the different signs the subjective nature of identifying presence of $\mathrm{IH}$ is a limitation. Cut-off values were given if applicable, but none of the signs is objective.

This study investigated the accuracy of the different signs and systematically reviewing in a controlled setting. We found an improvement of specificity in our study population when using structured assessment. However we cannot fully predict if structured assessment will also improve the accuracy in daily practice. A prospective study design to test the structured assessment as support in the diagnosis of $\mathrm{IH}$ is recommended.

In summary we found that systematically reviewing CT scans using a list of ten $\mathrm{CT}$ signs can improve specificity and thereby reduce unnecessary reoperations, especially in a high pre-test-probability population. All signs together assist in making a conclusion and combining all signs in assessing CT scans with suspicion of $\mathrm{IH}$ is advised. Furthermore, the tool can easily be taught to less experienced readers, who can use this tool with good diagnostic accuracy. 


\section{References}

1. Dilauro M, Mclnnes M, Schieda $\mathrm{N}$ et al. Internal Hernia after Laparoscopic Rouxen-Y Gastric Bypass: Optimal CT Signs for Diagnosis and Clinical Decision Making. Radiology 282[3], 752-760. 2017. doi: 10.1148/radiol.2016160956.

2. Goudsmedt F, Deylgat B, Coenegrachts K, Moortele Kvd, Dillemans B. Internal hernia after laparoscopic Roux-en-Y gastric bypass: a correlation between radiological and operative findings. Obes Surg 25[4], 622-627. 2015. doi: 10.1007/s11695-0141433-5, doi: 10.1007/s11695-014-1433-5.

3. Iannuccilli J, Grand D, Murphy B, Evangelista P, Roye G, Mayo-Smith W. Sensitivity and specificity of eight CT signs in the preoperative diagnosis of internal mesenteric hernia following Roux-en-Y gastric bypass surgery. Clin Radiol 64[4], 373-380. 2009. doi: 10.1016/j.crad.2008.10.008.

4. Welbourn R, Pournaras D, Dixon J et al. Bariatric Surgery Worldwide: Baseline Demographic Description and One-Year Outcomes from the Second IFSO Global Registry Report 2013-2015. Obes Surg doi: 10.1007/s11695-017-2845-9. 18-82017.

5. Geubbels N, Lijftogt N, Fiocco M, Leersum N, Wouters M, Brauw Ld. Meta-analysis of internal herniation after gastric bypass surgery. Br J Surg 102[5], 451-460. 2015. doi: $10.1002 /$ bjs. 9738 .

6. Agaba E, Gentles C, Shamseddeen $\mathrm{H}$ et al. Retrospective analysis of abdominal pain in postoperative laparoscopic Roux-en- $Y$ gastric bypass patients: is a simple algorithm the answer? Surg Obes Relat Dis 4[5], 587-593. 2008. doi: 10.1016/j. soard.2007.10.015.

7. Altieri M, Pryor A, Telem D, Hall K, Brathwaite C, Zawin M. Algorithmic approach to utilization of CT scans for detection of internal hernia in the gastric bypass patient. Surg Obes Relat Dis 11[6], 1207-1211. 2015. doi: 10.1016/j.soard.2015.02.010.

8. Lockhart M, Tessler F, Canon $\mathrm{C}$ et al. Internal hernia after gastric bypass: sensitivity and specificity of seven CT signs with surgical correlation and controls. Am J Roentgenol 188[3], 745-750. 2007.

9. Maier J, Herrasti Gallego A, Floyd A. Compression of the superior mesenteric vein - a sign of acute internal herniation in patients with antecolic laparoscopic Rouxen-Y gastric bypass. Eur Radiol 27[4], 1733-1739. 2017. doi: 10.1007/s00330-0164526-9.

10. Park J, Chung M, Teixeira J, Baer J, Frager D. Computed tomography findings of internal hernia after gastric bypass that may precede small bowel obstruction. Hernia 20[3], 471-477. 2016. doi: 10.1007/s10029-015-1424-z.

11. Likert R. A Technique for the Measurement of Attitudes. Archives of Psychology 140, 1-55. 1932.

12. Landis J, Koch G. The Measurement of Observer Agreement for Categorical Data. Biometrics 33[1], 159-174. 1-3-1977.

13. Karila-Cohen P, Cuccioli F, Tammaro P et al. Contribution of Computed Tomographic Imaging to the Management of Acute Abdominal Pain after Gastric Bypass: Correlation Between Radiological and Surgical Findings. Obes Surg 27[8], 19611972. 2017. doi: 10.1007/s11695-017-2601-1. 


\section{Chapter 4.}

\section{Structured CT reporting improves accuracy in diagnosing internal herniation after laparoscopic Roux-en-Y gastric bypass}

J.C. Ederveen, $\mathrm{MD}^{1}$

S.W. Nienhuijs, MD, PhD²

S. Jol, $\mathrm{MD}^{3}$

S.G.F. Robben, $\mathrm{MD}, \mathrm{PhD}^{1}$

J. Nederend, MD, $\mathrm{PhD}^{4}$

${ }^{1}$ Department of Radiology, Maastricht University Medical Centre, The Netherlands

${ }^{2}$ Department of Surgery, Catharina Hospital Eindhoven, The Netherlands

${ }^{3}$ Department of Radiology, Amsterdam University Medical Centres location VUmc, The Netherlands

${ }^{4}$ Department of Radiology, Catharina Hospital Eindhoven, The Netherlands

Eur Radiol (2020); 30(6): 3448-3454. doi: 10.1007/s00330-020-06688-x 


\begin{abstract}
Objectives

To confirm that structured reporting of CT scans using ten signs in clinical practice leads to a better accuracy in diagnosing internal herniation (IH) after gastric bypass surgery, compared with free-text reporting.

\section{Methods}

In this prospective study CT scans between June 1, 2017 and December 1, 2018 were included from a cohort of 2606 patients who had undergone laparoscopic gastric bypass surgery between January 1, 2011 and January 1, 2018. The CT scans were made for a suspicion of $\mathrm{IH}$ and structured reports were made using a standardized template with ten signs: (1) swirl sign, (2) small-bowel obstruction, (3) clustered loops, (4) mushroom sign, (5) hurricane eye sign, (6) small bowel behind superior mesenteric artery, (7) right-sided anastomosis, (8) enlarged nodes, (9) venous congestion, and (10) mesenteric oedema. Furthermore an overall impression of $\mathrm{IH}$ likelihood was given using a 5-point Likert-scale. CT scans performed in 2011 until 2017, without structured reporting, were included for comparison. Sensitivity, specificity, positive predictive value (PPV), negative predictive value (NPV), and accuracy were calculated using two-way contingency tables; the chi-square test was used for calculating $\mathrm{p}$-value. Reoperation and 3-month follow-up were used as reference.
\end{abstract}

\title{
Results
}

A total of 174 CT scans with structured reporting and 289 CT scans without structured reporting were included. Sensitivity was $81.3 \%$ (95\% Cl 67.7-94.8\%) and $79.5 \%(95 \% \mathrm{Cl} 67.6-91.5 \%)$, respectively $(p=0.854)$; specificity was $95.8 \%$ (95\% Cl 92.5-99.1\%) and $88.6 \%(95 \% \mathrm{Cl} 84.6-92.6 \%)$, respectively $(p=0.016)$; PPV was $81.3 \%$ (95\% Cl 67.7-94.8\%) and 55.6\% (95\% Cl 43.3-67.8\%), respectively ( $p=0.014)$; NPV was $95.8 \%$ (95\% Cl 92.5-99.1\%) and $96.0 \%(95 \%$ $\mathrm{Cl} 93.5-98.6 \%)$, respectively $(p=0.909)$; and accuracy was $93.1 \%(95 \% \mathrm{Cl} 88.0-$ $96.2 \%)$ and $87.2 \%$ (95\% Cl 82.7-90.7\%), respectively ( $p=0.045)$.

\section{Conclusion}

Structured reporting for the diagnosis of internal herniation after gastric bypass surgery improves accuracy and can be implemented in clinical practice with good results. 


\section{Introduction}

With the worldwide increase of bariatric surgery, the occurrence of complications also increases. Internal herniation $(\mathrm{IH})$ is one of these risks following gastric bypass surgery. An early and accurate diagnosis of $\mathrm{IH}$ is necessary to prevent potential ischaemic effects on bowel loops. CT scans are increasingly being used to enhance this diagnosis. To aid radiologists, different signs are described to differentiate between $\mathrm{IH}$ and normal postoperative anatomy ${ }^{1-6}$. However, these signs were never tested in clinical practice. In other diseases, structured reporting is found to help less experienced readers and improves surgeons' confidence in the CT conclusion ${ }^{7-9}$. Due to increased completeness of reports, structured reporting improves oncological staging and surgical planning ${ }^{10-13}$. If structured reporting using CT signs improves accuracy of CT scans, unnecessary surgery might be prevented.

Recently, a study was performed into the accuracy of ten CT signs: (1) swirled appearance of mesenteric fat or vessels at the root of the mesentery (swirl sign), (2) dilated small-bowel loops with air-fluid levels as a sign of smallbowel obstruction, (3) clustered loops of small bowel, (4) mushroom shape of the herniated mesenteric root with protrusion of bowel between the superior mesenteric artery (SMA) and its branches (mushroom sign), (5) tubular or round shape of distal mesenteric fat closely surrounded by bowel loops (hurricane eye sign), (6) small bowel other than duodenum passing posterior to the SMA, (7) right-sided location of the distal jejunal anastomosis, (8) the presence of enlarged mesenteric nodes as a secondary sign of lymphatic obstruction from mesenteric torsion (enlarged nodes), (9) tapering of mesenteric veins with subsequent engorgement (venous congestion, also referred to as beak sign), and (10) haziness of the mesenteric fat as a sign of mesenteric oedema, see Fig. $1^{14}$. Structured reporting using these CT signs improved the specificity. Furthermore, no difference between experience levels was found. However, this study was performed on retrospectively obtained CT scans. To accurately study the effect of structured reporting, it should be implemented in clinical practice.

The aim of this study was to investigate if using ten CT signs in a structured reporting template in clinical practice improves accuracy of CT scans in case of a suspicion of $\mathrm{IH}$, compared with non-structured free-text reporting previously performed. 


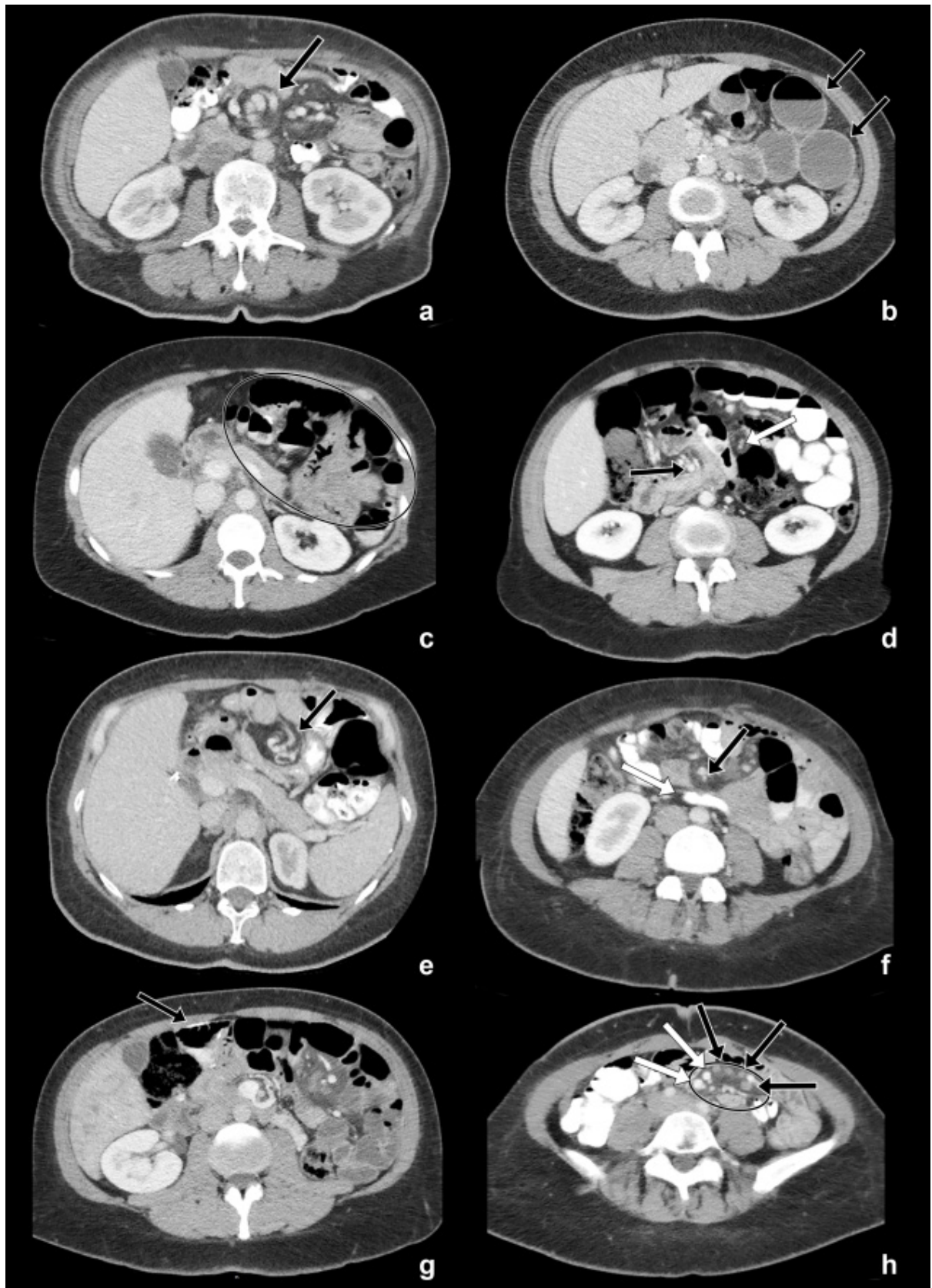

Fig. 1: Enhanced axial CT images after intravenous and oral contrast through the midabdomen. $\boldsymbol{a}$. Swirl sign (arrow): rotation of superior mesenteric artery and vein. $\boldsymbol{b}$. Small-bowel obstruction (arrow): multiple dilated bowel loops with air-fluid levels. $c$. Clustered bowel loops (circle): grouping of non-dilated small bowel near abdominal wall. d. Mushroom sign: protrusion of small bowel between superior mesenteric artery (black 
arrow) and one of its branches (white arrow). e. Hurricane eye sign (arrow): rotation of distal mesenteric fat and vessels closely surrounded by bowel. $f$. Small bowel posterior to superior mesenteric artery (SMA), other than duodenum. In this figure visible as a bowel (white arrow) behind the SMA (black arrow) caudal of the level of the duodenum. g. Right-sided anastomosis (arrow): right-sided location of the distal jejunal anastomosis. h. Enlarged lymph nodes (black arrows): multiple enlarged lymph nodes in the mesentery, venous congestion (white arrows): enlargement of the mesenteric veins compared with the corresponding arteries, and mesenteric oedema (circle): haziness of the mesenteric fat. Figure reprinted from Ederveen et al, $2018^{14}$

\section{Methods}

This prospective study was performed in all patients who underwent laparoscopic gastric bypass surgery in our bariatric centre of excellence between January 1, 2011 and January 1, 2018. No patients were excluded. All consecutive CT scans for a suspicion of IH between June 1, 2017 and December 1, 2018, were prospectively included. Furthermore, all consecutive CT scans for a suspicion of IH between January 1, 2011 and January 1, 2017, were retrospectively included for comparison. All reoperation reports in patients undergoing a CT scan were screened to select reoperations for a suspicion of $\mathrm{IH}$. Data on the presence of bowel herniation were extracted from surgery reports.

Episodes were considered IH positive if bowel herniation through a mesenteric defect was seen during reoperation within 90 days after the CT scan. An episode was considered negative when no $\mathrm{IH}$ was seen during surgery, or in case of negative clinical follow-up during a period of 90 days. The clinical follow-up was considered negative if no reoperation or no repeat CT scan was performed within these 90 days.

The local medical ethical review board approved the study design. Written informed consent was waived.

Part of the control group (1475 patients, undergoing gastric bypass surgery between 2011 and 2015) was previously reported in a study into the use of CT scans in case of suspicion of internal herniation and in a study into the accuracy of CT signs ${ }^{14,15}$.

\section{Surgical Technique}

All patients had undergone a laparoscopic Roux-en-Y gastric bypass (LRYGB) performed with an antecolic position of the jejunal limb. Both primary LRYGB and secondary LRYGB were included. Secondary LRYGB was performed on indication after sleeve gastrectomy, adjustable gastric banding, or vertical banded gastroplasty. Only from 2017 onwards mesenteric and Petersen defects were closed routinely in our hospital. 


\section{Image acquisition and analysis}

All CT scans were performed with either a Brilliance iCT 256 slice or a Brilliance 64 CT scanner, with a slice thickness of $1 \mathrm{~mm}$ (Philips Medical). Multiplanar reconstructions were available. One litre of diluted oral contrast (Telebrix, loxithalamaat $6 \mathrm{mg} \mathrm{I} / \mathrm{mL}$; Guerbet) was administered 90 min before the CT scan if possible. All scans were performed $70 \mathrm{~s}$ after administration of $100 \mathrm{~mL}$ intravenous contrast lomeron (lomeprol 300mg I/mL; Bracco Imaging).

All CT scans between June 1, 2017 and December 1, 2018 were rated in clinical practice by the attending radiologist or in-training radiologist (under supervision of a radiologist) using a standardized template stating ten signs. They had access to the clinical information provided by the clinicians. The ten signs used were (1) swirl sign, (2) small-bowel obstruction, (3) clustered loops of small bowel, (4) mushroom sign, (5) hurricane eye sign, (6) small bowel posterior to SMA, (7) right-sided distal anastomosis, (8) enlarged nodes, (9) venous congestion, and (10) mesenteric oedema. Each sign was scored as being present or absent. Furthermore, an overall impression was given using a 5-point Likert-scale, 1 being definitely no $\mathrm{IH}, 5$ being definite $\mathrm{IH}$.

If the standardized structured reporting template was not used in the study period June 2017 until December 2018, the CT scans were excluded from further analysis.

For the control group, the radiologic report and conclusion of the included CT scans were analysed for the use of CT signs and the overall impression. The reports were made by a radiologist or an in-training radiologist (under supervision of a radiologist) without structured use of the CT signs. They had access to the clinical information provided by the clinicians.

CT scans performed in other hospitals and revised in the study institution were included in this study as well.

\section{Statistical analysis}

All data were entered into a computerized spreadsheet (Excel; Microsoft) and were analysed with Statistical Package for Social Sciences 21.0 (SPSS Inc.). Patient characteristics are listed as mean $( \pm S D)$ or median (interquartile range (IQR) (25th - 75th percentile), depending on the normality of the distribution. Continuous data were compared with the independent sample t-test or MannWhitney test for not normally distributed data. Categorical data were compared with chi-square test or Fisher's exact test. The significance level was set at $p<0.05$. The sensitivity, specificity, positive predictive value (PPV), negative predictive value (NPV), and accuracy for overall impression were calculated using two-way contingency tables. A 5-point Likert-scale was used to score overall impression. The scale was digitised, considering 1-3 negative for $\mathrm{IH}$, and 4-5 positive. 


\section{Results}

\section{Demographics}

A total of 2606 patients underwent gastric bypass surgery in the study period, $83.7 \%$ were female with a mean age of $43.3( \pm 10.5)$ years and a median body mass index (BMI) of $41.5 \mathrm{~kg} / \mathrm{m}^{2}$ (IQR 38.9-44.7 kg/m²) (Table 1). In the study population, a total of 477 CT scans were performed in 354 patients. Patient characteristics are summarised in Table 1. The median follow-up time after CT scan was 31 months (IQR 13-52 months). The median time interval from gastric bypass until CT scan with an enquiry of IH was 555 days (IQR 276-1008 days).

Table 1: Patient demographics

\begin{tabular}{|c|c|c|c|c|}
\hline Characteristic & $\begin{array}{l}\text { Total population } \\
(n=2606)\end{array}$ & $\begin{array}{l}\text { Patients with CT } \\
\text { scan }(n=354)\end{array}$ & $\begin{array}{l}\text { Patients without } \\
\text { CT scan }(n=2252)\end{array}$ & $p$-value \\
\hline Sex & & & & $0.224^{3}$ \\
\hline Male (n (\%)) & $426(16.3)$ & $50(14.1)$ & $376(16.7)$ & \\
\hline Female (n (\%)) & 2180 (83.7) & 304 (85.9) & 1876 (83.3) & \\
\hline $\begin{array}{l}\text { Age }(y, \text { mean } \\
( \pm S D))\end{array}$ & $43.3(10.5)$ & $40.7(10.5)$ & $43.7(10.5)$ & $<0.001^{4}$ \\
\hline $\begin{array}{l}\text { Initial BMI (kg/m², } \\
\text { median ( IQR)) }\end{array}$ & $41.5(38.9-44.7)^{1}$ & $41.1(38.4-45.0)$ & $41.6(39.0-44.6)^{2}$ & $0.188^{5}$ \\
\hline Operation & & & & $<0.001^{3}$ \\
\hline Primary (n (\%)) & 1918 (73.6) & $243(68.6)$ & $1675(74.4)$ & \\
\hline $\begin{array}{c}\text { Secondary } \\
\text { after Sleeve (n (\%)) }\end{array}$ & $254(9.7)$ & $62(17.5)$ & $192(8.5)$ & \\
\hline $\begin{array}{c}\text { Secondary } \\
\text { after AGB (n (\%)) }\end{array}$ & $308(11.8)$ & 35 (9.9) & $273(12.1)$ & \\
\hline $\begin{array}{c}\text { Secondary } \\
\text { after VBG ( } \mathrm{n}(\%))\end{array}$ & $126(4.8)$ & $14(4.0)$ & $112(5.0)$ & \\
\hline
\end{tabular}

$\mathrm{SD}$ = standard deviation; $\mathrm{BMI}=$ body mass index; IQR = interquartile range (25th-75th percentile); $A G B=$ adjustable gastric banding; VBG = vertical banded gastroplasty; ${ }^{1} 2556$; patients; ${ }^{2} 2202$ patients; ${ }^{3} \mathrm{p}$-value calculated using Chi square test; ${ }^{4} \mathrm{p}$-value calculated using Independent samples t-test; ${ }^{5} \mathrm{p}$-value calculated using Mann-Whitney $\mathrm{U}$ test

CT scans with structured reporting

In the time period June 1, 2017 until December 1, 2018, 188 CT scans performed in 166 patients were prospectively included in this study (Fig. 2). The structured reporting template was used in $92.6 \%$ (174/188). The other 14 CT scans were excluded from further analysis. After the CT scans with structured reporting, 58 reoperations were performed, with a median of 1 day after CT scan (IQR 0-27 days). In $53.4 \%$ (31/58) of all these operations, an IH was confirmed. 


\section{CT scans with free-text reporting}

A total of 289 CT scans in 226 patients were included in the time period January 1, 2011 and January 1, 2017 (Fig. 2). After these CT scans, 80 reoperations were performed, with a median of 5 days after CT scan (IQR 1-24 days). In 55.0\% (44/80) of all these operations, an IH was confirmed.

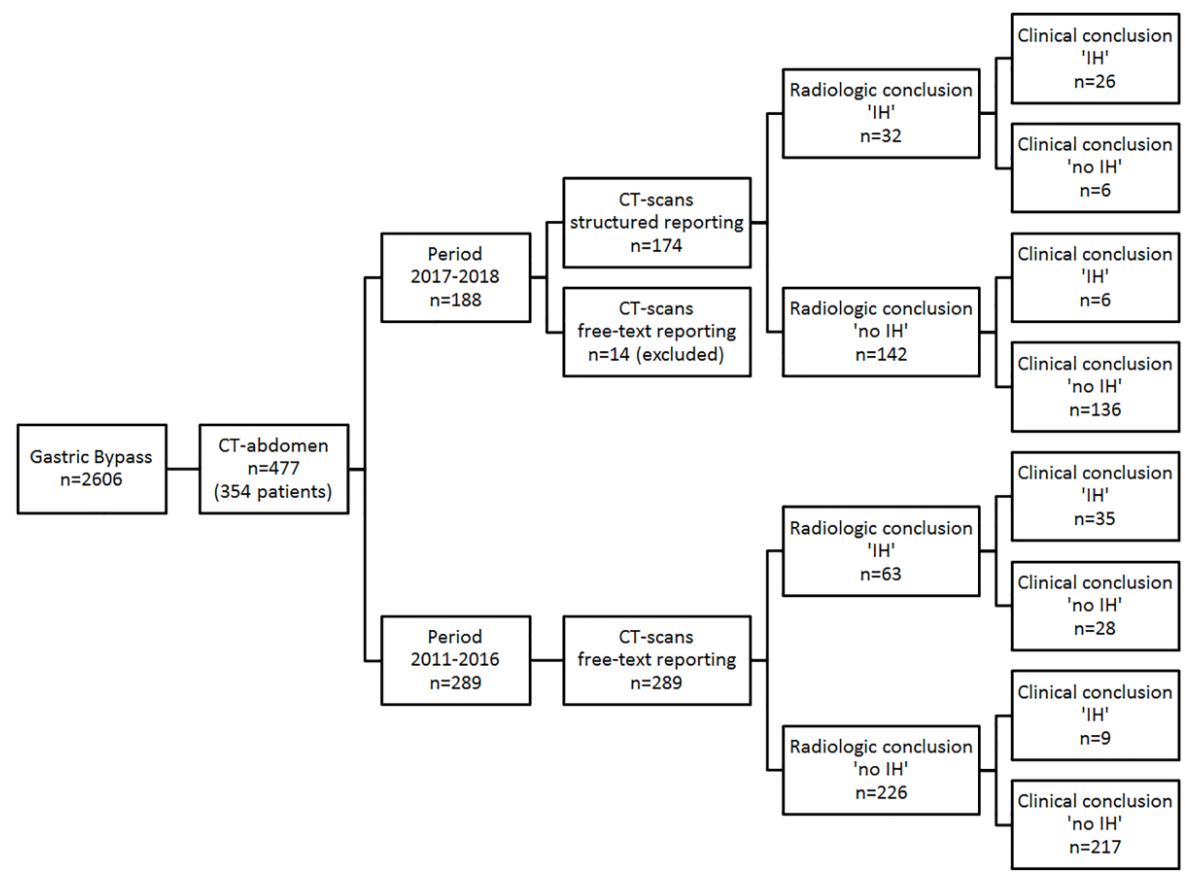

Fig. 2: Flow-chart of patient and CT scan inclusion in the study and outcomes of episodes. Clinical conclusion is the final diagnosis at the surgical intervention or after 90 days follow-up

\section{Comparison between free-text and structured reporting}

Using the conclusion of structured reporting resulted in a sensitivity and specificity for IH of $81.3 \%$ (26/32) and 95.8\% (136/142), respectively. Using the conclusion of the free-text reporting resulted in a sensitivity and specificity for $\mathrm{IH}$ of $79.5 \%$ (35/44) and $88.6 \%$ (217/245), respectively. Improvement of specificity was significant $(p=0.016)$. Also the accuracy improved from $87.2 \%$ $(252 / 289)$ in free-text reporting to $93.1 \%(162 / 174)$ in structured reporting $(p=0.045)$ (Table 2).

Table 3 shows the accuracy of the different signs when structured reporting was used. Table 4 shows the overall impression in terms of Likert scale. 
During structured reporting all signs were used per definition in $100 \%$ of the reports with the standardized template. Table 5 shows the signs mentioned in free-text reporting.

Table 2: Comparison structured reporting vs. free-text reporting

\begin{tabular}{llll}
\hline & Structured reporting & Free-text reporting & $p$-value \\
\hline Sensitivity & $26 / 32$ & $35 / 44$ & 0.854 \\
& $(81.3 ; 67.7-94.8)$ & $(79.5 ; 67.6-91.5)$ & \\
Specificity & $136 / 142$ & $217 / 245$ & 0.016 \\
& $(95.8 ; 92.5-99.1)$ & $(88.6 ; 84.6-92.6)$ & \\
Positive predictive value & $26 / 32$ & $35 / 63$ & 0.014 \\
& $(81.3 ; 67.7-94.8)$ & $(55.6 ; 43.3-67.8)$ & \\
Negative predictive value & $136 / 142$ & $217 / 226$ & 0.909 \\
& $(95.8 ; 92.5-99.1)$ & $(96.0 ; 93.5-98.6)$ & \\
Accuracy & $162 / 174$ & $252 / 289$ & 0.045 \\
& $(93.1 ; 88.0-96.2)$ & $(87.2 ; 82.7-90.7)$ & \\
\hline
\end{tabular}

Values are numerator/denominator (\%; 95\% confidence interval). $p$-value was calculated using chi-square test

Table 3: Signs and overall impression in structured reporting

\begin{tabular}{llll}
\hline Sign & Sensitivity & Specificity & Accuracy \\
\hline Swirl sign & $21 / 32$ & $135 / 142$ & $156 / 174$ \\
& $(65.6 ; 49.2-82.1)$ & $(95.1 ; 91.5-98.6)$ & $(89.7 ; 83.9-93.6)$ \\
Small bowel & $5 / 32$ & $134 / 142$ & $139 / 174$ \\
obstruction & $(15.6 ; 3.0-28.2)$ & $(94.4 ; 90.6-98.2)$ & $(79.9 ; 73.0-85.4)$ \\
Clustered loops & $8 / 32$ & $128 / 142$ & $136 / 174$ \\
& $(25.0 ; 10.0-40.0)$ & $(90.1 ; 85.2-95.0)$ & $(78.2 ; 71.1-83.9)$ \\
Mushroom sign & $11 / 32$ & $140 / 142$ & $151 / 174$ \\
& $(34.4 ; 17.9-50.8)$ & $(98.6 ; 96.7-100)$ & $(86.8 ; 80.6-91.3)$ \\
Hurricane sign & $12 / 32$ & $141 / 142$ & $153 / 174$ \\
& $(37.5 ; 20.7-54.3)$ & $(99.3 ; 97.9-100)$ & $(87.9 ; 81.9-92.2)$ \\
Small bowel behind & $7 / 32$ & $139 / 142$ & $146 / 174$ \\
SMA & $(21.9 ; 7.6-36.2)$ & $(97.9 ; 95.5-100)$ & $(83.9 ; 77.4-88.9)$ \\
Right-sided & $1 / 32$ & $141 / 142$ & $142 / 174$ \\
anastomosis & $(3.1 ; 0-9.2)$ & $(99.3 ; 97.9-100)$ & $(81.6 ; 74.9-86.9)$ \\
Enlarged nodes & $17 / 32$ & $119 / 142$ & $136 / 174$ \\
& $(53.1 ; 35.8-70.4)$ & $(83.8 ; 77.7-89.9)$ & $(78.2 ; 71.1-83.9)$ \\
Venous congestion & $26 / 32$ & $134 / 142$ & $160 / 174$ \\
& $(81.3 ; 67.7-94.8)$ & $(94.4 ; 90.6-98.2)$ & $(92.0 ; 86.6-95.4)$ \\
Mesenteric oedema & $22 / 32$ & $128 / 142$ & $150 / 174$ \\
& $(68.8 ; 52.7-84.8)$ & $(90.1 ; 85.2-95.0)$ & $(86.2 ; 80.0-90.8)$ \\
\hline
\end{tabular}

Values are numerator/denominator (\%; 95\% confidence interval).

$\mathrm{PPV}=$ positive predictive value; NPV = negative predictive value; $\mathrm{IH}=$ internal herniation;

$\mathrm{SMA}=$ superior mesenteric artery 
Table 4: Positive predictive value of Likert scale.

\begin{tabular}{llll}
\hline Overall impression & $\mathrm{IH}(\mathrm{n})$ & $\mathrm{No} \mathrm{IH}(\mathrm{n})$ & $\mathrm{PPV}(\%,(95 \%-\mathrm{Cl}))$ \\
\hline $\mathbf{1}$ & 3 & 113 & $2.6(0.7-7.9)$ \\
2 & 2 & 17 & $10.5(1.9-34.5)$ \\
3 & 2 & 6 & $25.0(0.4-64.4)$ \\
4 & 14 & 4 & $77.8(51.9-92.6)$ \\
5 & 11 & 2 & $84.6(53.7-97.3)$ \\
\hline
\end{tabular}

$\mathrm{IH}=$ internal herniation; $\mathrm{PPV}=$ positive predictive value; $\mathrm{Cl}=$ confidence interval

Table 5: Signs mentioned in free-text reporting

\begin{tabular}{llll}
\hline Sign & Mentioned & Not mentioned & Percentage \\
\hline Swirl sign & 170 & 119 & 58.8 \\
Small bowel obstruction & 156 & 133 & 54.0 \\
Clustered loops & 53 & 236 & 18.3 \\
Mushroom sign & 4 & 285 & 1.4 \\
Hurricane sign & 2 & 287 & 0.7 \\
Small bowel behind SMA & 2 & 287 & 0.7 \\
Right-sided anastomosis & 27 & 262 & 9.3 \\
Enlarged nodes & 94 & 195 & 32.5 \\
Venous congestion & 32 & 257 & 11.1 \\
Mesenteric oedema & 93 & 196 & 32.2 \\
\hline
\end{tabular}

SMA = superior mesenteric artery

\section{Discussion}

The aim of this study was to investigate if using structured reporting with the use of ten CT signs in clinical practice improves accuracy of CT scans in case of a suspicion of $\mathrm{IH}$, compared with free-text reporting. This study found that the use of ten $\mathrm{CT}$ signs improves accuracy in diagnosing $\mathrm{IH}$ on $\mathrm{CT}$ scans from $87.2 \%$ to $93.1 \%(p=0.045)$. Furthermore, an increase in specificity and positive predictive value was found from $88.6 \%$ to $95.8 \%$ ( $p=0.016)$ and from $55.6 \%$ to $81.3 \%(p=0.014)$, respectively, hereby reducing the number of unnecessary laparoscopies.

Our findings confirm the assumptions of previous studies, that also found that structured reporting using CT signs improved accuracy ${ }^{14,16}$. However, these previous studies performed blind reading of the CT scans retrospectively and compared them with the original report. To our knowledge, this is the first study to prospectively use structured reporting in clinical practice for the diagnosis of $\mathrm{IH}$. 
The accuracy of the different signs can only be compared to retrospectively performed studies $1-5,14,16$. The range of sensitivity and specificity in and between these studies is broad. Most noteworthy, the sensitivity of the swirl sign decreased compared to most previous studies with a comparable increased specificity. However, the accuracy is comparable to a previous study into the ten CT signs, $89.7 \%$ compared to $86.5-91.4 \%^{14}$. The accuracy of small bowel obstruction, clustered loops, right-sided anastomosis, and enlarged nodes decreased compared to this previous retrospective study. Of these signs, the sensitivity is rather poor and also the accuracy is not excellent. The decrease in accuracy might be explained due to the variety of (in-training) radiologists who reported the CT scans in the prospective setting. The poor sensitivity of these signs suggests these might not be valuable in clinical practice and could be excluded from the structured reporting. In the retrospective setting of this study most of these signs were also infrequently mentioned.

The use of Likert scale in determining the possibility of IH gives a positive predictive value of $25.0 \%$ for the "doubt category" of 3 . This means that radiologic doubt is in most cases not an IH. An independent experienced radiologist (SJ) blindly reviewed the nine CT scans with a Likert scale of 3 . She diagnosed one $\mathrm{IH}$ correctly; however, she missed the other $\mathrm{IH}$. Furthermore, one CT scan remained in category 3. All other CT scans previously given a 3 were found to be low suspect for $\mathrm{IH}$. Having an experienced radiologist as second opinion in case of doubt gives more certainty and thereby might prevent unnecessary surgeries. In the current study the ten most described signs in recent literature were used for the structured reporting template ${ }^{1-6}$. Some signs previously described differently in various articles were combined to one sign in our template. We found that the mushroom and hurricane eye sign were minimally sensitive, however had good specificity, PPV and NPV. Other minimally sensitive signs as clustered loops, small bowel behind the SMA, right-sided anastomosis, and enlarged nodes had also poorer PPV and NPV. Future research into the usefulness of all CT signs might be performed. Maybe not all currently used signs are necessary, or maybe other signs should be included in the structured reporting template.

Our study has several strengths and limitations. This study is the first prospective study into the use of CT signs for diagnosing $\mathrm{IH}$ in clinical practice. A limitation of this study is that radiologists in our hospital might be more aware of the signs that can be used for diagnosing IH on CT scans because of previous research on this subject performed in our hospital. To minimise this effect we excluded the time period January 2017 until June 2017. In May 2017, the signs were explained to all (in-training) radiologists and the implementation of the structured reporting was started. However, bias due to improvement in technical skills of the radiologists cannot be completely excluded. This bias is reduced because also new (in-training) radiologists, with minimal knowledge of $\mathrm{IH}$ and the signs, started working with the structured reporting template. Moreover, the in-training radiologists were the main reporters of the CT scans with suspicion 
of $\mathrm{IH}$. Another drawback is the fact that structured reporting was not used on all CT scans. This was mostly caused by an initial lack of knowledge of the structured reporting template in newly hired (in-training) radiologists. Surgeons in our hospital were also more aware of the diagnostic support radiologists could provide and more frequently requested CT scans before considering a reoperation. Due to the clear radiological reports with the use of standardised format, they might also be more inclined to rely on the radiological diagnosis, changing the reoperation considerations.

To increase the amount of includable patients in the accuracy analysis, 90 days follow-up was added as reference for the CT scan diagnosis. The cut-off of 90 days was chosen because an IH was considered unlikely after 90 days without further intervention. This cut-off of 90 days is debatable, but in this study, it was believed to be reasonable.

To conclude, this study found an increase in accuracy when using structured reporting in clinical practice compared with free-text reporting in diagnosing internal herniation on CT scans after gastric bypass surgery. Also, the found increase in positive predictive value can prevent unnecessary reoperations in patients with low probability of $\mathrm{IH}$. The use of structured reporting can possibly improve certainty of diagnosing IH on CT scans in less-experienced (in-training) radiologists. 


\section{References}

1. Dilauro $\mathrm{M}, \mathrm{Mclnnes} \mathrm{M}$, Schieda $\mathrm{N}$ et al. Internal Hernia after Laparoscopic Rouxen-Y Gastric Bypass: Optimal CT Signs for Diagnosis and Clinical Decision Making. Radiology 282[3], 752-760. 2017. doi: 10.1148/radiol.2016160956.

2. Goudsmedt F, Deylgat B, Coenegrachts K, Moortele Kvd, Dillemans B. Internal hernia after laparoscopic Roux-en-Y gastric bypass: a correlation between radiological and operative findings. Obes Surg 25[4], 622-627. 2015. doi: 10.1007/s11695-0141433-5, doi: 10.1007/s11695-014-1433-5.

3. Iannuccilli J, Grand D, Murphy B, Evangelista P, Roye G, Mayo-Smith W. Sensitivity and specificity of eight CT signs in the preoperative diagnosis of internal mesenteric hernia following Roux-en-Y gastric bypass surgery. Clin Radiol 64[4], 373-380. 2009. doi: 10.1016/j.crad.2008.10.008.

4. Lockhart M, Tessler F, Canon $\mathrm{C}$ et al. Internal hernia after gastric bypass: sensitivity and specificity of seven CT signs with surgical correlation and controls. Am J Roentgenol 188[3], 745-750. 2007.

5. Maier J, Herrasti Gallego A, Floyd A. Compression of the superior mesenteric vein - a sign of acute internal herniation in patients with antecolic laparoscopic Rouxen-Y gastric bypass. Eur Radiol 27[4], 1733-1739. 2017. doi: 10.1007/s00330-0164526-9.

6. Park J, Chung M, Teixeira J, Baer J, Frager D. Computed tomography findings of internal hernia after gastric bypass that may precede small bowel obstruction. Hernia 20[3], 471-477. 2016. doi: 10.1007/s10029-015-1424-z.

7. Brook O, Brook A, Vollmer C, Kent T, Sanchez N, Pedrosa I. Structured Reporting of Multiphasic CT for Pancreatic Cancer: Potential Effect on Staging and Surgical Planning. Radiology 274[2], 464-472. 2015. doi: 10.1148/radiol.14140206.

8. Johnson T, Brinjikji W, Doolittle D, Nagelschneider A, Welch B, Kotsenas A. Structured Head and Neck CT Angiography Reporting Reduces Resident Revision Rates. Curr Probl Diagn Radiol 48[2], 114-116. 2019. doi: 10.1067/j.cpradiol.2018.04.003.

9. Poullos P, Tseng J, Melcher M et al. Structured Reporting of Multiphasic CT for Hepatocellular Carcinoma: Effect on Staging and Suitability for Transplant. Am J Roentgenol 210, 766-774. 2018. doi: 10.2214/AJR.17.18725.

10. Schoeppe F, Sommer W, Norenberg D et al. Structured reporting adds clinical value in primary CT staging of diffuse large B-cell lymphoma. Eur Radiol 28[9], 37023709. 2018. doi: 10.1007/s00330-018-5340-3.

11. Franconeri A, Boos J, Fang J et al. Adnexal mass staging CT with a disease-specific structured report compared to simple structured report. Eur Radiol 29[9], 48514860. 2019. doi: 10.1007/s00330-019-06037-7.

12. Sala E, Freeman S. Structured reporting of pelvic MRI leads to better treatment planning of uterine leiomyomas. Eur Radiol 28[7], 3007-3008. 2018. doi: 10.1007/ s00330-018-5417-z.

13. Franconeri A, Fang J, Carney B et al. Structured vs narrative reporting of pelvic MRI for fibroids: clarity and impact on treatment planning. Eur Radiol 28[7], 3009-3017. 2018. doi: 10.1007/s00330-017-5161-9.

14. Ederveen J, van Berckel M, Jol S, Nienhuijs S, Nederend J. Diagnosing internal 
Chapter 4. Structured CT reporting improves accuracy in diagnosing IH

herniation after laparoscopic Roux-en-Y gastric bypass: usefulness of systematically reviewing CT scans using ten signs. Eur Radiol 28[9], 3583-3590. 2-3-2018. doi: 10.1007/s00330-018-5332-3.

15. Ederveen J, van Berckel M, Nienhuijs S, Weber R, Nederend J. Predictive value of abdominal CT in evaluating internal herniation after bariatric lapaoscopic Roux-en-Y gastric bypass. Br J Surg 105[12], 1623-1629. 2018. doi: 10.1002/bjs.10886.

16. Karila-Cohen P, Cuccioli F, Tammaro P et al. Contribution of Computed Tomographic Imaging to the Management of Acute Abdominal Pain after Gastric Bypass: Correlation Between Radiological and Surgical Findings. Obes Surg 27[8], 19611972. 2017. doi: 10.1007/s11695-017-2601-1. 


\section{Chapter 5.}

\section{Lessons learned after CT misdiagnoses of internal herniation after gastric bypass}

J.C. Ederveen, $\mathrm{MD}^{1}$

S.W. Nienhuijs, MD, $\mathrm{PhD}^{2}$

S.G.F. Robben, $\mathrm{MD}, \mathrm{PhD}^{1}$

J. Nederend, MD, $\mathrm{PhD}^{3}$

${ }^{1}$ Department of Radiology, Maastricht University Medical Centre, The Netherlands ${ }^{2}$ Department of Surgery, Catharina Hospital Eindhoven, The Netherlands

${ }^{3}$ Department of Radiology, Catharina Hospital Eindhoven, The Netherlands

Submitted 


\begin{abstract}
Background

With the increase of gastric bypass surgery also the amount of CT scans for suspicion of internal herniation $(\mathrm{IH})$ increases. CT scans have been found to have a good accuracy. The aim of this study was to learn from flawed diagnoses and formulate recommendations for radiologists in diagnosing $\mathrm{IH}$.
\end{abstract}

\title{
Methods
}

All patients that underwent a laparoscopic primary or revisional gastric bypass between January 1, 2011 and January 1, 2018 were retrospectively included. All CT scans and reoperation reports in these patients between January 1, 2011 and January 1, 2019 were screened for $\mathrm{IH}$. All cases with discrepancies between radiological and clinical conclusion were further investigated.

\section{Results}

Out of the 525 CT scans for IH 49(9.3\%) were found to be discrepant. After blinded revision by two experienced readers 30(61.2\%) of these were considered initially misdiagnosed. In the remaining 19 cases, 9 were false negative (FN), and 10 were false positive (FP). Eleven cases were considered to be an intermittent $\mathrm{IH}$ (7 FN and $4 \mathrm{FP}$ ). One FP had surgery much later due to persistent complaints, which did prove $\mathrm{IH}$. One CT diagnosis of intussusception (FN) was found to be an IH. Two FP were found to be adhesions. One FN and three FP remained unexplainable (4/525;0.8\%).

\section{Conclusion}

Specific radiological expertise of the signs of $\mathrm{IH}$ is the most important factor to prevent incorrect diagnosis. Second reading by an experienced reader can improve accuracy. However, intermittent internal herniation remains a pitfall and should be considered if there is delay between complaints, CT scan, and reoperation. Not all discrepancies can be avoided. 


\section{Introduction}

The amount of CT scans for the suspicion of internal herniation $(\mathrm{IH})$ after gastric bypass surgery increases with the increasing overweight population undergoing a gastric bypass. Since $\mathrm{IH}$ is a serious complication surgeons need to be able to rely on a correct radiological CT report. However, accuracy of CT scans is not a hundred percent.

Numerous signs are developed to help differentiate normal postoperative anatomy from changes matching with $\mathrm{IH}$. Two recent retrospective studies reviewing $\mathrm{CT}$ reports with the use of these signs found an accuracy for the diagnosis of $\mathrm{IH}$ ranging between $75.0 \%$ and $89.8 \%^{1,2}$. Without structured use of these signs the accuracy is lower, between $62 \%$ and $86.6 \%$ calculated from previous articles ${ }^{3-5}$. An accuracy of almost $90 \%$ can be considered good, however the risk of missing an $\mathrm{IH}$ and the risk of unnecessary operations should not be disregarded. Therefore further investigation of missed and wrongful diagnoses is necessary.

One of the main reasons for low accuracy is the possibility of intermittent $\mathrm{IH}^{6-8}$. In these cases bowel loops are herniated during CT scan but only open herniation sites are found during reoperation or the other way around. These scans are reported as misdiagnosed, but possibly the diagnosis was correct but changed in the time between CT scan and reoperation. Furthermore, lack of knowledge of the reading radiologist is also considered as a reason for wrongful diagnoses, with increase in accuracy after second opinion by an experienced radiologist in cases of radiological doubt ${ }^{9}$.

The aim of this study was to evaluate those cases with discrepancies between $\mathrm{CT}$ and clinical diagnosis to further improve strategies for radiologists to identify $\mathrm{IH}$ and to identify cases with possible intermittent $\mathrm{IH}$.

\section{Methods}

This retrospective study was performed on all patients who underwent laparoscopic gastric bypass surgery in our bariatric centre of excellence between January 1, 2011 and January 1, 2018. No patients were excluded. All consecutive CT scans for a suspicion of IH between January 1, 2011 and January 1, 2019 were included. All reoperation reports in patients undergoing a CT scan were screened to select reoperations for a suspicion of $\mathrm{IH}$. Data on the presence of bowel herniation were extracted from surgery reports.

Episodes were considered IH positive if bowel herniation through a mesenteric defect was seen during reoperation within 90 days after the CT scan. An episode was considered negative when no $\mathrm{IH}$ was seen during surgery, or in case of 
negative clinical follow-up during a period of 90 days. The clinical follow-up was considered negative if no reoperation or no repeat CT scan was performed within these 90 days.

Intermittent IH was considered when during reoperation defects were closed without $\mathrm{IH}$ and complaints disappeared after reoperation. Or no complaints were present during CT scan, but patients were operated on later on when complaints recurred.

Discrepancies between CT conclusion and clinical conclusion were further analysed. In these cases the electronic patient files were studied for the reasons for performing a reoperation or not, nature of complaints and final diagnosis. Furthermore, the timing of the CT scan (working hours or not) and level of experience of radiologist (in-training or abdominal or general) were included. All CT scans with discrepancies were reviewed by two experienced readers (JE and $\mathrm{JN}$ ) in consensus, without clinical information or knowledge of operation reports. They scored the CT scans as negative or positive for $\mathrm{IH}$ and alternative diagnosis such as adhesions were also given.

CT scans performed in other hospitals and revised in the study-institution were not included in this study. The local medical ethical review board approved the study design. Written informed consent was waived. This study population was previously reported in a study into the value of structured reporting of CT scans in case of suspicion of internal herniation?.

\section{Surgical Technique}

All patients had undergone a laparoscopic Roux-en-Y gastric bypass (LRYGB) performed with an antecolic position of the jejunal limb. Both primary and secondary LRYGB were included. Secondary LRYGB was performed on indication after sleeve gastrectomy, adjustable gastric banding or vertical banded gastroplasty. Only from 2017 onwards mesenteric and Petersen defects were closed routinely in our hospital.

\section{Image acquisition and analysis}

All CT scans were performed with either a Brilliance iCT 256 slice or a Brilliance 64 CT scanner, with a slice thickness of $1 \mathrm{~mm}$ (Philips Medical, Best, Netherlands). Multiplanar reconstructions were available. One litre of diluted oral contrast (Telebrix, loxithalamaat $6 \mathrm{mg} \mathrm{I/ml;} \mathrm{Guerbet)} \mathrm{was} \mathrm{administered} 90 \mathrm{~min}$ before the CT scan if possible. All scans were performed $70 \mathrm{~s}$ after administration of $100 \mathrm{ml}$ intravenous contrast lomeron (lomeprol 300mg I/ml; Bracco Imaging).

All CT scans were reported on by a radiologist or an in-training radiologist (under supervision of a radiologist). They had access to the clinical information provided by the clinicians. From May 30, 2017 a standardized template stating ten signs was implemented in the radiological report. The ten signs used were 
(1) swirl sign, (2) small-bowel obstruction, (3) clustered loops of small bowel, (4) mushroom sign, (5) hurricane eye sign, (6) small bowel posterior to superior mesenteric artery (SMA), (7) right-sided distal anastomosis, (8) enlarged nodes, (9) venous congestion, and (10) mesenteric oedema. Each sign was scored as being present or absent. Furthermore, an overall impression was given using a 5 -point Likert-scale, 1 being definitely no $\mathrm{IH}, 5$ being definite $\mathrm{IH}$.

Statistical analysis

All data were entered into a computerized spreadsheet (Excel; Microsoft) and were analysed with Statistical Package for Social Sciences 21.0 (SPSS Inc.). Patient characteristics are listed as mean $( \pm S D$ ) or median (interquartile range $(\mathrm{IQR}))$, depending on the normality of the distribution.

\section{Results}

A total of 2,606 patients underwent gastric bypass surgery in the study period, $83.7 \%$ were female with a mean age of $43.3( \pm 10.5)$ years, and a median body mass index (BMI) of $41.5 \mathrm{~kg} / \mathrm{m}^{2}\left(\mathrm{IQR} 38.9-44.7 \mathrm{~kg} / \mathrm{m}^{2}\right)$. The majority underwent a primary procedure $(73.6 \%)$. In the study population a total of $525 \mathrm{CT}$ scans were performed in 379 patients. The accuracy of all CT scans was $90.7 \%(476 / 525)$. Discrepancies between CT report and reoperation were found in 49 CT scans (9.3\%) which were subsequently included. Of the 49 CT scans, 30 (61.2\%) were scored correctly during revision, see figure 1 .

\section{Overall findings}

In $30 \mathrm{CT}$ scans the diagnosis was corrected during revision leading to an overall accuracy of $96.4 \%(506 / 525)$. The majority of the CT scans were performed during working hours $(67.3 \%$; $33 / 49)$ and reported on by a radiologist in-training (71.4\%; 35/49). Eleven of the 30 (36.7\%) corrected cases were reported on or supervised by a non-abdominal specialized radiologist, as well as seven of the 19 (36.8\%) misdiagnosed CT scans. There was also no significant difference in time period between corrected and misdiagnosed CT scans, respectively $31.6 \%$ and $33.3 \%$ of the CT scans were performed outside working hours.

\section{Analysis of false positive CT scans}

A total of 35 of the 49 CT scans (71.4\%) were false positive, see table 1. In 11/35 cases no reoperation was performed, either because complaints disappeared or because the surgeon did not agree with the radiological diagnosis.

In 24/35 cases a reoperation was performed, however no IH was seen during this operation. In 8 cases (33.3\%) open ports were closed and in 6 cases (25\%) an adhesion was seen. 
Fig. 1. Flow-chart of false positive and false negative CT scans after revision.

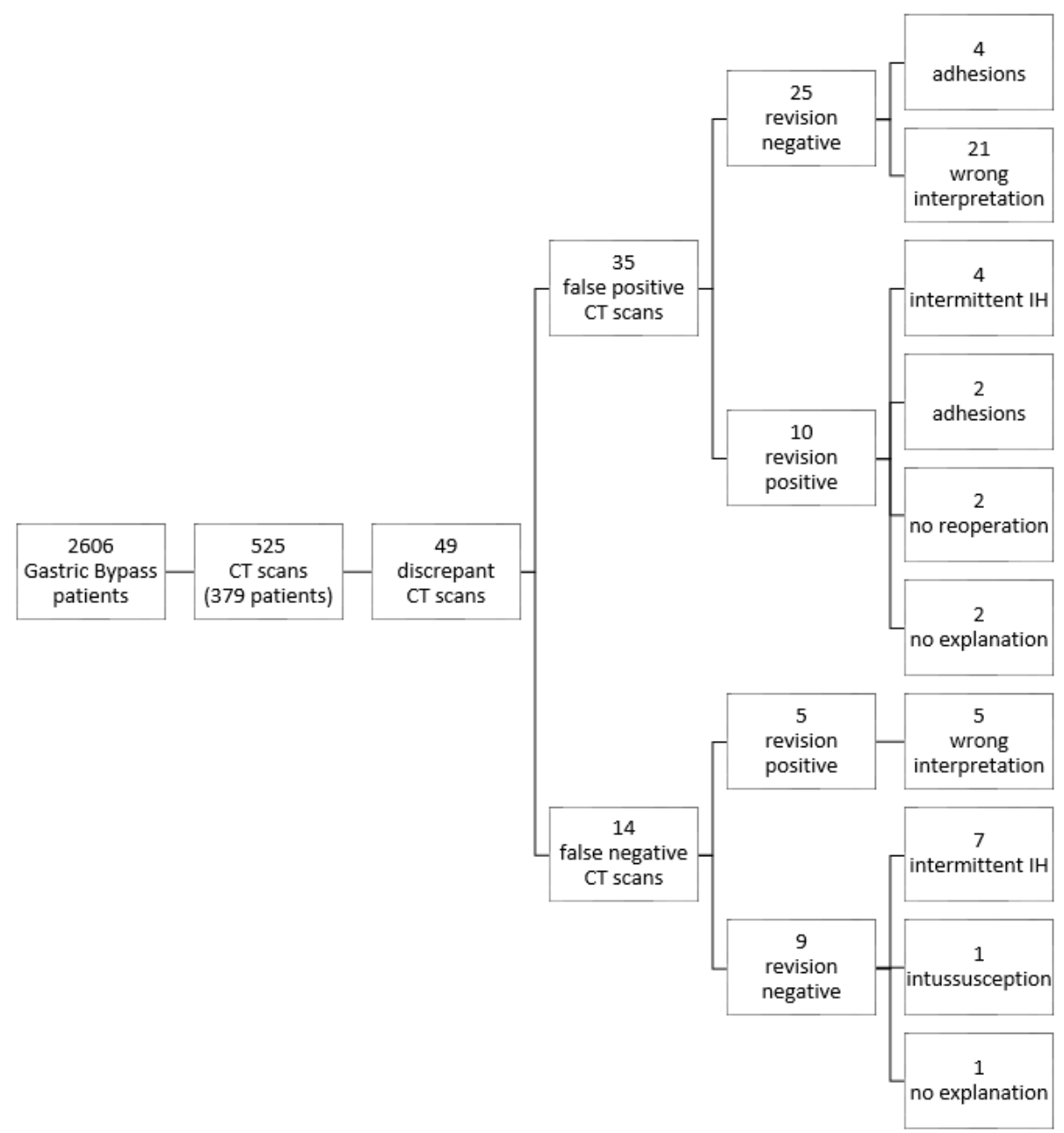

$\mathrm{IH}=$ internal herniation

In 25 of the 35 cases (71.4\%) without $\mathrm{IH}$ the diagnosis was corrected during revision, in these cases 3 of the 4 surgical found adhesion were scored correctly during revision. In the remaining 10 cases, 4 cases were considered intermittent $\mathrm{IH}$. Two adhesions were diagnosed as IH on CT scan. Two patients were not operated on within 90 days but had persistent complaints, one of which was operated on eventually and found to have an $\mathrm{IH}$. The remaining 2 cases remained false positive without explanation. One of these radiological looks as a classical scan of an $\mathrm{IH}$, but there was no resolve of complaints after closure of herniation sites, so intermittent IH was less likely. 


\section{Analysis of false negative CT scans}

A total of 14 of the 49 CT scans (28.6\%) were false negative, see table 2. In 7 cases patients had variable complaints and there was a delay between CT scan and reoperation of 16-42 days. One case was diagnosed as an intussusception and therefore operated on and one case was diagnosed as an adhesion and therefore operated on.

During revision five of the 14 cases (35.7\%) with IH were scored correctly. The 7 patients with variable complaints and delay between CT scan and reoperation were also scored negative during revision, therefore they were considered intermittent $\mathrm{IH}$. The case with the intussusception was scored no $\mathrm{IH}$ during revision, but remained an operation indication. One case remained false negative, with discrepancy between surgical and radiological interpretation.

\section{Discussion}

The aim of this study was to learn from the misdiagnoses and formulate recommendations for radiologists to further improve diagnosis of $\mathrm{IH}$ on CT scans after gastric bypass surgery. This study found a good accuracy of CT scans for diagnosing $\mathrm{IH}$ of $90.7 \%$, which increases to $96.4 \%(506 / 525)$ when an experienced abdominal radiologist reviews the discrepant cases. In $2.1 \%(11 / 525)$ of the cases an intermittent IH was considered, and in $0.6 \%(3 / 525)$ of the cases there was an operation indication other than $\mathrm{IH}$. One patient was initially not operated but was found to have an $\mathrm{IH}$ after persistent complaints. In the remaining $0.8 \%(4 / 525)$ of the cases no explanation could be found for the misdiagnoses.

The overall accuracy in this study was slightly higher than in previous studies with accuracies ranging between 72 and $88 \%^{2-4,10}$. Our findings are in line with the overall accuracy of $87.7-92.9 \%$ found in a previous study by Dilauro et al. ${ }^{11}$ using nine CT signs.

The use of CT signs is already found to be beneficial in diagnosing $\mathrm{IH}^{1,2,9}$. However, positive signs do not always conclude in being an $\mathrm{IH}$. In the current cohort we only found small bowel obstruction in patients with adhesions. Although this is an operation indication, the initial CT diagnosis was incorrect. Also, mesenteric oedema can be found in both internal herniation and adhesions.

Therefore, not only the presence of CT signs for IH but the overall findings should result in a diagnosis. With more experienced radiologists this results in more correct diagnoses. However, three adhesions were not diagnosed on the CT scans correctly during revision. These patients had no dilated bowel loops and possibly the adhesions were only minor. Nonetheless, adhesions should also be considered as cause of abdominal discomfort in case of persistent complaints and no signs of IH on CT scan. 
Table 1. False positive CT scans

\begin{tabular}{|c|c|c|c|c|c|c|}
\hline $\begin{array}{l}\mathrm{CT} \\
\text { number }\end{array}$ & $\begin{array}{l}\text { Revision } \\
\text { Corrected/ } \\
\text { False }\end{array}$ & $\begin{array}{l}\text { Operation } \\
\text { Yes/No }\end{array}$ & $\begin{array}{l}\text { Outside } \\
\text { working } \\
\text { hours } \\
\text { Yes/No }\end{array}$ & $\begin{array}{l}\text { Abdominal } \\
\text { radiologist } \\
\text { Yes/No }\end{array}$ & $\begin{array}{l}\text { Resident } \\
\text { Yes/No }\end{array}$ & $\begin{array}{l}\text { Structured } \\
\text { reporting } \\
\text { Yes/No } \\
\text { (Likert scale) }\end{array}$ \\
\hline 1 & $C$ & $\mathrm{~N}$ & $\mathrm{~N}$ & $\mathrm{Y}$ & $\mathrm{Y}$ & $\mathrm{N}$ \\
\hline 2 & $C$ & $\mathrm{~N}$ & $\mathrm{~N}$ & $Y$ & $Y$ & $\mathrm{~N}$ \\
\hline 3 & $C$ & $\mathrm{~N}$ & $\mathrm{~N}$ & $Y$ & $\mathrm{~N}$ & $\mathrm{~N}$ \\
\hline 4 & $C$ & $\mathrm{~N}$ & $\mathrm{~N}$ & $Y$ & $\mathrm{~N}$ & $\mathrm{~N}$ \\
\hline 5 & $C$ & $\mathrm{~N}$ & $Y$ & $\mathrm{~N}$ & $Y$ & $\mathrm{~N}$ \\
\hline 6 & C & $\mathrm{N}$ & $\mathrm{Y}$ & $\mathrm{Y}$ & $\mathrm{Y}$ & $\mathrm{N}$ \\
\hline 7 & C & $\mathrm{Y}$ & $\mathrm{N}$ & $\mathrm{Y}$ & $\mathrm{Y}$ & $Y(4)$ \\
\hline 8 & $C$ & $Y$ & $\mathrm{~N}$ & $Y$ & $Y$ & $\mathrm{~N}$ \\
\hline 9 & C & $Y$ & $\mathrm{~N}$ & $Y$ & $Y$ & $\mathrm{~N}$ \\
\hline 10 & $C$ & $Y$ & $\mathrm{~N}$ & $Y$ & $Y$ & $\mathrm{~N}$ \\
\hline 11 & C & $\mathrm{Y}$ & $\mathrm{N}$ & $\mathrm{Y}$ & $\mathrm{Y}$ & $\mathrm{N}$ \\
\hline 12 & C & $Y$ & $\mathrm{~N}$ & $Y$ & $Y$ & $\mathrm{~N}$ \\
\hline 13 & C & $Y$ & $\mathrm{~N}$ & $Y$ & $\mathrm{Y}$ & $\mathrm{N}$ \\
\hline 14 & C & $Y$ & $\mathrm{~N}$ & $Y$ & $\mathrm{~N}$ & $\mathrm{~N}$ \\
\hline 15 & C & $Y$ & $\mathrm{~N}$ & $\mathrm{Y}$ & $\mathrm{N}$ & $\mathrm{N}$ \\
\hline 16 & C & $Y$ & $\mathrm{~N}$ & $\mathrm{~N}$ & $Y$ & $Y(4)$ \\
\hline 17 & $C$ & $Y$ & $\mathrm{~N}$ & $\mathrm{~N}$ & $Y$ & $\mathrm{~N}$ \\
\hline 18 & C & Y & $\mathrm{N}$ & $\mathrm{N}$ & $\mathrm{N}$ & $Y(4)$ \\
\hline 19 & C & $\mathrm{Y}$ & $\mathrm{N}$ & $\mathrm{N}$ & $\mathrm{N}$ & $\mathrm{N}$ \\
\hline 20 & C & $\mathrm{Y}$ & $\mathrm{Y}$ & $\mathrm{Y}$ & $Y$ & $\mathrm{~N}$ \\
\hline 21 & $C$ & $Y$ & $\mathrm{Y}$ & $\mathrm{Y}$ & $\mathrm{Y}$ & $\mathrm{N}$ \\
\hline 22 & $C$ & $Y$ & $Y$ & $\mathrm{~N}$ & $Y$ & $Y(5)$ \\
\hline 23 & C & $Y$ & $Y$ & $\mathrm{~N}$ & $Y$ & $Y(5)$ \\
\hline 24 & $C$ & $Y$ & $Y$ & $\mathrm{~N}$ & $Y$ & $\mathrm{~N}$ \\
\hline 25 & $C$ & $Y$ & $Y$ & $\mathrm{~N}$ & $Y$ & $\mathrm{~N}$ \\
\hline 26 & $F$ & $\mathrm{~N}$ & $\mathrm{~N}$ & $Y$ & $Y$ & $\mathrm{~N}$ \\
\hline 27 & $\mathrm{~F}$ & $\mathrm{~N}$ & $Y$ & $Y$ & $Y$ & $\mathrm{~N}$ \\
\hline 28 & $F$ & $\mathrm{~N}$ & $\mathrm{~N}$ & $\mathrm{Y}$ & $\mathrm{N}$ & $\mathrm{N}$ \\
\hline 29 & $\mathrm{~F}$ & $\mathrm{~N}$ & $\mathrm{~N}$ & $Y$ & $\mathrm{~N}$ & $\mathrm{~N}$ \\
\hline 30 & $\mathrm{~F}$ & $\mathrm{~N}$ & $Y$ & $\mathrm{~N}$ & $Y$ & $\mathrm{~N}$ \\
\hline 31 & $\mathrm{~F}$ & $Y$ & $Y$ & $Y$ & $Y$ & $\mathrm{~N}$ \\
\hline 32 & $\mathrm{~F}$ & $Y$ & $\mathrm{~N}$ & $Y$ & $\mathrm{~N}$ & $\mathrm{~N}$ \\
\hline 33 & $\mathrm{~F}$ & $Y$ & $\mathrm{~N}$ & $\mathrm{~N}$ & $Y$ & $Y(4)$ \\
\hline 34 & $F$ & $Y$ & $\mathrm{~N}$ & $\mathrm{~N}$ & $Y$ & $\mathrm{~N}$ \\
\hline 35 & $\mathrm{~F}$ & $Y$ & $\mathrm{~N}$ & $\mathrm{~N}$ & $\mathrm{~N}$ & $\mathrm{~N}$ \\
\hline
\end{tabular}

$\mathrm{IH}=$ internal herniation 


\author{
Surgeon no suspicion \\ Surgeon no suspicion \\ Surgeon no suspicion, no complaints \\ Surgeon no suspicion and next morning no complaints \\ Surgeon no suspicion \\ Herniation sides already closed therefore surgeon no \\ suspicion
}

No dilatation or adhesion on CT, adhesiolysis

Adhesion

Adhesion

Adhesion on CT during revision, adhesiolysis

Adhesion

Adhesion on CT during revision, adhesiolysis

Adhesion

Adhesion on CT during revision, no adhesiolysis

Adhesion on CT during revision, no adhesiolysis

Surgeon no suspicion, persistent complaints, not operated

Surgeon no suspicion, 4 years later new CT-scan with similar images, operation with $\mathrm{IH}$

Displaced jejunum, patient no complaints

No complaints

Next morning no complaints, later new complaints with IH

Persistent complaints, change of anastomosis. Radiological classical

Radiological not very suspicious

Radiological classical, varying complaints

No dilatation or adhesion on CT, adhesiolysis

No dilatation or adhesion on CT, adhesiolysis
Possible false positive

Persistent complaints, intermittent IH Intermittent $\mathrm{IH}$ Intermittent IH Intermittent IH False positive

False positive Intermittent IH Adhesion Adhesion 
Table 2: False negative CT scans

\begin{tabular}{lllllll}
\hline $\begin{array}{l}\text { CT } \\
\text { number }\end{array}$ & $\begin{array}{l}\text { Revision } \\
\text { Corrected/ } \\
\text { False }\end{array}$ & $\begin{array}{l}\text { Operation } \\
\text { Yes/No }\end{array}$ & $\begin{array}{l}\text { Outside } \\
\text { working } \\
\text { hours } \\
\text { Yes/No }\end{array}$ & $\begin{array}{l}\text { Abdominal } \\
\text { radiologist } \\
\text { Yes/No }\end{array}$ & $\begin{array}{l}\text { Resident } \\
\text { Yes/No }\end{array}$ & $\begin{array}{l}\text { Structured } \\
\text { reporting } \\
\text { Yes/No } \\
\text { (Likert scale) }\end{array}$ \\
\hline 1 & $\mathrm{C}$ & $\mathrm{Y}$ & $\mathrm{N}$ & $\mathrm{Y}$ & $\mathrm{Y}$ & $\mathrm{Y}(3)$ \\
2 & $\mathrm{C}$ & $\mathrm{Y}$ & $\mathrm{N}$ & $\mathrm{Y}$ & $\mathrm{Y}$ & $\mathrm{N}$ \\
3 & $\mathrm{C}$ & $\mathrm{Y}$ & $\mathrm{N}$ & $\mathrm{Y}$ & $\mathrm{N}$ & $\mathrm{N}$ \\
4 & $\mathrm{C}$ & $\mathrm{Y}$ & $\mathrm{Y}$ & $\mathrm{N}$ & $\mathrm{Y}$ & $\mathrm{Y}(3)$ \\
5 & $\mathrm{C}$ & $\mathrm{Y}$ & $\mathrm{Y}$ & $\mathrm{N}$ & $\mathrm{Y}$ & $\mathrm{N}$ \\
6 & $\mathrm{~F}$ & $\mathrm{Y}$ & $\mathrm{N}$ & $\mathrm{Y}$ & $\mathrm{Y}$ & $\mathrm{Y}(1)$ \\
7 & $\mathrm{~F}$ & $\mathrm{Y}$ & $\mathrm{N}$ & $\mathrm{Y}$ & $\mathrm{Y}$ & $\mathrm{N}$ \\
8 & $\mathrm{~F}$ & $\mathrm{Y}$ & $\mathrm{N}$ & $\mathrm{Y}$ & $\mathrm{Y}$ & $\mathrm{N}$ \\
9 & $\mathrm{~F}$ & $\mathrm{Y}$ & $\mathrm{N}$ & $\mathrm{Y}$ & $\mathrm{N}$ & $\mathrm{Y}(1)$ \\
10 & $\mathrm{~F}$ & $\mathrm{Y}$ & $\mathrm{N}$ & $\mathrm{Y}$ & $\mathrm{N}$ & $\mathrm{Y}(1)$ \\
11 & $\mathrm{~F}$ & $\mathrm{Y}$ & $\mathrm{N}$ & $\mathrm{Y}$ & $\mathrm{N}$ & $\mathrm{N}$ \\
12 & $\mathrm{~F}$ & $\mathrm{Y}$ & $\mathrm{Y}$ & $\mathrm{N}$ & $\mathrm{Y}$ & $\mathrm{Y}(2)$ \\
13 & $\mathrm{~F}$ & $\mathrm{Y}$ & $\mathrm{Y}$ & $\mathrm{N}$ & $\mathrm{Y}$ & $\mathrm{N}$ \\
14 & $\mathrm{~F}$ & $\mathrm{Y}$ & $\mathrm{Y}$ & $\mathrm{N}$ & $\mathrm{Y}$ & $\mathrm{N}$ \\
\hline
\end{tabular}

$\mathrm{IH}=$ internal herniation

Interpretation of the CT scan by the attending surgeon resulted in no operation in 8 of the 11 false positive CT scans. However, in one of these cases the patient returned with persistent complaints and similar CT findings and was found to have an $\mathrm{IH}$. Another patient had persistent complaints but was never operated on. The remaining six patients had no complaints during follow-up and were also scored negative during revision. In four of the false negative CT scans the surgeon interpreted the CT scan as positive and therefore performed a reoperation and found an $\mathrm{IH}$. The other false negative CT scans were followed by an operation due to persistent complaints. In three of the four cases the experienced radiologist agreed with the surgeons interpretation, one of these cases was scored negative during revision and remains unclear false negative. Nonetheless, nine of the twelve cases (75\%) in which the surgeon had another interpretation would have been called correct by an experienced radiologist. Also in only $23.1 \%$ of the cases were surgeons operated after an negative CT scan an IH was found. Revision could decrease this to $15.3 \%$. Therefore, in case of discrepancy between radiological and surgical suspicion, a second opinion by an experienced abdominal radiologist should be considered. 
Varying complaints, documented no complaints during CT- Intermittent IH scan, operation after 33 days

Varying complaints, documented no complaints during CT- Intermittent IH scan, operation after 42 days

Varying complaints, operation after 21 days

Intermittent IH

Surgeon suspicion therefore operation

On MRI-scan signs of IH, therefore CT-scan performed without signs of $\mathrm{IH}$, operation after 33 days

False negative

Intermittent $\mathrm{IH}$

Varying complaints, operation after 16 days

Intermittent IH

CT-scan conform earlier, persistent complaints, operation after 40 days

Intermittent IH

Varying complaints, documented no complaints during CT- Intermittent IH scan, operation after 20 days

Intussusception

Operation indication

Noteworthy, there were no discrepancies between surgeons and radiologists after the implementation of the structured reporting template. All patients with a positive CT scan were operated on. However, even the structured reporting template is not flawless. Remarkable, the false diagnoses were corrected during revision or most probably based on intermittent $\mathrm{IH}$. Two false negatives were on basis of Likert scale 3, this should always be an indication for consulting an experienced radiologist.

Intermittent internal herniation remains an elusive diagnosis. In case of the seven false negative CT scans considered to be an intermittent $\mathrm{IH}$, there was a time delay of 16-42 days. Furthermore, these patients had documented no complaints during the CT scan or had variable complaints and were not scanned in the acute setting.

In case of the 4 false positive $\mathrm{CT}$ scans considered to be an intermittent $\mathrm{IH}$, all had improvement of symptoms shortly after the CT scan. Two of these patients had open ports at surgery ( 3 and 132 days respectively). The other two never 
showed symptoms until now and were not operated on.

Intermittent $\mathrm{IH}$ is found to cause discrepancies between radiological diagnosis and clinical diagnosis that might be improved by minimizing time delay between start of complaints, CT scan, and operation ${ }^{5}$. Patient's complaints should always be the first directive for operation. Persisting complaints even after negative CT scan should herald an operation, as well as delay of operation can be considered in case of disappearance of complaints after a positive CT scan. In this case the possibility of recurrence of symptoms should be communicated with the patients with an advice to present themselves at the emergency department in case of acute complaints. In these cases an emergency CT scan should also be made.

This study was set up to improve diagnosis of IH even more. However, there are also some limitations. First and foremost, the reviewing by two experienced readers was used as gold standard for the radiological report, however they might still be incorrect. Expert opinion was the best possible comparison that could be used in this study. Next to this, the operation report is also open for some interpretation; maybe not every mentioned adhesiolysis is relevant for patient complaints, and $\mathrm{IH}$ can reposition during insufflation of the abdomen or during the laparoscopy without being recognised and therefore mentioned in the report. Furthermore, in four cases we could not find the reason for discrepancy between radiological and surgical diagnosis. Therefore, CT scans remain not one hundred percent accurate, which should be kept into consideration.

To conclude, three recommendations can be made based on our results. Most importantly, experience with postoperative anatomy after gastric bypass and signs of $\mathrm{IH}$ improves radiological diagnosis and therefore second opinion by an experienced abdominal radiologist should be considered in case of disagreement between radiologists and surgeons. Second, the possible intermittent nature of $\mathrm{IH}$ can cloud the diagnostic process and therefore minimizing time delay between start of complaints, CT scan, and operation can be beneficial. Third, although dilated bowel loops is considered a sign of $\mathrm{IH}$, if it's the only sign adhesions should be considered as possible diagnosis. 


\section{References}

1. Ederveen J, van Berckel M, Jol S, Nienhuijs S, Nederend J. Diagnosing internal herniation after laparoscopic Roux-en-Y gastric bypass: usefulness of systematically reviewing CT scans using ten signs. Eur Radiol 28[9], 3583-3590. 2-3-2018. doi: 10.1007/s00330-018-5332-3.

2. Karila-Cohen P, Cuccioli F, Tammaro P et al. Contribution of Computed Tomographic Imaging to the Management of Acute Abdominal Pain after Gastric Bypass: Correlation Between Radiological and Surgical Findings. Obes Surg 27[8], 19611972. 2017. doi: 10.1007/s11695-017-2601-1.

3. Agaba E, Gentles C, Shamseddeen $\mathrm{H}$ et al. Retrospective analysis of abdominal pain in postoperative laparoscopic Roux-en-Y gastric bypass patients: is a simple algorithm the answer? Surg Obes Relat Dis 4[5], 587-593. 2008. doi: 10.1016/j. soard.2007.10.015.

4. Altieri M, Pryor A, Telem D, Hall K, Brathwaite C, Zawin M. Algorithmic approach to utilization of CT scans for detection of internal hernia in the gastric bypass patient. Surg Obes Relat Dis 11[6], 1207-1211. 2015. doi: 10.1016/j.soard.2015.02.010.

5. Ederveen J, van Berckel M, Nienhuijs S, Weber R, Nederend J. Predictive value of abdominal CT in evaluating internal herniation after bariatric lapaoscopic Roux-en-Y gastric bypass. Br J Surg 105[12], 1623-1629. 2018. doi: 10.1002/bjs.10886.

6. Al-Mansour M, Mundy R, Canoy J, Dulaimy K, Kuhn J, Romanelli J. Internal Hernia After Laparoscopic Antecolic Roux-en-Y Gastric Bypass. Obes Surg 25[11], 21062111. 2015. doi: 10.1007/s11695-015-1672-0.

7. Greenstein A, O'Rourke R. Abdominal pain after gastric bypass: suspects and solutions. Am J Med 201[6], 819-827. 2011. doi: 10.1016/j.amjsurg.2010.05.007.

8. Kristensen S, Jess P, Floyd A, Eller A, Engberg A, Naver L. Internal herniation after laparoscopic antecolic Roux-en-Y gastric bypass: a nationwide Danish study based on the Danish National Patient Register. Surg Obes Relat Dis 12[2], 297-303. 2016. doi: 10.1016/j.soard.2015.10.059.

9. Ederveen J, Nienhuijs S, Jol S, Robben S, Nederend J. Structured CT Reporting Improves Accuracy in Diagnosing Internal Herniation After Laparoscopic Roux-en-Y Gastric Bypass. Eur Radiol 30[6], 3448-3454. 2020. doi: 10.1007/s00330-02006688-x.

10. Frøkjær JB, Jensen WN, Holt G, Omar HK, Olesen SS. The diagnostic performance and interrater agreement of seven CT findings in the diagnosis of internal hernia after gastric bypass operation. Abdom Radiol (NY) 43[12], 3220-3226. 2018. doi: 10.1007/s00261-018-1640-y.

11. Dilauro M, Mclnnes M, Schieda N et al. Internal Hernia after Laparoscopic Rouxen-Y Gastric Bypass: Optimal CT Signs for Diagnosis and Clinical Decision Making. Radiology 282[3], 752-760. 2017. doi: 10.1148/radiol.2016160956. 



\section{Chapter 6.}

\section{Internal herniation and weight loss in patients after Roux-en-Y gastric bypass}

M.M.G. van Berckel, MD ${ }^{1}$

J.C. Ederveen, $\mathrm{MD}^{2}$

J. Nederend, $\mathrm{MD}, \mathrm{PhD}^{3}$

S.W. Nienhuijs, MD, $\mathrm{PhD}^{1}$

${ }^{1}$ Department of Surgery, Catharina Hospital Eindhoven, The Netherlands

${ }^{2}$ Department of Radiology, Maastricht University Medical Centre, The Netherlands

${ }^{3}$ Department of Radiology, Catharina Hospital Eindhoven, The Netherlands

M.M.G. van Berckel and J.C. Ederveen contributed equally to this work.

Obes Surg (2020); 30(7): 2652-2658. doi: 10.1007/s11695-020-04542-z 


\begin{abstract}
Introduction

Weight loss is one of the desired outcomes after a gastric bypass, in order to reduce co-morbidity, and even mortality. However, weight loss might contribute to a serious complication: internal herniation (IH). Pre-operative diagnosis of $\mathrm{IH}$ is demanding. This study was conducted to investigate if percentage total weight loss (\%TWL) is clinically usable in recognising patients with $\mathrm{IH}$.
\end{abstract}

\title{
Methods
}

Patients who had undergone a gastric bypass between 2011 and 2014, were included retrospectively if a CT scan or reoperation was performed for suspected IH between 2011 and 2016. Differences in \%TWL were calculated in patients with $\mathrm{IH}$ and without (NO-IH). A sub analysis was done in patients with complaints. A multivariate analysis to identify risk factors for $\mathrm{IH}$ was performed.

\section{Results}

Out of 1007 patients, 31 patients were diagnosed with an $\mathrm{IH}(3.1 \%)$ after a median time of 16.5 months (range 6.5-46.1). The \%TWL was higher in patients with an $\mathrm{IH}(34.2 \% \pm 12.7)$ vs. NO-IH $(30.8 \% \pm 9.6)$. This result was also seen in patients presenting with symptoms (IH 34.2\% 12.7 vs. NO-IH 27.0\% \pm 14.8 ). If $\%$ TWL is above $30 \%$, IH is significantly more diagnosed in patients presenting with symptoms. A multivariate logistic model for $\mathrm{IH}$ in patients presenting with symptoms identified both $\geq 30 \%$ TWL (adjusted OR 3.1, 95\% Cl 1.1-8.8, $p=0.036$ ), and abdominal cramping (adjusted $\mathrm{OR} 3.2,95 \% \mathrm{Cl} 1.2-8.5, p=0.0021$ ) as risk factors.

\section{Conclusion}

Our study showed significant more $\% \mathrm{TWL}$ in patients with an $\mathrm{IH}$. Both $\geq 30 \% \mathrm{TWL}$ and cramping abdominal pain, result in a threefold higher risk of presence of $\mathrm{IH}$. 


\section{Introduction}

Weight loss is one of the desired outcomes after gastric bypass (GBP). The results are excellent, both in terms of weight reduction, as well as in improvement of comorbidities, leading to a significant reduction in mortality ${ }^{1-4}$. However, reduction in weight might contribute to one of the well-known and serious complications of gastric bypass surgery: internal herniation $(\mathrm{IH})^{5-8}$. In general, experts assume that increased rates of IH after laparoscopic surgery occur due to lack of adhesions", and as a result of weight loss as the amount of intraabdominal fat declines ${ }^{5,10-17}$. This shift leads to subsequent enlargement of the surgically created mesenteric defects and a consecutive loosening of the mesenteric sutures. Any small defect in the mesentery becomes wider, resulting in an increase of internal herniation. As IH may lead to severe complications, such as small bowel obstruction and subsequent bowel ischemia ${ }^{18}$, it is crucial to recognise a patient with an $\mathrm{IH}$.

Three recent studies showed a significant weight reduction in patients with an $\mathrm{IH}$ after a laparoscopic antecolic gastric bypass. Schneider et al. ${ }^{19}$ found that patients undergoing periods of rapid weight loss, defined as excess weight loss (EWL) above 90th percentile of the group average, are at nearly twice the risk for development of IH. Geubbels et al. ${ }^{20}$ showed a significant higher \%TWL loss in patients with an $\mathrm{IH}$ within the first year after GBP. Stenberg et al. ${ }^{21}$ found that \%EWL is a significant risk factor for reoperation because of $\mathrm{IH}$. Surprisingly, in the only meta-analysis about internal herniation after GBP, weight loss was not included due to too much diversity in reporting weight loss, and lack of quality of the included studies ${ }^{22}$. In patients presenting with symptoms, only three studies were conducted. Lockhart et al. ${ }^{23}$ found an increase in weight reduction of 126 vs. $76 \mathrm{lb}(p=0.005)$ in patients with $\mathrm{IH}$ in comparison with patients with symptoms without an IH. Dilauro et al. ${ }^{24}$ found a higher total post-operative weight loss of $54 \mathrm{~kg}$ vs. $37 \mathrm{~kg}(p<0.0001)$. In a study with a different cohort selection (all patients received a re-laparoscopy) without further information regarding operation technique, no difference was found in $\% \mathrm{EWL}^{25}$. Besides discrepancies in results, in clinical perspective none of these results can be used to determine which patient presenting with symptoms is more likely to have an $\mathrm{IH}$.

The importance to investigate features and risk factors of patients presenting with symptoms is because $\mathrm{IH}$ is probably the most elusive complication to diagnose. In accordance with a very large variation of $\mathrm{IH}$ incidence $(0-14.4 \%)^{6}$, $15,26-38$, the presentation of $\mathrm{IH}$ can be very non-specific. It ranges from vague abdominal discomfort to acute small bowel obstruction, and from an acute onset to an intermittent character ${ }^{20,39}$. IH can develop at any time after the

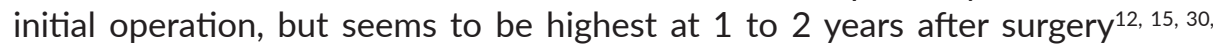
34, 40. CT has gained importance as a diagnostic tool since the introduction of systematically reviewing CT scans ${ }^{41,42}$. But as a substantial part of patients after GBP experience a certain (chronic) abdominal pain (33\% in a recent study ${ }^{9}$ ), it is 
important to clinically select the patients with symptoms that need further and immediate action.

The aim of this study was to detect factors of influence in $\mathrm{IH}$ formation, as well as to determine a threshold of percentage total weight loss (\%TWL) clinically usable in the diagnostic process of $\mathrm{IH}$.

\section{Methods}

\section{Cohort selection}

Patients were selected retrospectively from a prospectively collected database following a primary or revision gastric bypass performed between January 2011 and December 2014 and at least a follow-up of 12 months. The local medical ethical board waived ethical approval for this study.

All patients underwent a laparoscopic Roux-en-Y gastric bypass (GBP) performed with an antecolic position of the jejunal limb, with placement of an anticlockwise rotation of the Roux limb, left Roux limb configuration, and without division of the jejunal mesentery. During this study period, Petersen defects were never closed; mesenteric defects were only closed in the last study year (2014) by one surgeon, responsible for approximately $25 \%$ of the operations. Secondary GBP was performed after sleeve gastrectomy, adjustable gastric banding or vertical banded gastroplasty.

\section{Data collection}

Data on type of surgery, sex, age, height, initial and follow-up weight were extracted from the database. If a CT scan or an additional operation was performed in the study period, information regarding type of complaints, date of start of complaints, weight at start of complaints, and information regarding the CT scan or additional operation, were extracted from the electronic patient file. The conclusions of the CT reports were used for defining presence of IH on CT scans. In case of additional surgery, operation reports were checked on type of operation, and the presence of an $\mathrm{IH}$. Patients with a negative laparoscopy for $\mathrm{IH}$ were checked for alternative diagnoses by searching the electronic patient file. In case no herniation or alternative diagnosis was found, but the defects were closed, electronic patient file was searched for follow-up on relief of symptoms.

\section{Definitions and analysis}

Complaints were divided into five different symptoms; abdominal pain, abdominal cramping or colic pain, nausea or vomiting, abnormal defecation, and anorexia. Abnormal defecation was scored when defecation was changed from the normal routine after GBP, e.g., diarrhea or constipation. Anorexia was considered present in case of decreased sensation of appetite. 
An IH was defined as a protrusion of bowel through a mesenteric defect. Open or closed mesenteric defects, and protrusion of bowel through these defects, were extracted from the operation reports. If a bowel protrusion was mentioned, it was scored as an IH. Both herniation in Peterson's space and mesenteric defects at the jejuno-jejunostomy were included. Open defects during operation without protrusion were scored as not having an $\mathrm{IH}(\mathrm{NO}-\mathrm{IH})$. NO-IH was also scored when (1) no IH or open defects were seen during additional surgery, or (2) when neither CT nor reoperation was performed within 90 days after the initial CT.

Differences in \%TWL were compared between (1) patients with a confirmed IH and $\mathrm{NO}-\mathrm{IH}$, and (2) patients presenting with complaints with a confirmed $\mathrm{IH}$ and $\mathrm{NO}-\mathrm{IH}$. In case of a confirmed IH or complaints, the weight of that particular moment was used. In case patients did not have an IH or complaints, weight was used at the median time between operation and start of complaints of the total cohort, which is 350-450 days. In case multiple weights in this time frame were available, the lowest weight was included. To see if a possible \%TWL is related with presence of $\mathrm{IH}$ in patients presenting with symptoms, steps of $10 \%$ were used.

\section{Statistical analysis}

All data extracted from electronic patient files and databases was entered into a computerized spreadsheet (Excel; Microsoft, Redmond, WA, USA). Analysis was done by two independent researchers by using Statistical Package for Social Sciences 21.0 (SPSS Inc. Chicago, IL, USA) and STATA 12.0 (College Station, TX). Patient characteristics were listed as mean $( \pm S D$ ) or median (range), depending on the normality of the distribution. Continuous data were compared with the independent sample $t$ test or Mann-Whitney test for not normally distributed data. Categorical data were compared with chi-square test or Fisher's exact test. Missing values in type of symptom were excluded. The significance level was set at $p<0.05$.

Each of possible confounding variables was retained for the multivariate analysis if either the univariate effect of that variable was (near) significant or if the interaction with presence of $\mathrm{IH}$ was (near) significant.

\section{Results}

\section{Baseline characteristics}

A total of 1475 patients underwent primary or secondary GBP between 2011 and 2014. No patients died within 30 days of operation. After excluding patients without available weight measurements at initial operation or during follow-up, 1007 patients were included in the definitive cohort. Median follow-up was 45 months (range $24-72$ months). Most patients were female (84.7\%) with a mean age of 43.2 years, and initial body mass index (BMI) of $42.3 \mathrm{~kg} / \mathrm{m}^{2}$. Of these 
patients, 136 patients presented with complaints. Thirty-one patients were diagnosed with an $\mathrm{IH}$ (3.1\%), after a median time of 16.5 months after operation (range 6.5-46.1). Of the patients with complaints but with $\mathrm{NO}-\mathrm{IH}(n=105), 22$ had a negative laparoscopy. Of these patients, in 17, an alternative diagnosis $(n=14)$ could be diagnosed or the defects were already closed $(n=3)$, in one patient, the defects were closed during the operation but there was no relief of symptoms afterwards (\%TWL 39.1\%), and in four patients, defects were closed with afterwards complete relief of symptoms (average \%TWL 32.2\%). There were no differences in demographics between patients with complaints with a confirmed $\mathrm{IH}$ and $\mathrm{NO}-\mathrm{IH}$ (Table 1). Also in patients presenting with complaints $(n=136)$, no differences in demographics were found (Table 2).

\section{Bivariate analysis}

The \%TWL was higher $(p=0.020)$ in patients with a confirmed $\mathrm{IH}(34.2 \% \pm 12.7)$ in comparison with $\mathrm{NO}-\mathrm{IH}(30.8 \% \pm 9.6)$ (Table 1).

Table 1. Demographics in patients with and without IH

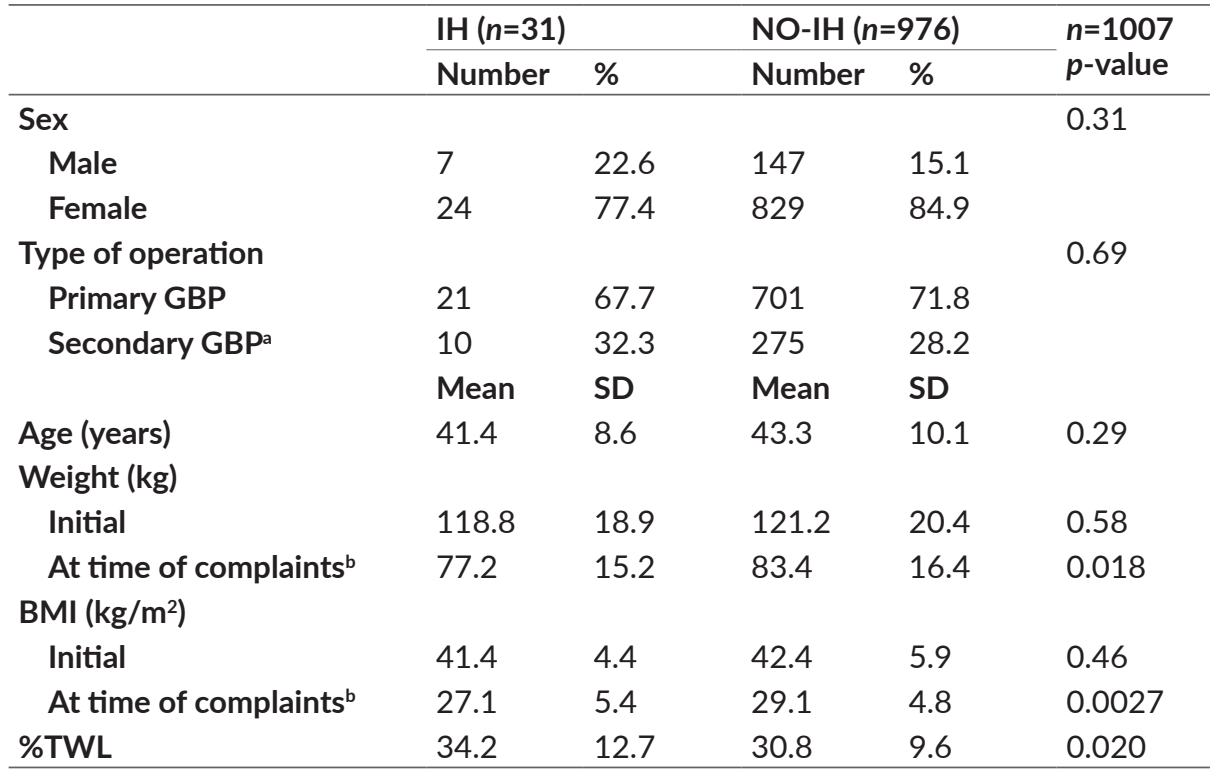

$\mathrm{IH}=$ internal herniation; $\mathrm{GBP}=$ gastric bypass; $\mathrm{kg}$ = kilogram; $\mathrm{BMI}=$ body mass index; $\mathrm{m}^{2}=$ square meter; \%TWL = percentage total weight loss; $\mathrm{SD}=$ standard deviation; ${ }^{\text {aSecondary }}$ GBP is a GBP after sleeve gastrectomy $(n=99)$, after adjustable gastric banding $(n=133)$, or after vertical banded gastroplasty $(n=53)$; 'Weight/BMI at time of complaints is weight/ $\mathrm{BMI}$ at the moment of diagnosis of $\mathrm{IH}$ or in case $\mathrm{NO}-\mathrm{IH}$ was diagnosed, the lowest weight/BMI was used 350-450 days after operation 
In patients presenting with complaints, the \%TWL was higher $(p=0.012)$ in patients with a confirmed $\mathrm{IH}(34.2 \% \pm 12.7)$ than in patients with $\mathrm{NO}-\mathrm{IH}$ (27.0\% \pm 14.8 ) (Table 2). In Table 3, our analysis shows that when \%TWL is equal or above $30 \%$, IH is significantly more diagnosed in patients presenting with symptoms $(p=0.0080)$.

Table 2. Subanalysis: demographics in patients presenting with complaints with and without IH

\begin{tabular}{|c|c|c|c|c|c|}
\hline & \multicolumn{2}{|c|}{$\mathrm{IH}(n=31)$} & \multicolumn{2}{|c|}{ NO-IH (n=105) } & \multirow{2}{*}{$\begin{array}{l}n=136 \\
p \text {-value }\end{array}$} \\
\hline & Number & $\%$ & Number & $\%$ & \\
\hline Sex & & & & & 0.26 \\
\hline Male & 7 & 22.6 & 14 & 13.3 & \\
\hline \multirow[t]{2}{*}{ Female } & 24 & 77.4 & 91 & 86.7 & \\
\hline & Mean & SD & Mean & SD & \\
\hline Age (years) & 41.4 & 8.6 & 41.2 & 11.0 & 0.98 \\
\hline $\begin{array}{l}\text { Time until complaints } \\
(\text { months) }\end{array}$ & 18.0 & 9.7 & 14.8 & 11.5 & 0.087 \\
\hline \multicolumn{6}{|l|}{ Weight (kg) } \\
\hline Initial & 118.8 & 18.9 & 116.2 & 21.0 & 0.59 \\
\hline At time of complaints & 77.2 & 15.2 & 83.5 & 17.3 & 0.060 \\
\hline \multicolumn{6}{|l|}{$\mathrm{BMI}\left(\mathrm{kg} / \mathrm{m}^{2}\right)$} \\
\hline Initial & 41.4 & 4.4 & 41.3 & 6.5 & 0.94 \\
\hline At time of complaints & 27.1 & 5.4 & 29.7 & 5.5 & 0.010 \\
\hline \%TWL & 34.2 & 12.7 & 27.0 & 14.8 & 0.012 \\
\hline
\end{tabular}

$\mathrm{IH}$ = internal herniation; $\mathrm{kg}$ = kilogram; $\mathrm{BMI}$ = body mass index; $\mathrm{m}^{2}$ = square meter; \%TWL = percentage total weight loss; SD = standard deviation; ${ }^{\text {TTime }}$ until complaints after the initial gastric bypass

Table 3. \%TWL and diagnosis of $\mathrm{IH}$ in patient presenting with complaints

\begin{tabular}{llll}
\hline \%TWL & Number of patients $(\mathbf{n}=\mathbf{1 3 6})$ & Number of $\mathrm{IH}(\mathbf{n}=\mathbf{3 1})$ & $\begin{array}{l}\mathbf{n}=\mathbf{1 3 6} \\
\boldsymbol{p} \text {-value }\end{array}$ \\
\hline$<\mathbf{1 0}$ & 19 & 2 & 0.24 \\
$\geq 10$ & 117 & 29 & \\
$<\mathbf{2 0}$ & 33 & 5 & 0.34 \\
$\geq \mathbf{2 0}$ & 103 & 26 & \\
$<\mathbf{3 0}$ & 64 & 8 & 0.0080 \\
$\geq \mathbf{3 0}$ & 72 & 23 & \\
$<40$ & 101 & 18 & 0.033 \\
$\geq \mathbf{4 0}$ & 35 & 13 & \\
\hline
\end{tabular}

$\% \mathrm{TWL}=$ percentage total weight loss; $\mathrm{IH}=$ internal herniation 
Patients with an IH experienced more $(p=0.037)$ abdominal cramping or colic pain $(n=11,47.8 \%)$ in comparison with patients with complaints but with $\mathrm{NO}-\mathrm{IH}$ ( $n=32,23.9 \%)$. No differences were seen in presence of abdominal pain, nausea or vomiting, abnormal defecation, or anorexia (Table 4).

Table 4. Type of complaint

\begin{tabular}{|c|c|c|c|c|c|}
\hline \multirow[t]{3}{*}{ Symptom } & \multirow{2}{*}{\multicolumn{2}{|c|}{$\begin{array}{l}\mathrm{IH}(n=31) \\
\text { Present }\end{array}$}} & \multirow{2}{*}{\multicolumn{2}{|c|}{$\begin{array}{l}\text { NO-IH }(n=105) \\
\text { Present }\end{array}$}} & \multirow{3}{*}{$\begin{array}{l}n=136 \\
p \text {-value }\end{array}$} \\
\hline & & & Present & & \\
\hline & Number & $\%$ & Number & $\%$ & \\
\hline Abdominal pain $(n=134)$ & 31 & 100 & 103 & 98.1 & 1.0 \\
\hline Abdominal cramping/colic ( $n=32)$ & 11 & 47.8 & 21 & 23.9 & 0.037 \\
\hline Nausea/vomiting $(n=67)$ & 12 & 46.2 & 55 & 66.3 & 0.11 \\
\hline Abnormal defecation $(n=34)$ & 10 & 43.5 & 24 & 28.6 & 0.21 \\
\hline Anorexia $(n=25)$ & 6 & 27.3 & 19 & 26.0 & 1.0 \\
\hline
\end{tabular}

$\mathrm{IH}=$ internal herniation

\section{Adjusted odds ratios}

A multivariate logistic model for $\mathrm{IH}$ identified an association with \%TWL, and abdominal cramping or colic pain. For $\geq 30 \%$ TWL, an adjusted odds ratio of 3.1 was found (95\% confidence interval (CI) 1.1-8.8), standard error (SE) 1.7, $p=0.036$ ), and for abdominal cramping or colic pain an adjusted odds ratio of 3.2 was found (95\% Cl 1.2-8.5, SE 1.6, $p=0.0021$ ) (Table 5).

Table 5. Multivariate analysis for diagnosing $\mathrm{IH}$ in patient presenting with complaints

\begin{tabular}{llllll}
\hline Explanatory variable & $\begin{array}{l}\text { Adjusted odds } \\
\text { ratio }\end{array}$ & $95 \% \mathrm{Cl}$ & $\mathrm{SE}$ & Pseudo $\mathrm{R}^{2}$ & $\begin{array}{l}n=111^{\text {a }} \\
\boldsymbol{p} \text {-value }\end{array}$ \\
\hline$\geq 30 \% \mathrm{TWL}$ & 3.1 & $1.1-8.8$ & 1.7 & 0.085 & 0.036 \\
Abdominal cramping & 3.2 & $1.2-8.5$ & 1.6 & & 0.021 \\
\hline
\end{tabular}

$\mathrm{IH}=$ internal herniation; $\mathrm{Cl}=$ confidence interval; $\mathrm{SE}=$ standard error; \% $\mathrm{TWL}=$ percentage total weight loss; ${ }^{\text {aPatients }}$ without information regarding abdominal cramping were excluded in this analysis

\section{Discussion}

A significant reduction was found in \%TWL at time of complaints in patients with an $\mathrm{IH}$ in comparison with \%TWL at the same median time after operation (350-450 days). Also in patients presenting with the suspicion of $\mathrm{IH}, \% \mathrm{TWL}$ was higher in patients with an actual $\mathrm{IH}$. Patients presenting with suspicion of $\mathrm{IH}$ have a threefold higher risk on presence of $\mathrm{IH}$ when $\% \mathrm{TWL} \geq 30 \%$. Cramping abdominal pain also leads to a threefold higher risk of $\mathrm{IH}$. 
Our results are in line with existing literature. An incidence of $3.1 \%$ of $\mathrm{IH}$ in patients after GBP was found in this study, when defining $\mathrm{IH}$ as being present during re-laparoscopy. Meta-analysis found an incidence of $\mathrm{IH}$ after laparoscopic antecolic GBP of 2.0 to 3.0\%, with no closure of any defects vs. closure of only the jejuno-jejunostomy defect ${ }^{22}$. Weight reduction was difficult to compare with literature due to different reporting standards. Geubbels et $\mathrm{al}^{20}$ found a \%TWL of $35 \%$ vs. $28 \%$ in patients with IH vs. NO-IH. This is comparable with $34.2 \%$ vs. $30.8 \%$ in patients with $\mathrm{IH}$ vs. $\mathrm{NO}-\mathrm{IH}$ in this study, and in patients with symptoms, \%TWL $34.2 \%$ vs. $27.0 \%$. No earlier literature has been published about a cut-off value of $\%$ TWL that can be used in order to evaluate the risk on the presence of $\mathrm{IH}$. This study showed that $\geq 30 \% \mathrm{TWL}$ gives a threefold higher risk on $\mathrm{IH}$.

In terms of symptoms, abdominal cramping was the only clinical symptom significantly associated with the presence of $\mathrm{IH}$. In $47.8 \%$ of all patients with an $\mathrm{IH}$, abdominal cramping was present. Literature supports this finding; an incidence of $65-80.4 \%$ was found in literature in patients with $\mathrm{IH}^{20}, 39$. Interestingly, also $23.9 \%$ of the NO-IH group experienced abdominal cramping. This might represent a part of the group of patients after a GBP with unexplained abdominal pain without an $\mathrm{IH}^{43,44}$. Nausea was presented in $46.2 \%$ of patients with $\mathrm{IH}$, but not significantly different from patients presenting with symptoms with NO-IH. In literature, the incidence of nausea was $27.5-57.2 \%{ }^{20,39}$.

In literature, researchers identified also other risk factors associated with $\mathrm{IH}$, such as age (HR 0.97, 95\% Cl 0.96-0.99, $p=0.002)^{21}$, absence of hypertension (HR 0.70, 95\% Cl 0.55-0.91, $p=0.006)$, previous anti-reflux surgery (HR 4.16, $95 \% \mathrm{Cl} 1.32-13.10, p=0.015)$, and rapid excess weight loss $(\mathrm{OR}=1.83,95 \% \mathrm{Cl}$ $=1.07-3.02)^{19}, 21$. In univariate analysis, no association was found for age and $\mathrm{IH}$. No information was available regarding anti-reflux surgery or hypertension. This study did not look into rapid weight loss. Regarding technical risk factors associated with $\mathrm{IH}$, the following risk factors were identified in literature: nonclosure of the mesenteric defects (HR 3.39, 95\% $\mathrm{Cl} 2.22-5.17, p<0.0001)^{21}$, laparoscopic antecolic technique of $\mathrm{GBP}^{22}$, division of the jejunal mesentery ${ }^{26,28}$, placement of an anti-obstruction stitch ${ }^{36}$, left or right Roux limb configuration ${ }^{17}$, and anticlockwise rotation of the Roux limb ${ }^{45}$. All patients in this study received the same operation (see "Methods"). Convincing evidence regarding routinely closure of all defects was not available during the study period, unlike these days $^{21,46,47}$.

The current study was the first to investigate a cut-off value for \%TWL in the diagnostic process of $\mathrm{IH}$. However, there are certain limitations that should be taken into account when interpreting this study. First of all, the incidence of $\mathrm{IH}$ could be underestimated. The incidence of $\mathrm{IH}$ (3.1\%) addresses only patients that were symptomatic, and during reoperation, an actual herniation was present. This is a major shortcoming for any study attempting to determine risk factors for $\mathrm{IH}$. It is likely that due to the existence of asymptomatic (or intermittent) hernia, 
the incidence is higher than reported. In order to estimate the potential amount of patients with an intermittent $\mathrm{IH}$, an extra analysis of patients with a negative laparoscopy was performed. A maximum of four patients were discovered who might have suffered from an intermittent $\mathrm{IH}$. Another imperfection of this study is that in order to be able to include asymptomatic patients, weight was used at the median time between operation and start of complaints of the total cohort (350-450 days). We believe this was the best and only way to be able to include this group of patients. Another limitation is the retrospective study design and therefore subjected to all potential flaws associated with this form of analysis, such as loss to follow up due to lack of follow up weight. However, no differences were found in demographics, when conducting an extra analysis between the included and excluded group. Also due to the study design, the described symptoms were retrospectively extracted. Therefore, there is lack of proper documentation and uniformity of description of symptoms. In order to further research symptoms at the presentation of $\mathrm{IH}$, we suggest a prospective study with a questionnaire for patients that present with abdominal pain after GBP. Another limitation is due to the relative small number of $\mathrm{IH}$, no extra potential risk factors of $\mathrm{IH}$ could be added in the multivariate analysis in order to avoid the statistical phenomenon multiple testing. In addition, no information regarding co-morbidities or medical history such as anti-reflux surgery was available, which could have potentially influenced our results ${ }^{21}$.

In conclusion, our study showed a difference in \%TWL between patients with IH and NO-IH. A high \%TWL, especially equal to and over 30\% TWL, and cramping abdominal pain are two risk factors in developing $\mathrm{IH}$, and if present further investigation by a CT scan should be performed. In case of a negative CT scan but persistent clinical suspicion, a diagnostic laparoscopy should be considered. 


\section{References}

1. Spivak H, Abdelmelek MF, Beltran OR, Ng AW, Kitahama S. Long-term outcomes of laparoscopic adjustable gastric banding and laparoscopic Roux-en-Y gastric bypass in the United States. Surg.Endosc. 2012; 26: 1909-19.

2. Colquitt JL, Pickett K, Loveman E, Frampton GK. Surgery for weight loss in adults. Cochrane.Database.Syst.Rev. 2014; CD003641.

3. Courcoulas AP, Goodpaster BH, Eagleton JK et al. Surgical vs medical treatments for type 2 diabetes mellitus: a randomized clinical trial. JAMA Surg. 2014; 149: 707-15.

4. Sjostrom L. Bariatric surgery and reduction in morbidity and mortality: experiences from the SOS study. Int.J.Obes.(Lond) 2008; 32 Suppl 7: S93-S97.

5. lannelli A, Buratti MS, Novellas $S$ et al. Internal hernia as a complication of laparoscopic Roux-en-Y gastric bypass. Obes.Surg. 2007; 17: 1283-6.

6. Aghajani E, Jacobsen HJ, Nergaard BJ, Hedenbro JL, Leifson BG, Gislason H. Internal hernia after gastric bypass: a new and simplified technique for laparoscopic primary closure of the mesenteric defects. J.Gastrointest.Surg. 2012; 16: 641-5.

7. Quezada N, Leon F, Jones A et al. High frequency of internal hernias after Roux-en-Y gastric bypass. Obes.Surg. 2015; 25: 615-21.

8. Higa KD, Ho T, Boone KB. Internal hernias after laparoscopic Roux-en-Y gastric bypass: incidence, treatment and prevention. Obes.Surg. 2003; 13: 350-4.

9. Garrard CL, Clements RH, Nanney L, Davidson JM, Richards WO. Adhesion formation is reduced after laparoscopic surgery. Surg.Endosc. 1999; 13: 10-3.

10. Blachar A, Federle MP. Gastrointestinal complications of laparoscopic roux-en-Y gastric bypass surgery in patients who are morbidly obese: findings on radiography and CT. AJR Am.J.Roentgenol. 2002; 179: 1437-42.

11. Champion JK, Williams M. Small bowel obstruction and internal hernias after laparoscopic Roux-en-Y gastric bypass. Obes.Surg. 2003; 13: 596-600.

12. Ahmed AR, Rickards G, Husain S, Johnson J, Boss T, O'Malley W. Trends in internal hernia incidence after laparoscopic Roux-en-Y gastric bypass. Obes.Surg. 2007; 17: 1563-6.

13. Scheirey CD, Scholz FJ, Shah PC, Brams DM, Wong BB, Pedrosa M. Radiology of the laparoscopic Roux-en-Y gastric bypass procedure: conceptualization and precise interpretation of results. Radiographics 2006; 26: 1355-71.

14. Hamdan K, Somers S, Chand M. Management of late postoperative complications of bariatric surgery. Br.J.Surg. 2011; 98: 1345-55.

15. de IC-M, Cabrera JC, Cuesta M, Hartnett S, Rojas R. Closure of mesenteric defect can lead to decrease in internal hernias after Roux-en-Y gastric bypass. Surg.Obes. Relat Dis. 2011; 7: 176-80.

16. Rogula T, Yenumula PR, Schauer PR. A complication of Roux-en-Y gastric bypass: intestinal obstruction. Surg.Endosc. 2007; 21: 1914-8.

17. Quebbemann BB, Dallal RM. The orientation of the antecolic Roux limb markedly affects the incidence of internal hernias after laparoscopic gastric bypass. Obes. Surg. 2005; 15: 766-70.

18. Merkle EM, Hallowell PT, Crouse C, Nakamoto DA, Stellato TA. Roux-en-Y gastric bypass for clinically severe obesity: normal appearance and spectrum of 
complications at imaging. Radiology 2005; 234: 674-83.

19. Schneider C, Cobb W, Scott J, Carbonell A, Myers K, Bour E. Rapid excess weight loss following laparoscopic gastric bypass leads to increased risk of internal hernia. Surg.Endosc. 2011; 25: 1594-8.

20. Geubbels N, Roell EA, Acherman YI, Bruin SC, van de Laar AW, de Brauw LM. Internal Herniation After Laparoscopic Roux-en-Y Gastric Bypass Surgery: Pitfalls in Diagnosing and the Introduction of the AMSTERDAM Classification. Obes.Surg. 2016; 26: 1859-66.

21. Stenberg E, Szabo E, Agren G et al. Closure of mesenteric defects in laparoscopic gastric bypass: a multicentre, randomised, parallel, open-label trial. Lancet 2016; 387: 1397-404.

22. Geubbels N, Lijftogt N, Fiocco M, van Leersum NJ, Wouters MW, de Brauw LM. Meta-analysis of internal herniation after gastric bypass surgery. Br.J.Surg. 2015; 102: 451-60.

23. Lockhart ME, Tessler FN, Canon CL et al. Internal hernia after gastric bypass: sensitivity and specificity of seven CT signs with surgical correlation and controls. AJR Am.J.Roentgenol. 2007; 188: 745-50.

24. Dilauro M, Mclnnes MD, Schieda $\mathrm{N}$ et al. Internal Hernia after Laparoscopic Rouxen-Y Gastric Bypass: Optimal CT Signs for Diagnosis and Clinical Decision Making. Radiology 2017; 282: 752-60.

25. Goudsmedt F, Deylgat B, Coenegrachts K, Van De MK, Dillemans B. Internal hernia after laparoscopic Roux-en-Y gastric bypass: a correlation between radiological and operative findings. Obes.Surg. 2015; 25: 622-7.

26. Madan AK, Lo ME, Dhawan N, Tichansky DS. Internal Hernias and Nonclosure of Mesenteric Defects During Laparoscopic Roux-en-Y Gastric Bypass. Obes.Surg. 2009; 19: 549-52.

27. Cho M, Carrodeguas L, Pinto D et al. Diagnosis and management of partial small bowel obstruction after laparoscopic antecolic antegastric Roux-en-Y gastric bypass for morbid obesity. J.Am.Coll.Surg. 2006; 202: 262-8.

28. Finnell CW, Madan AK, Tichansky DS, Ternovits C, Taddeucci R. Non-closure of defects during laparoscopic Roux-en-Y gastric bypass. Obes.Surg. 2007; 17: 145-8.

29. Han SH, Gracia C, Mehran A et al. Improved outcomes using a systematic and evidence-based approach to the laparoscopic Roux-en-Y gastric bypass in a single academic institution. Am.Surg. 2007; 73: 955-8.

30. Abasbassi M, Pottel H, Deylgat B et al. Small bowel obstruction after antecolic antegastric laparoscopic Roux-en-Y gastric bypass without division of small bowel mesentery: a single-centre, 7-year review. Obes.Surg. 2011; 21: 1822-7.

31. Nelson LG, Gonzalez R, Haines K, Gallagher SF, Murr MM. Spectrum and treatment of small bowel obstruction after Roux-en-Y gastric bypass. Surg.Obes.Relat Dis. 2006; 2: 377-83, discussion.

32. Escalona A, Devaud N, Perez G et al. Antecolic versus retrocolic alimentary limb in laparoscopic Roux-en-Y gastric bypass: a comparative study. Surg.Obes.Relat Dis. 2007; 3: 423-7.

33. Steele KE, Prokopowicz GP, Magnuson T, Lidor A, Schweitzer M. Laparoscopic antecolic Roux-en-Y gastric bypass with closure of internal defects leads to fewer 
internal hernias than the retrocolic approach. Surg.Endosc. 2008; 22: 2056-61.

34. Rodriguez A, Mosti M, Sierra M et al. Small bowel obstruction after antecolic and antegastric laparoscopic Roux-en-Y gastric bypass: could the incidence be reduced? Obes.Surg. 2010; 20: 1380-4.

35. Himpens J, Verbrugghe A, Cadiere GB, Everaerts W, Greve JW. Long-term results of laparoscopic Roux-en-Y Gastric bypass: evaluation after 9 years. Obes.Surg. 2012; 22: 1586-93.

36. Brolin RE, Kella VN. Impact of complete mesenteric closure on small bowel obstruction and internal mesenteric hernia after laparoscopic Roux-en-Y gastric bypass. Surg.Obes.Relat Dis. 2013; 9: 850-4.

37. Gandhi AD, Patel RA, Brolin RE. Elective laparoscopy for herald symptoms of mesenteric/internal hernia after laparoscopic Roux-en-Y gastric bypass. Surg.Obes. Relat Dis. 2009; 5: 144-9.

38. Ortega J, Cassinello N, Sanchez-Antunez D, Sebastian C, Martinez-Soriano F. Anatomical basis for the low incidence of internal hernia after a laparoscopic Rouxen-Y gastric bypass without mesenteric closure. Obes.Surg. 2013; 23: 1273-80.

39. Kristensen SD, Jess P, Floyd AK, Eller A, Engberg A, Naver L. Internal herniation after laparoscopic antecolic Roux-en-Y gastric bypass: a nationwide Danish study based on the Danish National Patient Register. Surg.Obes.Relat Dis. 2016; 12: 297-303.

40. Bauman RW, Pirrello JR. Internal hernia at Petersen's space after laparoscopic Rouxen-Y gastric bypass: $6.2 \%$ incidence without closure--a single surgeon series of 1047 cases. Surg.Obes.Relat Dis. 2009; 5: 565-70.

41. Ederveen JC, van Berckel MMG, Jol S, Nienhuijs SW, Nederend J. Diagnosing internal herniation after laparoscopic Roux-en-Y gastric bypass: usefulness of systematically reviewing CT scans using ten signs. Eur.Radiol. 2018; 28: 3583-90.

42. Ederveen JC, van Berckel MMG, Nienhuijs SW, Weber RJP, Nederend J. Predictive value of abdominal CT in evaluating internal herniation after bariatric laparoscopic Roux-en-Y gastric bypass. Br.J.Surg. 2018; 105: 1623-9.

43. Pierik AS, Coblijn UK, de Raaff CAL, van Veen RN, van Tets WF, van Wagensveld BA. Unexplained abdominal pain in morbidly obese patients after bariatric surgery. Surg. Obes.Relat Dis. 2017; 13: 1743-51.

44. Blom-Hogestol IK, Stubhaug A, Kristinsson JA, Mala T. Diagnosis and treatment of chronic abdominal pain 5 years after Roux-en-Y gastric bypass. Surg.Obes. Relat Dis. 2018; 14: 1544-51.

45. Nandipati KC, Lin E, Husain F, Srinivasan J, Sweeney JF, Davis SS. Counterclockwise rotation of Roux-en-Y limb significantly reduces internal herniation in laparoscopic Roux-en-Y gastric bypass (LRYGB). J.Gastrointest.Surg. 2012; 16: 675-81.

46. Stenberg E, Ottosson J, Szabo E, Naslund I. Comparing Techniques for Mesenteric Defects Closure in Laparoscopic Gastric Bypass Surgery-a Register-Based Cohort Study. Obes.Surg. 2019; 29: 1229-35.

47. Aghajani E, Nergaard BJ, Leifson BG, Hedenbro J, Gislason H. The mesenteric defects in laparoscopic Roux-en-Y gastric bypass: 5 years follow-up of non-closure versus closure using the stapler technique. Surg.Endosc. 2017; 31: 3743-8. 

Chapter 7.

General discussion 
With the increase of gastric bypass operations there is also an increase in complications. One of the long term complications after a Roux-en-Y gastric bypass is internal herniation $(\mathrm{IH})$. The incidence of $\mathrm{IH}$ is documented to range between 1.1 and $16 \%^{1-4}$. Between 2013 and 2018 approximately 20.000 gastric bypass operations were performed in the Netherlands 5 . This counts up to around $80 \mathrm{IH}$ s every year. The main symptom for $\mathrm{IH}$ is abdominal pain, which is not very specific. Therefore, surgeons need other diagnostic tools before they perform laparoscopic surgery, which is considered the golden standard in diagnosing $\mathrm{IH}$. Imaging is increasingly used as a non-invasive tool to diagnose IH. CT is the most used imaging technique for the diagnosis of $\mathrm{IH}$, with the use of MRI in case of pregnancy to prevent radiation exposure ${ }^{6,7}$. Limitations of MRI include availability, study duration and costs. This results in less experience in postbariatric patients, resulting in lower accuracy. Ultrasound and fluoroscopy are considered of lesser value. Ultrasound due to the presence of bowel air and abdominal fat in obese patients, which hampers the usability. Fluoroscopy is also considered of lesser value since it can only visualize the bowel lumen and doesn't visualize the mesentery and surrounding abdominal structures ${ }^{6}$.

\section{Use and accuracy of CT scans}

Since CT scans are increasingly being used to assist in the diagnostic process, we wanted to investigate the use and accuracy of CT in diagnosing IH in patients after gastric bypass surgery, and if CT scans are truly beneficial before laparoscopy.

Two large multicentre studies from the Netherlands ${ }^{8}$ and Denmark ${ }^{2}$ found the use of CT scans preoperatively in $60-78.1 \%$ of patients. In the Danish study ${ }^{2}$ signs of $\mathrm{IH}$ were present on CT scan in $68.9 \%$ of the patients. Other smaller studies found sensitivities ranging between 32 and 76\%, and specificities between 29 and $60 \%{ }^{9-11}$. With the development and use of CT signs for the diagnosis of $\mathrm{IH}$ the accuracy increased ${ }^{11-13}$.

In Chapter 2 we found that the incidence of $\mathrm{IH}$ in our population of gastric bypass patients was $2.5 \%$, conform a previous meta-analysis ${ }^{1}$. However, $13 \%$ reported with symptoms suspected for $\mathrm{IH}$ to either the emergency room or the out-patient clinic. Some patients even had multiple episodes of complaints. A total of 265 episodes were investigated. In 93.2\% of these episodes a CT scan was performed. We not only included patients with surgical confirmation but added a follow-up period of 90 days after the CT scan as an additional end-point. If there were no subsequent CT scans or reoperations an IH was considered unlikely. Therefore, we had a larger group in which accuracy was calculated. We documented better sensitivity and specificity of 83.8 and $87.1 \%$, respectively, compared to previous research ${ }^{9-11}$. Especially the high specificity may contribute to a decline in unnecessary reoperations. We did not investigate all patients with 
abdominal complaints, only those in need of a CT scan or reoperation, which leads to a certain selection bias in our cohort. The risk of $\mathrm{IH}$ was considered very low if complaints were not severe enough to herald CT and/or reoperation. However, patients with minimal complaints and intermittent $\mathrm{IH}$ are possibly overlooked in the current study ${ }^{14}$.

ACT scan should be included in the diagnostic work-up of patients with abdominal complaints after gastric bypass surgery. With this a minimization of unnecessary diagnostic laparoscopies could be established. This is not only beneficial for the patient because of the greater risks involved with a laparoscopy, but also reduces healthcare costs, since a laparoscopy with its subsequent ward day is four times more expensive than a CT scan ${ }^{15}$. Because of the possible intermittent nature of $\mathrm{IH}$, negative CT scans can be repeated at time of complaints to increase the likelihood of $\mathrm{IH}$ at time of CT scan. However, since the sensitivity of CT scans is still not a hundred percent, patients with persistent complaints might still benefit from a diagnostic laparoscopy. To increase this sensitivity we further investigated systematic viewing and structured reporting in additional studies.

\section{Systematic viewing and structured reporting}

Considering the accuracy of CT scans was not a hundred percent, we searched for methods to further improve this accuracy. In literature different CT signs were described for diagnosing $\mathrm{IH}$. To evaluate these signs as means to increase accuracy we performed systematic viewing and implemented structured reporting.

Systematic viewing with the use of ten specific CT signs increases specificity, as documented in Chapter 3. The most sensitive signs were swirl sign (71.477.1\%), venous congestion (54.3-74.3\%), and mesenteric oedema (62.9-71.4\%). This was comparable to previous studies although they had a broad range in sensitivities of $53-100 \%, 39-73 \%$, and $67-88 \%$, respectively ${ }^{11-13,16-19}$. In patients who underwent a reoperation we found that the combination of all ten signs resulted in a better specificity with an increase from $52.8 \%$ to $77.8-86.1 \%$. In this subgroup clinical suspicion was high and in case of radiological uncertainty radiologists tended to confirm $\mathrm{IH}$. Due to the systematic viewing radiological uncertainty decreased. This might prevent unnecessary reoperations.

Furthermore, the difference in experience levels was investigated. The interobserver agreement was overall slight to substantial, with no significant difference in overall impression between the experience levels. Also in studies with two experienced readers interobserver agreement had a broad range ${ }^{12,16,17}$. The systematic viewing using ten CT signs results in a good diagnostic accuracy even in less experienced readers. 
In Chapter 4 the ten CT signs were implemented in clinical practice by means of a structured reporting template in a prospective study. Our previous study and recent literature already showed an increase in accuracy when retrospective blind reading of CT scans was compared to the original report ${ }^{11}$. To our knowledge we were the first to investigate the usefulness of these CT signs in a prospective study with the use of structured reporting.

The accuracy increased from $87.2 \%$ in the free-text report to $93.1 \%$ in the structured report $(p=0.045)$. An overall impression of diagnostic confidence on a 5-point scale was given in the structured reporting template. In only eight of 174 CT-scans (4.6\%) a score of 3 was given, indicating radiological doubt. In the free-text report doubt was more often expressed by using words as probable, possible, potential and cannot be excluded. The structured reporting template can help less experienced (in-training) radiologist in making a more certain diagnosis. Second opinion by an experienced radiologist in case of doubt increases the accuracy even more.

We chose to validate our structured reporting template in the same centre and therefore there is a risk that the increase in accuracy is not solely based on the use of the template but also on the increased knowledge of $\mathrm{IH}$ and its signs in the reporting radiologists. This bias is reduced because also new (in-training) radiologists started working in our centre during the implementation period. However, bias due to improvement in technical skills of the radiologists cannot be completely excluded.

In our current studies ten signs were used for the systematic reviewing and subsequent structured reporting template. These were selected from previous studies investigating seven to nine different CT signs ${ }^{12,18-21}$. We composed a list of the ten most feasible signs from these previous studies, in our opinion. However, different (combination of) signs might be more accurate. Therefore, further research into these signs, possible combinations of signs, and other and/or more signs is necessary. Furthermore, the presence of signs is objective, some cut-off points were given, but the conclusion remains in the hands of the performing radiologist.

Radiologists need to be aware of the signs that are helpful in diagnosing an $\mathrm{IH}$ and our study supports the view that structured reporting helps to increase this awareness. Structured reporting is already found to be beneficial in other diseases ${ }^{22-24}$. The current study shows that this also holds true for the diagnosis of $\mathrm{IH}$, and structured reporting should become more common practice. 


\section{Misdiagnoses}

Although accuracy increased with systematic viewing and structured reporting, still misdiagnoses were present. To evaluate these missed and wrongful diagnoses we further investigated these CT scans and corresponding patient data.

Misdiagnoses were found in $9.3 \%$ of the investigated CT scans. However, after revision by two experienced readers this decreased to only $3.6 \%$. Which again supports our previous statement that second reading by an experienced reader is of added value. Intermittent internal herniation remains a difficulty in the diagnostic process and was considered to have contributed to a substantial part of the wrongful diagnoses. CT scans at time of complaints is not always logistically possible and resolving complaints before surgery might postpone surgical intervention without finding an $\mathrm{IH}$. Furthermore, adhesions were found as other diagnosis wrongfully considered to be an $\mathrm{IH}$, however correctly considered to be a possible operation indication. In $0.8 \%$ of the CT scans there was no explanation for the discrepancy between radiological and surgical diagnosis.

In this study not only extra clinical information was used to study the misdiagnoses, but also a revision by two experienced readers. Nevertheless, these experienced readers are not the gold standard and intermittent $\mathrm{IH}$ cannot be proven with certainty.

On basis of this study, second opinion by an experienced abdominal radiologist is encouraged in case of radiological doubt or disagreement between radiologists and surgeons. Intermittent $\mathrm{IH}$ should be considered, especially in case of persistent, variable complaints. Minimizing delay between complaints, CT scan, and operation can be beneficial. Finally, adhesions should be considered in case of dilated bowel loops.

\section{Other risk factors}

Laparoscopic performance of gastric bypass surgery is known to be a greater risk for $\mathrm{IH}$ compared to open surgery. But the advantages such as less perioperative complications and quicker recovery, outweigh the increased risk of $\mathrm{IH}^{25}$, 26. However, there might be other factors that can be kept in consideration when a patient presents with abdominal complaints. Weight loss is not only the desired outcome of a gastric bypass operation, but possibly also a factor in the emergence of $\mathrm{IH}^{2,27-29}$. In Chapter 6 we evaluated risk factors for $\mathrm{IH}$ and investigated if weight loss is clinically useable in recognizing patients with $\mathrm{IH}$.

A percentage total weight loss (\%TWL) of $30 \%$ or more was found to result in a threefold higher risk of $\mathrm{IH}$. Comparison with previous literature was difficult due 
to the variety in weight loss documentation. Geubbels et al. ${ }^{8}$ documented $\%$ TWL between patients with and without IH (35\% vs. $28 \%$ ), which was comparable to our study (34.2\% vs. 27.0-30.8\%).

Additionally, cramping abdominal pain was found to have a threefold higher risk of $\mathrm{IH}$. Abdominal cramping was present in $47.8 \%$ of all patients with $\mathrm{IH}$. This is comparable to findings in literature of $65-80.4 \% 2,8$.

A limitation of this study was that due to the relative small number of $\mathrm{IH}$, no extra potential risk factors of $\mathrm{IH}$, such as age and previous anti-reflux surgery, could be added in the multivariate analysis in order to avoid the statistical phenomenon multiple testing. In addition, no information regarding co-morbidities or medical history such as anti-reflux surgery was available, which could have potentially influenced the results.

In patients presenting with abdominal complaints suspect for IH both \%TWL of $30 \%$ or more and cramping abdominal pain should raise the suspicion of $\mathrm{IH}$ and additional CT scanning should be considered. A negative CT scan in patients with these risk factors should be carefully interpreted, and possible second opinion by an experienced radiologist or diagnostic laparoscopy should be considered. Other risk factors for developing an $\mathrm{IH}$ should be investigated to optimize the diagnostic process.

\section{Conclusions}

Internal herniation $(\mathrm{IH})$ can be an elusive diagnosis in a patient population with a diverse range of postoperative complaints. This thesis focused on improving the diagnostic process of patients with abdominal complaints after laparoscopic gastric bypass surgery, by defining risk factors and improving radiological accuracy.

Overall diagnostic accuracy of CT scans was found to be good. CT scans can reliably exclude $\mathrm{IH}$ and thereby prevent unnecessary surgery. Uncertainty in the radiology report is therefore not wanted. Structured reporting improved accuracy and can be used with good results even by inexperienced readers. Also in clinical practice the implementation of a structured reporting template improved accuracy and diagnostic confidence. In case of uncertainty an experienced abdominal radiologist can prevent wrongful diagnoses.

This thesis found two clinical risk factors for $\mathrm{IH}$, namely cramping abdominal pain and a \%TWL of $30 \%$ or more. Both were found to cause a threefold higher risk of $\mathrm{IH}$. In the general post-gastric bypass patient with abdominal complaints the presence of these risk factors should herald a CT scan and potentially a reoperation. 


\section{Future recommendations}

The diagnosis of $\mathrm{IH}$ in patients after gastric bypass surgery is a joint effort of both surgeons and radiologist. Clinical symptoms and radiological signs are good indicators for $\mathrm{IH}$. Radiologists need to be aware of the different CT signs and should be taught more of this subject during their residency. Furthermore, in bariatric centres a dedicated abdominal/bariatric radiologist is recommended. We encourage the use of specific standardized reporting templates for all CT diagnoses, but we want to emphasize here that structured reporting for the diagnosis of $\mathrm{IH}$ should be implemented in all bariatric centres. Good communication between surgeons and radiologists can further optimize the diagnosis of $\mathrm{IH}$ by exchanging feedback of the found diagnosis. The radiological exclusion of $\mathrm{IH}$ should not be disregarded and only in patients with persistent symptoms after negative CT scan(s) a diagnostic laparoscopy should be considered. 


\section{References}

1. Geubbels N, Lijftogt N, Fiocco M, Leersum N, Wouters M, Brauw Ld. Meta-analysis of internal herniation after gastric bypass surgery. Br J Surg 102[5], 451-460. 2015. doi: $10.1002 /$ bjs. 9738 .

2. Kristensen S, Jess P, Floyd A, Eller A, Engberg A, Naver L. Internal herniation after laparoscopic antecolic Roux-en-Y gastric bypass: a nationwide Danish study based on the Danish National Patient Register. Surg Obes Relat Dis 12[2], 297-303. 2016. doi: 10.1016/j.soard.2015.10.059.

3. Rausa E, Bonavina L, Asti E, Maddalena G, Ricci C. Rate of Death and Complications in Laparoscopic and Open Roux-en-Y Gastric Bypass. A Meta-analysis and Metaregression Analysis on 69,494 Patients. Obes Surg 26[8], 1956-1963. 2016. doi: 10.1007/s11695-016-2231-z.

4. Magouliotis D, Tzovaras G, Tasiopoulou V, Christodoulidis G, Zacharoulis D. Closure of Mesenteric Defects in Laparoscopic Gastric Bypass: a Meta-Analysis. Obes Surg . 18-1-2020. doi: 10.1007/s11695-020-04418-2.

5. Welbourn R, Hollyman M, Kingsman R et al. Bariatric Surgery Worldwide: Baseline Demographic Description and One-Year Outcomes from the Fourth IFSO Global Registry Report 2018. Obes Surg 29[3], 782-795. 2019. doi: 10.1007/s11695-0183593-1.

6. Krishna S, Kielar A. Controversies and Pitfalls of Imaging Patients Postoperative Bariatric Surgery. Curr Radiol Rep 4[25], 1-11. 2016. doi: 10.1007/s40134-0160152-1.

7. Krishna S, McInnes M, Schieda N, Narayanasamy S, Sheikh A, Kielar A. Diagnostic Accuracy of MRI for Diagnosis of Internal Hernia in Pregnant Women With Prior Roux-en-Y Gastric Bypass. AJR Am J Roentgenol 211[4], 755-759. 2018. doi: 10.2214/AJR.17.19252.

8. Geubbels N, Röell E, Acherman Y, Bruin S, Laar Avd, Brauw Ld. Internal Herniation After Laparoscopic Roux-en-Y Gastric Bypass Surgery: Pitfalls in Diagnosing and the Introduction of the AMSTERDAM Classification. Obes Surg 26[8], 1859-1866. 268-2016. doi: 10.1007/s11695-015-2028-5.

9. Agaba E, Gentles C, Shamseddeen $\mathrm{H}$ et al. Retrospective analysis of abdominal pain in postoperative laparoscopic Roux-en-Y gastric bypass patients: is a simple algorithm the answer? Surg Obes Relat Dis 4[5], 587-593. 2008. doi: 10.1016/j. soard.2007.10.015.

10. Altieri M, Pryor A, Telem D, Hall K, Brathwaite C, Zawin M. Algorithmic approach to utilization of CT scans for detection of internal hernia in the gastric bypass patient. Surg Obes Relat Dis 11[6], 1207-1211. 2015. doi: 10.1016/j.soard.2015.02.010.

11. Karila-Cohen P, Cuccioli F, Tammaro P et al. Contribution of Computed Tomographic Imaging to the Management of Acute Abdominal Pain after Gastric Bypass: Correlation Between Radiological and Surgical Findings. Obes Surg 27[8], 19611972. 2017. doi: 10.1007/s11695-017-2601-1.

12. Dilauro M, Mclnnes $M$, Schieda $N$ et al. Internal Hernia after Laparoscopic Rouxen-Y Gastric Bypass: Optimal CT Signs for Diagnosis and Clinical Decision Making. Radiology 282[3], 752-760. 2017. doi: 10.1148/radiol.2016160956. 
13. Lockhart $\mathrm{M}$, Tessler $\mathrm{F}$, Canon $\mathrm{C}$ et al. Internal hernia after gastric bypass: sensitivity and specificity of seven CT signs with surgical correlation and controls. Am J Roentgenol 188[3], 745-750. 2007.

14. Tartamella F, Ziccarelli A, Cecchini S et al. Abdominal pain and internal hernias after Roux-en-Y Gastric Bypass: are we dealing with the tip of an iceberg? Acta Biomed 90[2], 251-258. 23-5-2019. doi: 10.23750/abm.v90i2.7145.

15. Bransen J, Gilissen L, van Rutte P, Nienhuijs S. Costs of Leaks and Bleeding After Sleeve Gastrectomies. Obes Surg 25[10], 1767-1771. 2015. doi: 10.1007/s11695015-1584-z.

16. Goudsmedt F, Deylgat B, Coenegrachts K, Moortele Kvd, Dillemans B. Internal hernia after laparoscopic Roux-en-Y gastric bypass: a correlation between radiological and operative findings. Obes Surg 25[4], 622-627. 2015. doi: 10.1007/s11695-0141433-5, doi: 10.1007/s11695-014-1433-5.

17. Iannuccilli J, Grand D, Murphy B, Evangelista P, Roye G, Mayo-Smith W. Sensitivity and specificity of eight CT signs in the preoperative diagnosis of internal mesenteric hernia following Roux-en-Y gastric bypass surgery. Clin Radiol 64[4], 373-380. 2009. doi: 10.1016/j.crad.2008.10.008.

18. Maier J, Herrasti Gallego A, Floyd A. Compression of the superior mesenteric vein - a sign of acute internal herniation in patients with antecolic laparoscopic Rouxen-Y gastric bypass. Eur Radiol 27[4], 1733-1739. 2017. doi: 10.1007/s00330-0164526-9.

19. Park J, Chung M, Teixeira J, Baer J, Frager D. Computed tomography findings of internal hernia after gastric bypass that may precede small bowel obstruction. Hernia 20[3], 471-477. 2016. doi: 10.1007/s10029-015-1424-z.

20. Iannuccilli J, Grand D, Murphy B, Evangelista P, Roye G, Mayo-Smith W. Sensitivity and specificity of eight CT signs in the preoperative diagnosis of internal mesenteric hernia following Roux-en-Y gastric bypass surgery. Clin Radiol 64[4], 373-380. 2009. doi: 10.1016/j.crad.2008.10.008.

21. Lockhart M, Tessler F, Canon $\mathrm{C}$ et al. Internal hernia after gastric bypass: sensitivity and specificity of seven CT signs with surgical correlation and controls. Am J Roentgenol 188[3], 745-750. 2007.

22. Brook O, Brook A, Vollmer C, Kent T, Sanchez N, Pedrosa I. Structured Reporting of Multiphasic CT for Pancreatic Cancer: Potential Effect on Staging and Surgical Planning. Radiology 274[2], 464-472. 2015. doi: 10.1148/radiol.14140206.

23. Johnson T, Brinjikji W, Doolittle D, Nagelschneider A, Welch B, Kotsenas A. Structured Head and Neck CT Angiography Reporting Reduces Resident Revision Rates. Curr Probl Diagn Radiol 48[2], 114-116. 2019. doi: 10.1067/j.cpradiol.2018.04.003.

24. Poullos P, Tseng J, Melcher M et al. Structured Reporting of Multiphasic CT for Hepatocellular Carcinoma: Effect on Staging and Suitability for Transplant. Am J Roentgenol 210, 766-774. 2018. doi: 10.2214/AJR.17.18725.

25. Cho M, Pinto D, Carrodeguas $L$ et al. Frequency and management of internal hernias after laparoscopic antecolic antegastric Roux-en-Y gastric bypass without division of the small bowel mesentery or closure of mesenteric defects: review of 1400 consecutive cases. Surg Obes Relat Dis 2[2], 87-91. 2006.

26. Parakh S, Soto E, Merola S. Diagnosis and Management of Internal Hernias after 
Laparoscopic Gastric Bypass. Obes Surg 17[11], 1498-1502. 2007.

27. Aghajani E, Jacobsen H, Nergaard B, Hedenbro J, Leifson B, Gislason H. Internal hernia after gastric bypass: a new and simplified technique for laparoscopic primary closure of the mesenteric defects. J Gastrointest Surg 16[3], 641-645. 2012. doi: 10.1007/s11605-011-1790-5.

28. Higa K, Ho T, Boone K. Internal Hernias after Laparoscopic Roux-en-Y Gastric Bypass: Incidence, Treatment and Prevention. Obes Surg 13[3], 350-354. 2003.

29. Quezada N, León E, Jones A et al. High frequency of internal hernias after Roux-en-Y gastric bypass. Obes Surg 25[4], 615-621. 2015. doi: 10.1007/s11695-014-13022. 


\title{
Chapter 8.
}

\author{
Valorisation
}




\section{Relevance}

Obesity is a global health problem with increasing prevalence in the total world population ${ }^{1}$. To reduce the burden of obesity and related health problems bariatric surgery has become an accepted therapeutic measure. In the Netherlands laparoscopic Roux-en-Y gastric bypass is currently the most performed operation ${ }^{2}$. Presently there are more than 25,000 patients who have undergone a gastric bypass which increases with 5,000 patients every year. However, this procedure has it's downsides. This thesis focussed on one of these downsides, a complication named internal herniation (IH).

The incidence of $\mathrm{IH}$ in this thesis was found to be $2.5 \%$. With a total number of around 400 gastric bypass procedures every year in the current study centre only, this amounts to a substantial number of patients. With vague symptoms such as abdominal pain and reduced intake the diagnosis of $\mathrm{IH}$ is seldom clear at initial presentation. The number of patients with complaints indicating a possible $\mathrm{IH}$ are numerous with differential diagnoses of for example dumping, gallstones, and gastric ulcers. Therefore, the number of patients undergoing diagnostic measures such as CT-scans is substantially larger than the patients with $\mathrm{IH}$ alone. In our population $13.6 \%$ of patients underwent one or multiple CT scans after the gastric bypass procedure for an enquiry of $\mathrm{IH}$.

Radiological examination is used to help differentiate between the differential diagnoses. The gold standard for diagnosing $\mathrm{IH}$ is considered to be a diagnostic laparoscopy. Two major disadvantages of laparoscopy are the invasive nature of the procedure and the costs. The costs of a laparoscopy with an additional ward day are four times higher than that of an abdominal CT scan ${ }^{3}$. Abdominal CT scans can help prevent unnecessary laparoscopies and are increasingly being used.

\section{Main findings}

In Chapter 2 we found that the accuracy of CT for diagnosing $\mathrm{IH}$ is relatively good. Certainly in the acute setting CT scans can diagnose IH with good certainty. However, the accuracy could be improved.

All CT scans of Chapter 2 were reviewed using a structured report of ten CT signs and overall impression in Chapter 3 and an increase in specificity was found. Also, we found in Chapter 3 that difference is experience levels were minimized due to the structured report.

In Chapter 4 the structured report was tested in clinical practice and an improvement of accuracy was seen. There were now only few CT scans with radiological uncertainty in diagnosis. And in these cases expert second opinion helped make a good diagnosis. 
The accuracy in Chapter 4 was not a hundred percent and therefore the missed and wrongful diagnoses were investigated in Chapter 5. Adhesions and intermittent IH were found to cause a substantial number of the wrongful diagnoses. Furthermore, inexperience remained an obstacle.

Clinical suspicion remains an important reason to operate regardless of CT results. Therefore, in Chapter 6 we investigated clinical risk factors for $\mathrm{IH}$. Patients with complaints indicating an $\mathrm{IH}$ with a percentage total weight loss (\%TWL) of $30 \%$ or more or colic pain were found to have a threefold increased risk for $\mathrm{IH}$.

\section{Implications}

CT scans should be the first diagnostic tool used in patients suspected of $\mathrm{IH}$. It can discriminate other non-surgical diagnoses, reduce healthcare costs and is easily accessible. Accuracy is good, especially with the use of structured reporting. Also in-training radiologist or radiologist without an abdominal or bariatric specialization can diagnose or exclude $\mathrm{IH}$ with sufficient certainty when using structured reporting. Support from a specialized radiologist can further improve diagnosis and should be available in all bariatric clinics. In case of radiological doubt a second opinion of an experienced abdominal (bariatric) radiologist can be decisive. It is therefore important that radiology residents learn about bariatric patients and their complications. Not only knowledge about postoperative anatomy is necessary but also habituation with the different signs of IH on CT scans.

Structured reporting is more and more used in the different fields of radiology. With the increase in images per scan the risk of forgetting important information in the report increases. A checklist ascertains that all relevant findings are described. In this thesis structured reporting was also found to benefit the diagnosis of $\mathrm{IH}$. Consequently, we also advocate for the use of structured reporting in case of an enquiry of $\mathrm{IH}$. Structured reporting can be implemented in clinical practice rather easily, especially with the recent picture archiving and communication systems and speech recognition reporting systems. We used a prewritten report with input fields which could be filled in with speech recognition or manually. This reduces reporting time and improves readability of the reports for the surgeons.

Two alternative diagnoses found in the current cohort were adhesions and intermittent $\mathrm{IH}$. Since adhesions are also an operation indication in most cases, a misdiagnosis on CT scans is not definitely a problem, but still it is not desirable. Dilated bowel loops, with or without presence of other signs of $\mathrm{IH}$, should be carefully examined on CT and not be considered an IH instantly. 
Intermittent $\mathrm{IH}$ is a rather elusive diagnosis. Because of its intermittent nature it cannot always be diagnosed with certainty, and is more a diagnosis per exclusionem. Patients with typical complaints for $\mathrm{IH}$ with reduction of complaints after closure of herniation spaces during laparoscopy are considered to have intermittent $\mathrm{IH}$. This might result in false positive but also false negative outcomes of CT scans which can never be completely reduced. Limiting the time interval between start of complaints and CT scan and subsequent reoperation will improve the diagnostic accuracy, but is not always feasible.

Documentation of and research into the different risk factors of $\mathrm{IH}$ is broad. Some risk factors can easily be reduced, for example the closure of herniation spaces during the initial gastric bypass procedure. Other risk factors cannot be reduced straightforwardly or are even desirable, such as weight loss. In case of significant weight loss it is necessary to be aware of risk factors and symptoms linked with the presence of $\mathrm{IH}$ to improve the clinical decision making. A thorough documentation of initial weight and weight during complaints and the nature of the complaints can help estimate the risk of an $\mathrm{IH}$. In case of a negative CT scan the clinical risk estimation of an $\mathrm{IH}$ can further contribute in the diagnostic process and can even be a reason to choose for watchful waiting.

\section{Future perspectives}

Radiological diagnosis can be improved even more by sufficient feedback between surgeons and radiologists. Documentation of reasons to operate or wait-and-see after a CT scan can help radiologist in their future reporting. For radiologist it is important to actively verify their diagnosis in comparison with the operation report or clinical information. In future maybe even support from the electronic patient file in the form of a notification of operation or follow-up examinations can improve this feedback. This electronic support is helpful in general and can improve the learning curve, especially in inexperienced readers. In difficult cases or cases with discrepancy between the CT and clinical picture direct review in person with the surgeon can further optimise the accuracy. Clinical input in this way may change visions on some CT signs with subsequent alteration of the structured reporting template or conclusions linked to specific signs. Therefore, an active collaboration between surgeons and radiologist is desirable. Especially in cases with persistent complaints where there is a tendency to repeat CT scans, direct communication with the surgeon might improve the diagnostic process.

Furthermore, the surgeons have to rely on the radiological diagnose in order to prevent unnecessary surgeries. The standardised report can help in this process, because the surgeons can better understand the decision making process of the radiologist. Good feedback in cases of missed diagnosis or misinterpreted CT scans can further build the trust between surgeons and radiologists. 
Not only our reporting technique improved in recent years, also the operation technique and $\mathrm{CT}$ reconstruction abilities have undergone developments. The closure of possible herniation sites during the gastric bypass procedure is known to reduce the risk of $\mathrm{IH}$ and is now standard practice. Maybe in the following years extra sutures will further reconstruct the physiological situation in which the mesentery prevents the movability of the bowel structures. This leading to further diminishing the risk of $\mathrm{IH}$.

The development in $\mathrm{CT}$ reconstructions in abdominal imaging mainly focused on three dimensional reconstructions. The ability to visualise the position of the bowels in a 3D setting, might highlight wrongful position of bowel loops even more. This technique is currently only used in research setting in our hospital, but its value is promising. However, it will need considerable research and extensive training of radiologist before this technique can be implemented in clinical practice.

This thesis only focused on $\mathrm{IH}$ after Roux-en-Y gastric bypass in the bariatric population. In theory, all findings are applicable to a Roux-en-Y reconstruction in other situations, for example in case of gastric cancer. The CT signs will be relatively similar, and in our hospital the structured report is already used in other cases of Roux-en-Y reconstruction. However, the weight loss criterion is of lesser value in these patients. Further research into the signs in the broader Roux-en-Y reconstruction population might be helpful. 


\section{References}

1. Ng M, Fleming T, Robinson M, Thomson B, Graetz N. Global, regional, and national prevalence of overweight and obesity in children and adults during 1980-2013 a systematic analysis for the Global Burden of Disease Study 2013. Lancet 384[9], 766-781. 30-8-2014. doi: 10.1016/S0140-6736(14)60460-8.

2. Welbourn R, Hollyman M, Kingsman R et al. Bariatric Surgery Worldwide: Baseline Demographic Description and One-Year Outcomes from the Fourth IFSO Global Registry Report 2018. Obes Surg 29[3], 782-795. 2019. doi: 10.1007/s11695-0183593-1.

3. Bransen J, Gilissen L, van Rutte P, Nienhuijs S. Costs of Leaks and Bleeding After Sleeve Gastrectomies. Obes Surg 25[10], 1767-1771. 2015. doi: 10.1007/s11695015-1584-z. 
Chapter 9.

Summary 
The aim of this thesis was to find appropriate methods to diagnose internal herniation $(\mathrm{IH})$ after gastric bypass surgery. Due to the potentially life threatening risk of $\mathrm{IH}$ a clear diagnosis with subsequent therapeutic measures is necessary. CT scans can assist in this diagnosis and thereby prevent unnecessary reoperations.

Chapter 2 explores the use of CT scans in patients after gastric bypass surgery. We documented on every patient with abdominal complaints with suspicion of $\mathrm{IH}$ that underwent CT scan and/or re-operation. We found that CT scans can reliably diagnose $\mathrm{IH}$, but because of uncertainty in radiologist, but also in surgeons, still too many patients were operated unnecessary.

In Chapter 3 we search for a way to help diagnose IH on CT scans with more certainty. After literature search we found different CT signs that might indicate an $\mathrm{IH}$. We chose ten $\mathrm{CT}$ signs which were the most promising in our eyes. All CT scans we investigated in chapter 1 were reviewed again by an experienced abdominal radiologist, a radiology resident with affiliation with abdominal radiology, and a radiology intern with little to no experience. They blindly reviewed the CT scans with the systematical use of the ten CT signs. We found an increase in accuracy, also for the less-experienced readers.

To investigate if the ten CT signs also improve accuracy in the clinical setting we implemented a standardized reporting template with the ten signs and an overall impression in Chapter 4. All CT scans that were made with an enquiry of $\mathrm{IH}$ were reported using this standardized template. After comparing these structured reports with the free-text reports that were previously used, we found an increase in accuracy. Structured reporting using the ten CT signs improves accuracy and thereby prevents unnecessary operations. It was an easy tool to use and improved certainty of the diagnosis in the radiologists and residents.

Although accuracy increased with the use of structured reporting it still was not a hundred percent. Therefore, we investigated al misdiagnoses in Chapter 5. An increase in accuracy was found after revision by experienced readers. However, intermittent $\mathrm{IH}$ remained a pitfall which can never be completely diminished. Only in a very small number of cases there was no explanation for the discrepancy between CT scan and surgical findings. Second opinion by an experienced radiologist supports correct diagnosis, but in case of persistent complaints an operation should be considered to close herniation sides and prevent intermittent $\mathrm{IH}$.

In Chapter 6 we investigated another possible factor that can improve certainty of diagnosis, namely weight loss. It is theorized that when a patient loses more weight the bowels can move more freely through the abdomen, increasing the risk of $\mathrm{IH}$. We searched for a cut-off value that can be used to determine if a patient is more at risk for $\mathrm{IH}$. After calculating the percent total weight loss 
(\%TWL), at the moment of $\mathrm{IH}$, or at the moment of complaints suspect for $\mathrm{IH}$, we compared these values with the \%TWL in the overall patient population at the peak incidence of $\mathrm{IH}$. We found that an \%TWL of $30 \%$ gives a threefold higher risk of $\mathrm{IH}$.

Abdominal CT scans are an important tool in diagnosing $\mathrm{IH}$, with a high specificity and negative predictive value. The structured use of ten CT signs improved specificity in research and clinical setting. Furthermore structured reporting can be used with good results by less experienced readers. Second opinion by an experienced abdominal radiologist increases the accuracy even more. Another tool in diagnosing $\mathrm{IH}$ is the \%TWL, with a \% TWL of $30 \%$ or more the risk of $\mathrm{IH}$ increased threefold. Also cramping abdominal pain is considered a risk factor for $\mathrm{IH}$. 



\section{Chapter 10.}

Samenvatting (Dutch) 


\section{Achtergrond}

Overgewicht en obesitas zijn wereldwijd een veelvoorkomend probleem, niet alleen in westerse landen maar ook steeds meer in ontwikkelingslanden. Naast vele diëten, leefstijladviezen en medicamenteuze hulpmiddelen om af te vallen, bestaat tegenwoordig ook de mogelijkheid van een "maagverkleining". Wat in de volksmond maagverkleining heet, bestaat in de medische wereld uit verschillende operatieve mogelijkheden. Naast het daadwerkelijk verkleinen van de maag (sleeve gastrectomie) bestaat ook de mogelijkheid tot het omleiden van de darmen met een verminderde vertering als gevolg (gastric bypass). Daarnaast zijn er ook nog verschillende vormen van maagbandjes. Dit proefschrift is gericht op de gastric bypass operatie (Fig. 1).

Fig. 1. Anatomie na gastric bypass operatie

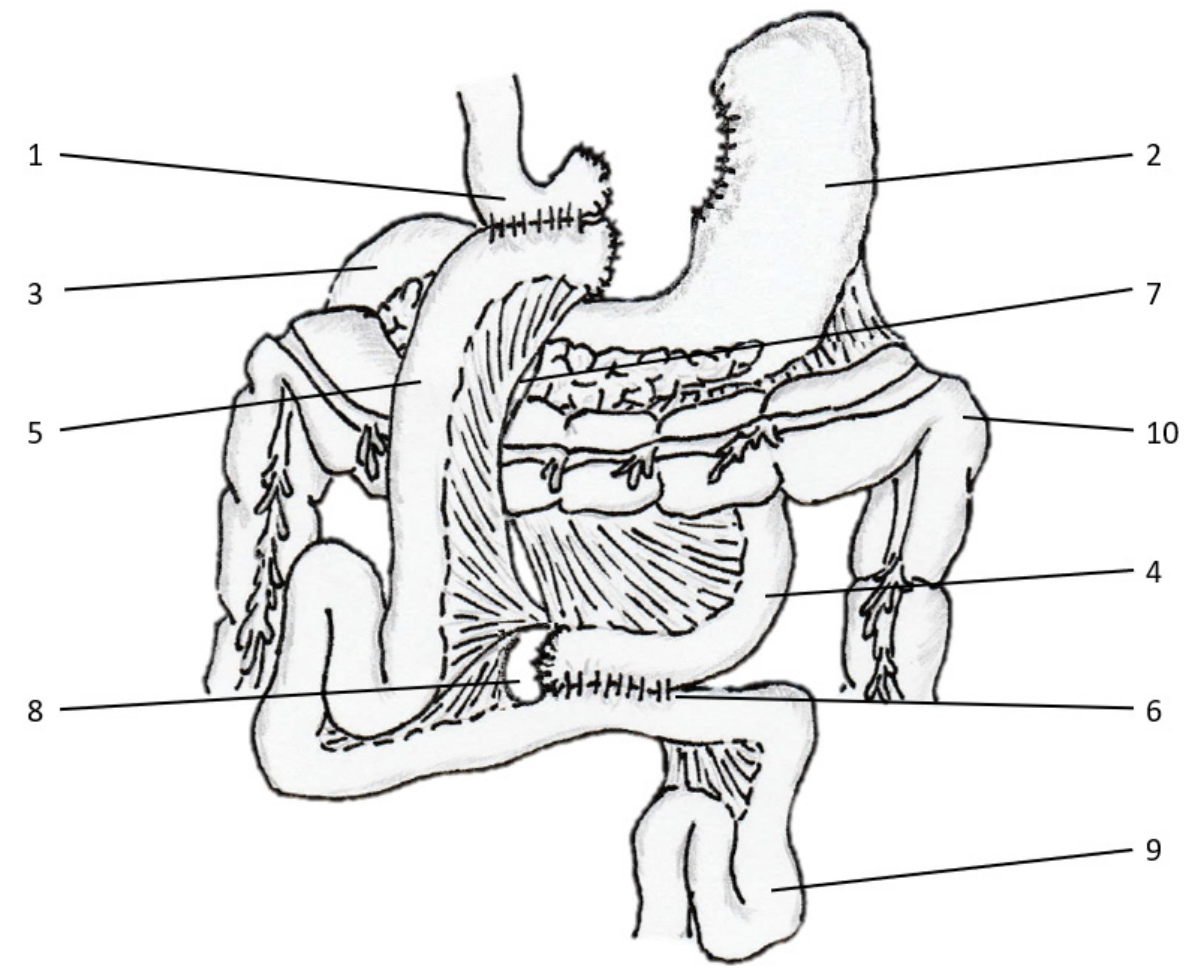

1 = pouch; 2 = restmaag; 3 = twaalfvingerige darm; 4 = biliaire lis; 5 = alimentaire lis; 6 = jejuno-jejunostomie; 7 = Petersen's space; 8 = mesenteriale opening; 9 = dunne darm; 10 = dikke darm 
De gastric bypass is een operatie waarbij de maag wordt opgedeeld in twee delen, een klein deel aan de slokdarm en het grootste deel met alle cellen die de verteringssappen vormen en de overgang naar de twaalfvingerige darm. Het kleine deel aan de slokdarm wordt de pouch genoemd, hieraan wordt een dunne darm lis bevestigd. Hierdoor gaat het eten direct van de slokdarm in de dunne darm, dit stuk wordt de alimentaire lis genoemd. De maag waar alle verteringssappen geproduceerd worden en de twaalfvingerige darm waar het gal en de alvleeskliersappen in de darm terecht komen, worden ongeveer anderhalve meter verder op de dunne darm aangesloten. Dit stuk dunne darm wordt de biliaire lis genoemd. De aansluiting van dunne darm op dunne darm heet de jejuno-jejunostomie. Om de dunne darm op de pouch aan te kunnen sluiten is er enige bewegelijkheid van de darmen nodig. De dunne darmen zitten met een dun vlies aan de buikwand vast, het mesenterium. Om de beweeglijkheid te creëren worden er kleine stukken van dit mesenterium losgemaakt. Door de verplaatsing van de darm en het losmaken van het mesenterium ontstaan openingen waardoor de darmen kunnen bewegen. Als een darm klem zit in zo'n opening noemen we dit een inwendige herniatie (IH). Na de standaard gastric bypass operatie zijn er twee openingen, de eerste bevindt zich tussen de dunne darm en de dikke darm die onder de maag van de rechterkant naar de linkerkant van de buik loopt. Deze opening wordt Petersen's space genoemd en een herniatie hier heet een Petersen hernia. Daarnaast is er een opening ter hoogte van de jejuno-jejunostomie, de herniatie hier heet een mesenteriale hernia.

Als de openingen groot genoeg zijn kan de darm vrij in en uit bewegen en zullen er weinig tot geen klachten zijn. Als de darm echter blijft steken in de opening kan de bloedtoevoer gecomprimeerd raken en in het ergste geval sterft de darm dan af. Patiënten ervaren buikpijn door de verminderde bloedtoevoer, dit kan erger zijn net na de maaltijd omdat de zuurstofbehoefte van de darm dan groter is. Daarnaast kan de peristaltiek van de darm toenemen als poging om weer in de goede positie te komen, dit zorgt voor krampende buikpijn, ook wel koliek genoemd.

Soms gaat de darm vanzelf terug in de goede positie en verdwijnen de klachten weer. Er zijn ook patiënten die herhaalde episodes hebben van klachten, waarschijnlijk doordat de darm af en toe klem zit in de opening. Dit wordt een intermitterende $\mathrm{IH}$ genoemd.

Aangezien het belangrijkste symptoom van een IH dus vooral buikpijn is, is de diagnose moeilijk te stellen. Er zijn veel verschillende redenen waarom patiënten na een gastric bypass buikpijn krijgen. De chirurg moet dan het onderscheid maken tussen een potentieel ernstige $\mathrm{IH}$ waarvoor een nieuwe operatie nodig is, of een andere diagnose. De diagnose $\mathrm{IH}$ kan alleen met zekerheid worden gesteld met een operatie, maar niet alle patiënten met buikpijn zullen deze operatie ondergaan aangezien er ook risico's verbonden zijn aan deze operatie. Om te helpen met de diagnose wordt steeds meer gebruik gemaakt van CT scans. 
Het belangrijkste doel van dit proefschrift was om de diagnostische accuratesse van $\mathrm{CT}$ scans voor het diagnosticeren van een inwendige herniatie na een gastric bypass te verbeteren. Daarnaast hebben we gekeken naar andere factoren die de diagnose van IH kunnen ondersteunen.

\section{Hoofdstuk 2}

$\mathrm{Na}$ het opbouwen van een database met alle patiënten die een gastric bypass hebben ondergaan in het Catharina Ziekenhuis Eindhoven (CZE) in de periode 2011-2014, werden alle patiënten met een verdenking op een IH geselecteerd aan de hand van de CT scans en operaties bij deze patiënten na de gastric bypass. Een IH kwam in deze populatie in $2,5 \%$ van de patiënten voor. Echter in $13 \%$ van de patiënten werd een CT scan of operatie gedaan met verdenking $\mathrm{IH}$. Er werden in totaal 247 CT scans en 90 operaties uitgevoerd. Met CT werd de juiste diagnose gesteld in $86,6 \%$ van de gevallen. De conclusie van dit onderzoek was dat CT een goed hulpmiddel is om de diagnose $\mathrm{IH}$ te stellen. Maar misschien nog wel belangrijker CT scans zijn ook geschikt om een IH uit te sluiten, waardoor een patiënt niet onnodig geopereerd wordt.

\section{Hoofdstuk 3}

In hoofdstuk 2 werd een accuratesse van CT voor de diagnose van IH gevonden van $86,6 \%$. Om dit te verbeteren worden verschillende tekenen beschreven in de literatuur die de diagnose IH op CT ondersteunen. Hiervan hebben we de tien naar ons idee meest toepasbare gekozen. De eerder onderzochte CT scans (245 van de 247) werden opnieuw beoordeeld aan de hand van deze tien signs. Deze beoordeling werd blind uitgevoerd door een ervaren radioloog met interessegebied abdomen (de buikregio), een assistent in opleiding tot radioloog met interessegebied abdomen en een coassistent met weinig tot geen CT ervaring. Er werd hierbij een verbetering van de accuratesse gevonden, zonder significant verschil tussen de verschillende ervaringsniveaus.

\section{Hoofdstuk 4}

Om de verschillende CT signs echt te testen moesten ze toegepast worden in de klinische praktijk. Daarom hebben de radiologen en assistenten in het CZE alle CT scans met in de vraagstelling IH van juni 2017 tot en met november 2018 beoordeeld aan de hand van een standaardverslag met de tien signs. Dit werd vergeleken met de uitkomsten van de verslagen van de CT scans zonder zo'n standaardverslag in de periode 2011-2016. Hierbij werd ook in de klinische praktijk een verbetering van de accuratesse gevonden door het gebruik van de tien signs. Het standaardverslag geeft met name meer zekerheid bij het uitsluiten 
van een $\mathrm{IH}$, wat onnodige operaties voorkomt.

\section{Hoofdstuk 5}

$\mathrm{Na}$ het toepassen van dit standaardverslag was de accuratesse van de CT scan voor het diagnosticeren van $\mathrm{IH}$ echter nog steeds geen honderd procent. Om te kijken of dit nog verder verbeterd kon worden, zijn we ons gaan verdiepen in de verkeerde diagnoses. In de gehele periode 2011 t/m 2018 werden er 525 CT scans gedaan met op 49 (9.3\%) scans een verkeerde diagnose. $\mathrm{Na}$ herbeoordeling van deze 49 scans door twee ervaren beoordelaars bleven er 19 incorrect. Een groot deel hiervan lijkt te berusten op de eerder genoemde intermitterende $\mathrm{IH}$. Daarnaast werden er andere diagnoses zoals verklevingen en invaginatie gesteld. Slechts 4 van de casussen konden niet worden verklaard.

\section{Hoofdstuk 6}

Een IH ontstaat door een combinatie van de beweeglijkheid van de darmlissen in de buik en het ontstaan van openingen tussen de darmlissen na een gastric bypass operatie. De beweeglijkheid van de darmen en de grootte van de openingen nemen toe als het vet tussen de darmen afneemt. Hoewel gewichtsverlies de gewenste uitkomst van een gastric bypass is, zorgt het dus mogelijk ook voor een verhoogd risico op een $\mathrm{IH}$. Om te onderzoeken of de hoeveelheid gewichtsverlies gebruikt kan worden als ondersteuning in het stellen van de diagnose $\mathrm{IH}$, werden alle gewichten ten tijde van klachten met verdenking $\mathrm{IH}$ vergeleken met het gewichtsverlies in de gehele populatie. Dit gewichtsverlies van de gehele populatie werd berekend in het tijdsinterval na de operatie waarin een IH het vaakste voorkomt. Omdat gewichtsverlies een lastige maat is, werd er gebruik gemaakt van het percentage totale gewichtsverlies (\%TWL) ten opzichte van het gewicht van voor de operatie. Hierbij vonden we dat een \%TWL van $30 \%$ of meer een risicofactor is voor $\mathrm{IH}$. Daarnaast geeft ook de eerder beschreven koliekpijn een driemaal verhoogd risico op het hebben van een IH dan bij patiënten zonder koliekpijn.

\section{Discussie}

Ons onderzoek was het eerste grote onderzoek naar het gebruik en de accuratesse van CT scans. Eerder werden al onderzoeken uitgevoerd naar de accuratesse van CT scans in patiënten met een operatie met verdenking $\mathrm{IH}$. Wij hebben echter ook alle patiënten geïncludeerd die na de CT scan geen operatie ondergingen. Indien zij in een periode van 90 dagen na de CT scan klachtenvrij waren, werd een IH onwaarschijnlijk geacht. Hoofdstuk 2 toonde een gebruik van CT scans in $13 \%$ van de patiënten na een gastric bypass met een goede 
accuratesse. De sensitiviteit en specificiteit in ons onderzoek waren ook beter dan eerdere studies lieten zien. Daarom pleiten wij voor het gebruik van CT scans bij alle patiënten met een verdenking IH om zo onnodige operaties te voorkomen.

Ook het gebruik van specifieke CT signs verbeterde de specificiteit van CT scans wat reeds in eerder elders uitgevoerd onderzoek werd aangetoond. In hoofdstuk 3 werd echter ook aangetoond dat minder ervaren radiologen (in opleiding) door het gebruik van de CT signs ook een correcte diagnose konden stellen. Met de implementatie van de CT signs in de klinische praktijk in hoofdstuk 4 werd dit verder bevestigd. Een standaardverslag zou daarom vaker gebruikt moeten worden. Er is echter nog meer onderzoek nodig naar de signs die in het standaardverslag thuis horen. Mogelijk zijn er andere signs die in dit onderzoek niet gebruikt zijn of zijn er combinaties van signs die een beter beeld geven.

Om de accuratesse nog verder te verbeteren werden in hoofdstuk 5 enkele adviezen geformuleerd. Bij discrepantie tussen het radiologische verslag en de klinische verdenking van de chirurg wordt een second opinion door een ervaren abdomen radioloog geadviseerd. Daarnaast moet het tijdsinterval tussen de klachten, CT scan en operatie niet te lang zijn om zo een intermitterende IH te kunnen vinden.

Andere factoren die meespelen in het risico voor IH en dus mee moeten wegen in de diagnose zijn de hoeveelheid gewichtsverlies en specifieke symptomen. Overeenkomstig met de literatuur toonde hoofdstuk 6 aan dat patiënten met een $\mathrm{IH}$ meer gewichtsverlies hebben dan de algemene populatie en ook vaker krampende buikpijn vertonen. Verder onderzoek naar andere factoren die het risico op $\mathrm{IH}$ verhogen is echter nog wel nodig.

\section{Conclusie}

$\mathrm{IH}$ is geen makkelijke maar wel een belangrijke diagnose om op tijd te stellen. CT scans en vooral het gebruik van een standaardverslag met CT signs bevorderen de diagnose en kunnen $\mathrm{IH}$ met voldoende zekerheid uitsluiten. Hierdoor kunnen onnodige operaties voorkomen worden. Verder moeten de hoeveelheid gewichtsverlies en de aanwezigheid van koliekpijnen van invloed zijn op de diagnostische overwegingen van de chirurg. Samen met de radiologische bevindingen kan hierdoor een goed behandelplan voor de patiënt worden gemaakt. 


\section{Chapter 11.}

Dankwoord (Dutch) 
Graag wil ik iedereen bedanken die me de afgelopen jaren hebben bijgestaan bij de totstandkoming van dit proefschrift. Daarnaast ook dank aan de commissie die tijd en energie heeft gestoken in het beoordelen van mijn proefschrift.

Prof. Dr. Robben, Simon, mijn promotor. Tijdens mijn eerste dag van de geneeskunde opleiding in Maastricht leerden wij elkaar kennen en werd jij mijn mentor voor het eerste jaar. In de jaren die volgden kwamen we elkaar nog geregeld tegen en was er altijd een blijk van herkenning. Toen ik aan mijn opleiding radiologie begon, was je opeens Simon, een van de bazen, die omschakeling heeft nog wel even geduurd. Inmiddels was mijn onderzoek zo ver gekomen dat het tijd was om een promotor te zoeken, en toen was het leuk dat jouw leerstoel eigenlijk het beste paste bij mijn proefschrift. Zo ben je betrokken geweest bij alle onderdelen van mijn opleiding.

Dr. Nederend, Joost, als copromotor was jij vanaf het allereerste begin bij mijn onderzoek betrokken. En dat vond ik best een beetje spannend. Toen ik met Harrie in overleg was over een wetenschappelijke stage bij jullie op de afdeling en hij jou voordroeg als begeleider, dacht ik vooral aan de momenten dat ik je hoorde mopperen tegen de assistenten. Gelukkig stellen wij dezelfde hoge eisen aan ons werk en liep de samenwerking goed. Zo goed zelfs dat mijn wetenschappelijke stage is uitgedraaid in een heel proefschrift. Bedankt voor al je hulp in de afgelopen jaren.

Dr. Nienhuijs, Simon, ook mijn copromotor. Aangezien het onderwerp van mijn proefschrift niet alleen radiologisch is, werd jij ook al snel bij mijn wetenschappelijke stage betrokken. Met jouw andere invalshoek zorgde je altijd voor de puntjes op de "i" in mijn artikelen. Daarnaast hebben we samen heel wat gebrainstormd over mogelijke onderzoeksvragen, en wat hier nu ligt is maar een klein deel van de plannen. Laten we dus vooral niet stoppen met het gecombineerde onderzoek tussen onze disciplines.

Andrew en Roy, zonder jullie had dit boekje hier niet gelegen, of nou ja, dan was het waarschijnlijk over prostaten gegaan. Andrew, bedankt voor het goede idee, en mocht je toch nog ooit onderzoek willen doen, ik heb ook nog wel wat ideeën liggen. Roy, bedankt voor het helpen met de eerste stappen op onderzoeksgebied.

Marijn en Saskia, jullie bijdragen hebben gezorgd voor een verbetering van de kwaliteit van mijn artikelen, zowel op tekstueel als analytisch gebied, waarvoor dank.

Magaly en Lianne, bedankt voor het helpen vullen van mijn database, jullie werk heeft mij heel wat avondjes gescheeld. 
Geert-Jan, zoals beloofd: Alle databases in dit proefschrift werden medemogelijk gemaakt door Geert-Jan van Brakel. Waarvoor oprechte dank! Al heb ik hopelijk al wel iets goed gemaakt met alle zelfgebakken koekjes die er tegenover stonden.

Reinoud en Lieke, samen sparrend over onze onderzoeken hebben we elkaar nog best eens vooruit geholpen. Lieke, bedankt dat je me hielp relativeren en zorgde dat ik ook af en toe rust nam. Reinoud, het feit dat de tekening in dit boekje versie 3 is, zegt al genoeg over je teken kwaliteiten, of misschien meer over hoe goed je snapt wat ik bedoel terwijl ik het zelf niet goed kan uitleggen.

Joost, wat was het fijn om samen te kunnen mopperen als het even tegenzat, te weten dat je niet de enige bent die op zaterdagmiddag achter de computer zit om de revisies van weer een artikel af te maken of op zoek naar die ene patiënt in de database die niet klopt, en natuurlijk ook om samen de kleine overwinningen te vieren. Extra fijn is het dat we nu ook samen ons doctor-schap kunnen vieren! Maar waar gaan we dan nog over mopperen?

Vriendinnen, zonder jullie afleiding, etentjes, filmavondjes, wandelingen, weekendjes weg en vooral heel veel knuffels was ik er niet doorheen gekomen. Laten we hier vooral mee doorgaan.

Amber, ik hoefde je geeneens te vragen of je mijn paranimf wilde zijn, dat had je zelf al besloten. En dat is ook precies wat onze relatie typeert. Soms zien we elkaar veel te weinig, maar als we elkaar dan weer zien is het als vanouds. Dus het was ook niet meer dan logisch dat jij naast mij staat.

Wim, om jou zo ver te krijgen dat je mijn paranimf wilde zijn kostte iets meer moeite. Gelukkig doe je alles voor je kleine zusje. En het scheelt dat je deze keer niet het woord hoeft te voeren, toch?

Cate, obrigada por ter certeza de que ele está realmente aqui.

Pap en mam, ook al snapten jullie niet altijd precies waar ik mee bezig was, toch kon ik altijd rekenen op jullie steun. Of het nu was bij het oefenen van presentaties of tegenslagen tijdens het schrijven, jullie waren er altijd als luisterend oor.

Lieve Laurens, je bent alleen betrokken geweest bij de afrondende fase, maar het was fijn om je daarbij te hebben. Voor de laatste input en spellingscheck, maar ook voor de steun tijdens de laatste loodjes en spannende momenten. $\mathrm{Nu}$ kunnen we lekker samen gaan genieten van alle vrije tijd die ik overhoud. 



\section{Chapter 12.}

Curriculum Vitae 

Jannetje Clasina (Jeannette) Ederveen was born on March $3^{\text {rd }}, 1994$ in Erp. After cum laude graduation from Gymnasium Bernrode in Heeswijk-Dinther in 2011, she studied medicine at Maastricht University.

Most of her internships were situated in the Catharina Hospital Eindhoven, and it was also here she discovered her love for Radiology. After an internship at this department the choice was clear and a scientific internship followed. What started as a mandatory part of the medical training, turned out to be quite more enjoyable than anticipated, and was the beginning of this promotion.

After obtaining her medical degree in December 2017, she started working as resident at the department of Radiology and Nuclear Medicine in Maastricht University Medical Centre.

The residency was combined with her research in spare hours. This resulted in this thesis and presentations during the Dutch Radiology Days (2017, 2019 (top 5 abstract)), the $22^{\text {nd }}$ World Congress of the International Federation for the Surgery of Obesity and Metabolic Disorders (2017), and the European Congress of Radiology (2019).

Jannetje Clasina (Jeannette) Ederveen werd geboren op 3 maart 1994 in Erp. Na het cum laude behalen van haar diploma aan Gymnasium Bernrode in HeeswijkDinther in 2011, studeerde ze Geneeskunde aan Universiteit Maastricht.

Haar coschappen volgde ze grotendeels in het Catharina Ziekenhuis Eindhoven, waar ze ook haar liefde voor de radiologie ontdekte. Na een coschap op de afdeling radiologie was de keuze snel gemaakt en een wetenschappelijke stage volgde. Dit startte als een verplicht deel van de opleiding maar bleek veel leuker te zijn en heeft gezorgd voor een mooie basis voor het verdere promotietraject. $\mathrm{Na}$ het behalen van haar bul in december 2017, startte ze als arts-assistent in opleiding bij de afdeling Radiologie en Nucleaire Geneeskunde in Maastricht Universitair Medisch Centrum.

Gedurende haar opleiding werden de vrije uren gebruikt voor het verdere promotieonderzoek. Dit heeft uiteindelijk geresulteerd in dit proefschrift en presentaties tijdens de Nederlandse Radiologen Dagen (2017, 2019 (top 5 abstract)), het congres van de International Federation for the Surgery of Obesity and Metabolic Disorders (2017) en het Europese Congres voor de Radiol 



\section{Chapter 13.}

List of Publications 

J.C. Ederveen, M.M.G. van Berckel, R.J.P. Weber, S.W. Nienhuijs, J. Nederend. Predictive value of abdominal CT in evaluating internal herniation after bariatric laparoscopic Roux-en-Y gastric bypass. Br J Surg. 2018 Nov;105(12):1623-1629. doi: 10.1002/bjs.10886.

J.C. Ederveen, M.M.G. van Berckel, S. Jol, S.W. Nienhuijs, J. Nederend. Diagnosing internal herniation after laparoscopic Roux-en-Y gastric bypass: usefulness of systematically reviewing CT scans using ten signs. Eur Radiol. 2018 Sep;28(9):35833590. doi: 10.1007/s00330-018-5332-3.

J.C. Ederveen. Correspondence on Predictive value of abdominal CT in evaluating internal herniation after bariatric laparoscopic Roux-en-Y gastric bypass. Br J Surg. 2019 Feb;106(3):296. doi: 10.1002/bjs.11089.

J.C. Ederveen, S.W. Nienhuijs, S. Jol, S.G.F. Robben, J. Nederend. Structured CT reporting improves accuracy in diagnosing internal herniation after laparoscopic Roux-en-Y gastric bypass. Eur Radiol. 2020 Jun;30(6):3448-3454. doi: 10.1007/ s00330-020-06688-x

M.M.G. van Berckel, J.C. Ederveen, J. Nederend, S.W. Nienhuijs. Internal herniation and weight loss in patients after Roux-en-Y gastric bypass. Obes Surg. 2020 Jul;30(7):2652-2658. doi: 10.1007/s11695-020-04542-z

J.C. Ederveen, S.W. Nienhuijs, S.G.F. Robben, J. Nederend. Lessons learned after CT misdiagnoses of internal herniation after gastric bypass. Submitted. 
